Portland State University

PDXScholar

Summer 8-10-2017

\title{
Anthropogenic Effects on the Fouling Community: Impacts of Biological Invasions and Anthropogenic Structures on Community Structure
}

Whitney Elizabeth McClees

Portland State University

Follow this and additional works at: https://pdxscholar.library.pdx.edu/open_access_etds

Part of the Environmental Sciences Commons, and the Marine Biology Commons Let us know how access to this document benefits you.

\section{Recommended Citation}

McClees, Whitney Elizabeth, "Anthropogenic Effects on the Fouling Community: Impacts of Biological Invasions and Anthropogenic Structures on Community Structure" (2017). Dissertations and Theses. Paper 3883.

https://doi.org/10.15760/etd.5771

This Thesis is brought to you for free and open access. It has been accepted for inclusion in Dissertations and Theses by an authorized administrator of PDXScholar. Please contact us if we can make this document more accessible: pdxscholar@pdx.edu. 
Anthropogenic Effects on the Fouling Community: Impacts of Biological Invasions and Anthropogenic Structures on Community Structure

by

Whitney Elizabeth McClees

A thesis submitted in partial fulfillment of the requirements of the degree of

Master of Science

in

Environmental Science and Management

Thesis Committee:

Catherine de Rivera, Chair

Sarah Eppley

Gregory Ruiz

Portland State University

2017 
(C) 2017 Whitney Elizabeth McClees 


\begin{abstract}
Coastal anthropogenic infrastructure has significantly modified nearshore environments. Because these structures often have a strong association with shipping as would be found in ports and harbors, they have been identified as invasion hotspots. Due to propagule pressure from shipping and recreational boating and suitable uncolonized substrate that provides a refuge from native predators, a greater number of non-native species have been found on these structures compared to nearby natural substrate. The mechanisms that limit the spread of non-native species from anthropogenic structures to natural substrate have been explored for several taxa at a species-specific level, but less so from an overall community perspective. Predation has been identified as one of the biotic interactions limiting invasion success. In addition to predation, dispersal ability may also prevent the spread of non-native species from anthropogenic structures to natural substrate.
\end{abstract}

This thesis addresses how these two mechanisms interact to limit the spread of non-native species from anthropogenic structures to natural substrate and how that alters overall community composition. I aimed to explore differences between communities inside and outside of a marina and determine the extent to which predator and dispersal limitation were structuring these communities. I used a three-factor design, deploying seven unglazed ceramic tiles per each treatment combination of 1) in versus outside a marina in Yaquina Bay, Oregon; 2) cage keeping out predators greater than the mesh size, no cage, or partial cage; 3 ) fixed near the substrata (benthic) versus suspended 1 meter below the surface. I also transplanted caged, suspended tiles of either adults or recruits from inside the marina to benthic and suspended caging treatments outside of the 
marina. These tiles allowed me to examine predation when dispersal limitation was not a factor for the community inside the marina, i.e. what happens to both recruits and adults if they can get outside of the marina. I found that the communities inside and outside of the marina were different and the data suggest that both predation and dispersal limitation interact to limit the spread of non-native species. Additionally, I found that mesopredators that could fit through the caging may be influencing predation results and community structure.

This research addresses gaps in scientific knowledge regarding the mechanisms that prevent or facilitate the spread of non-native species. Future work could include the further exploration of mesopredation as an important factor in limiting the spread of nonnative species and exploring dispersal limitation more in depth as well as broadening the geographic scope to see if the same trends hold true across bays and bioregions. 


\section{Acknowledgements}

I would first like to thank my advisor, Dr. Cat de Rivera. I would not have made it this far without her support, guidance, reassurance, and unfailing good humor. I would also like to extend my thanks to my committee members, Drs. Greg Ruiz and Sarah Eppley, for their guidance and input throughout this process. This research would not have been possible without funding from the NSF Cascades to Coast GK-12 Program, the GK-12 Mini-Grant, and two Edward D. and Olive C. Bushby Scholarships. Thank you to the Embarcadero Marina in Newport, especially the dock master Matt Williams, for being such generous hosts to my research by providing me with boats to use, allowing me to store equipment on site, and permitting me to hammer nails into their docks. Along a similar vein, thanks to Hatfield Marine Science Center for providing me with lab and tank space and a few of their summer interns to help with my research.

To everyone who assisted me with this work, I could not have done it without you: Corinne Heath, Roxanne Valencia, Yen Vu, Hayley Hinrichs, Chase Spearing, Gabriel Court, Alissa Harrison, Jessica Schutt, John Zalusky, Sebastien Eichvalds, Inez Lawson, Amy Ehrhart, Alex Drinkard, Kazia Mermel, Olivia Blondheim, and anyone else I am forgetting. A big thank you to my de Rivera lab mates who helped in the lab, in the field, provided constructive criticism, experimental design input, and many, many laughs. I would also like to extend heartfelt thanks to the staff of the Environmental Science and Management Department at Portland State University, especially to Sherie Huffman for helping me stay sane while navigating all the appropriate paperwork. Thank 
you to Jim Carlton for starting me on this crazy fouling journey and for letting me send him barnacle bits in the mail for identification.

A huge thank you to my family and friends who have supported me through this whole journey. Thank you to my parents, Jock and Carol; without your support and guidance, I would not be where I am today (and thanks, Dad, for passing along your bio nerd genes). To my sister, Cameron: thank you for enduring field and lab work when you came to visit; I promise I won't steal your vacation again. And finally, a huge thank you to my partner, Stephanie, whose unflappable and unfailing love and support have been an integral part of this whole process. She has been my copy editor, my sounding board, my captive defense audience, my shoulder to cry one, but above all, she has been my love. 


\section{Table of Contents}

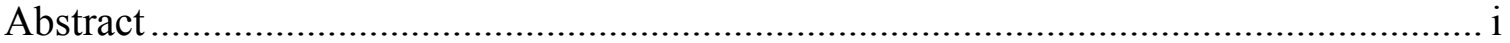

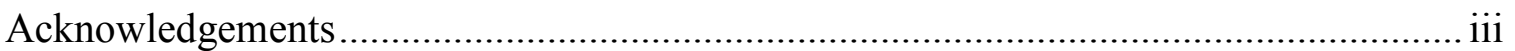

List of Tables ..................................................................................................... vi

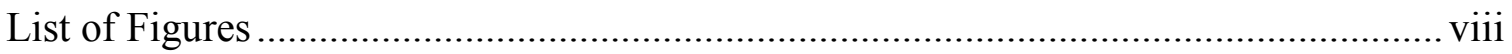

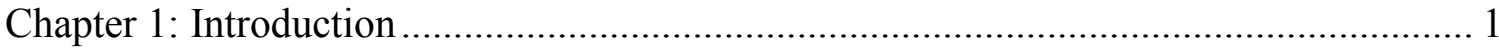

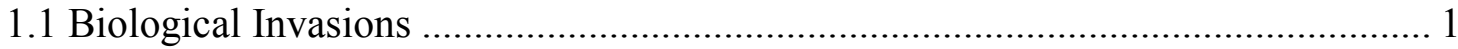

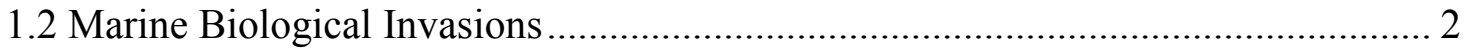

1.3 The Fouling Community and Biological Invasions ............................................ 5

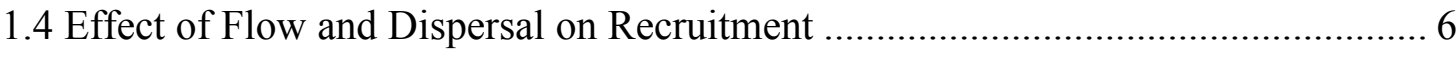

1.5 Predation and Biotic Resistance in Fouling Communities .................................. 9

Chapter 2: The limitation of spread of non-native marine invertebrates from

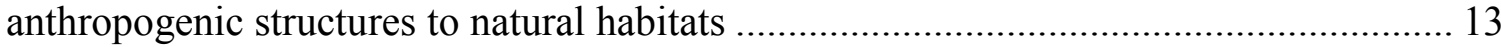

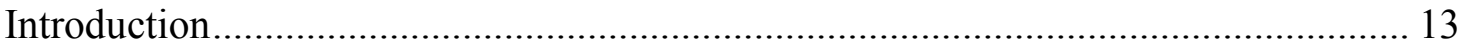

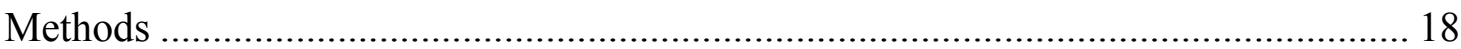

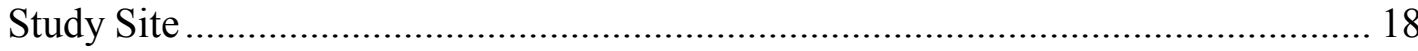

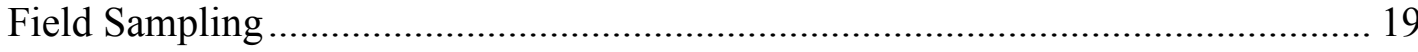

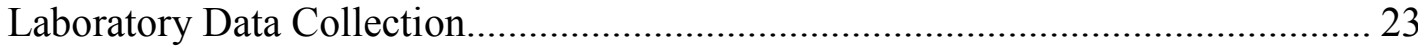

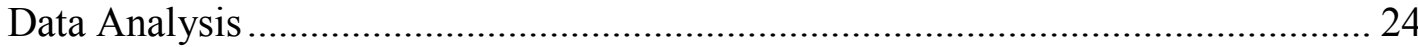

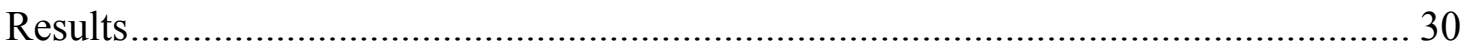

Does Community Characterization Change Across Location and Depth? ............... 30

Does Dispersal Play a Role in Structuring Fouling Communities and Contribute to

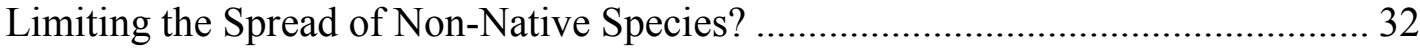

Does Predation Play a Role in Structuring Fouling Communities and Contribute to Limiting the Spread of Non-Native Species? ..................................................... 34

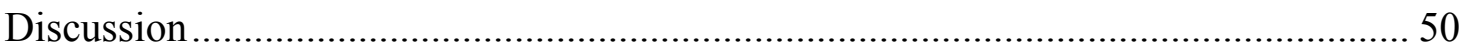

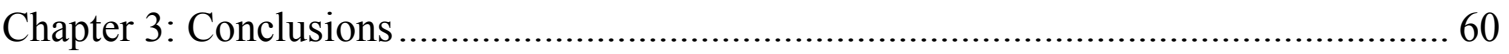

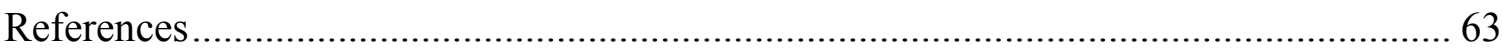

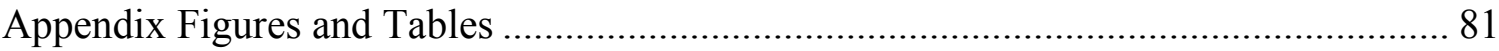




\section{List of Tables}

Table 1. Analysis of distance tables assessing if there are caging artifacts (No cage vs. Partial cage) that might influence fouling community assemblages. Adult $=$ inside the marina fully caged near the surface for 12 weeks and then moved outside of the marina across 2 depths and 3 caging treatments for one week. Inside $=$ inside the marina for the duration of the experiment. Outside $=$ outside the marina for the duration of the experiment. Suspended $=$ near surface. Benthic $=$ near benthos. $*$ indicates statistical significance $(\mathrm{p}<0.05)$

Table 2. Generalized linear model summary output for species richness on No Cage tiles across 2 depths (Suspended and Benthic) and 2 locations (Inside = inside the marina for the duration of the experiment, Outside $=$ outside the marina for the duration of the experiment). Model: Species Richness $\sim$ Location*Depth. * indicates statistical significance $(\mathrm{p}<0.05)$.

Table 3. Summary output of post-hoc generalized linear model comparisons of means for average species richness on No Cage tiles across 2 depths (Suspended and Benthic) and 2 locations (Inside Marina and Outside Marina). p-values are unadjusted. * indicates statistical significance $(\mathrm{p}<0.05)$.

Table 4. Summary output of post-hoc generalized linear model comparisons of means for average non-native species richness on No Cage tiles across 2 depths (Suspended and Benthic) and 2 locations (Inside Marina and Outside Marina). p-values are unadjusted. Model: Non-Native Species Richness Location*Depth. * indicates statistical significance $(\mathrm{p}<0.05)$.

Table 5. Analysis of distance tables showing the effect of location (Inside Marina or Outside Marina) and depth (Suspended or Benthic) on No Cage fouling community assemblage. * indicates statistical significance $(\mathrm{p}<0.05$ for $\mathrm{A}, \mathrm{p}<0.008$ for $\mathrm{B}-\mathrm{G}) \ldots \ldots .41$

Table 6. Results of indicator species analysis showing significant indicator taxa for each location, depth, and cage treatment. Indicator value indicates how representative the species is of a group. $\mathrm{S}=$ Suspended, $\mathrm{B}=$ Benthic. $\mathrm{NC}=$ No Cage, $\mathrm{FC}=$ Full Cage. Inside = Inside Marina, inside the marina for the duration of the experiment; Outside = Outside Marina, outside the marina for the duration of the experiment.

Table 7. Analysis of distance tables showing the effect of location inside or outside of the marina on caged fouling community assemblage. Inside Marina = inside the marina for the duration of the experiment, Outside Marina = outside the marina for the duration of the experiment. Suspended $=$ near surface, Benthic $=$ near benthos. * indicates significance $(p<0.05$ for $A$ and $p<0.008$ for $B-G)$

Table 8. Comparison of Inside Marina Suspended species to Inside Marina Benthic, Outside Marina Suspended, and Outside Marina Benthic. For each species, life history strategy and invasion status are listed, if known. Larval Type: $\mathrm{L}=$ Lecithotrophic, $\mathrm{P}=$ 
Planktotrophic. Invasion Status for Oregon: Crypto $=$ Cryptogenic, Nat $=$ Native, Intro $=$ Introduced. In = Inside Marina, Out = Outside Marina, Sus $=$ Suspended, Ben $=$ Benthic

Table 9. Analysis of distance tables showing the effects of location (Inside or Outside Marina), depth (Suspended or Benthic), and predation (No Cage or Full Cage) on fouling community assemblage. * indicates statistical significance $(\mathrm{p}<0.05$ for $\mathrm{A}, \mathrm{p}<0.008$ for B-G) 46

Table 10. Analysis of distance tables showing the effect of caging treatment (No Cage or Full Cage) and depth (Suspended or Benthic) on Adult Transplant Experiment fouling community assemblage. * indicates statistical significance $(p<0.05$ for $A, p<0.008$ for B-G)

Table 11. Analysis of distance tables showing the effect of caging treatment (No Cage or Full Cage), depth (Suspended or Benthic), and location (Inside Marina or Adult Transplant Experiment) on fouling community assemblage. Inside = Inside Marina, inside the marina for the duration of the experiment; Adult $=$ Adult Transplant Experiment, moved from inside to outside of the marina. * indicates significance $(\mathrm{p}<$ 0.05 for $\mathrm{A}, \mathrm{p}<0.017$ for $\mathrm{B}-\mathrm{D})$. 


\section{List of Figures}

Figure 1. A) Map of study site. B) Experimental apparatus with paired settling tiles 1 meter below the surface (Suspended) and just above the cinder block near the substrate (Benthic) for Full Cage (FC), Partial Cage (PC), and No Cage (NC) predation treatments. 7 apparatuses were deployed inside the marina and 7 were deployed outside the marina. C) Three-factor experimental design set up. D) Settling tile transplant design set up. ... 29

Figure 2. Average species richness on No Cage tiles across 2 depths (Suspended and Benthic) and 2 locations (Inside = inside the marina for the duration of the experiment, Outside $=$ outside the marina for the duration of the experiment). Error bars are \pm 1 standard error.

Figure 3. Average species richness by invasion status on No Cage tiles across 2 depths (Suspended and Benthic) and 2 locations (Inside = inside the marina for the duration of the experiment, Outside $=$ outside the marina for the duration of the experiment). Error bars are \pm 1 standard error. Solid colored bars indicate native species. Faded bars indicate non-native species. White bars indicate unknown species, including cryptogenic species and morphospecies for which I was unable to identify invasion status.

Figure 4. Nonmetric multidimensional scaling (NMDS) results showing the comparison between Suspended and Benthic No Cage sessile invertebrate assemblages inside and outside of the marina. Ellipses include standard error around the centroids. Stress $=0.06$

Figure 5. Average cover of identifiable non-native species across two depths (Suspended and Benthic) in two locations (Inside = Inside Marina, inside the marina for the duration of the experiment; Outside $=$ Outside Marina, outside the marina for the duration of the experiment) for No Cage tiles, the base community. Error bars are \pm 1 standard error.... 42

Figure 6. Average proportion of identified species cover that was non-native across two depths (Suspended and Benthic) in two locations (Inside = Inside Marina, inside the marina for the duration of the experiment; Outside = Outside Marina, outside the marina for the duration of the experiment) for No Cage tiles, the base community. Error bars are \pm 1 standard error.

Figure 7. Nonmetric multidimensional scaling (NMDS) results showing the comparison between Full Cage sessile invertebrate assemblages near the surface (Suspended) and near the benthos (Benthic) for inside and outside of the marina. Ellipses include standard error around the centroid. Stress $=0.06$.

Figure 8. Nonmetric multidimensional scaling (NMDS) results showing the comparison among sessile invertebrate assemblages between caged (Full Cage) and uncaged (No Cage) tiles inside the marina near the surface (Inside Marina Suspended) and outside near the benthos (Outside Marina Benthic). Ellipses include standard error around the centroid. Stress $=0.08$ 
Figure 9. Nonmetric multidimensional scaling (NMDS) results showing the comparison among sessile invertebrate assemblages for the Adult Transplant Experiment (moved from inside to outside of the marina) tiles among caging treatments (Caged = Full Cage, Uncaged $=$ No Cage) and depths (Suspended, Benthic). Ellipses include standard error around the centroid. Stress $=0.216$

Figure 10. Nonmetric multidimensional scaling (NMDS) results showing the comparison among sessile invertebrate assemblages between Adult Transplant Experiment Benthic Full and No Cage and Inside Marina Suspended Full Cage. Ellipses include standard error around the centroid. Stress $=0.11$

Figure 11. The average proportion of bare space across 2 depths $(\mathrm{S}=$ Suspended, $\mathrm{B}=$ Benthic), 2 caging treatments $(\mathrm{NC}=$ No Cage, $\mathrm{FC}=$ Full Cage), and 3 locations (Inside $=$ inside the marina for the duration of the experiment; Outside = outside the marina for the duration of the experiment; Adult $=$ Adult Transplant Experiment, moved from inside to outside of the marina). Error bars are \pm 1 standard error.

Figure 12. Total abundance of small predators upon retrieval across 2 depths $(\mathrm{S}=$ Suspended, $\mathrm{B}=$ Benthic), 2 caging treatments $(\mathrm{NC}=$ No Cage, $\mathrm{FC}=$ Full Cage), and 3 locations (Inside $=$ inside the marina for the duration of the experiment; Outside $=$ outside the marina for the duration of the experiment; Adult = Adult Transplant Experiment, moved from inside to outside of the marina). 


\section{Chapter 1: Introduction}

\subsection{Biological Invasions}

Biological invasions are major drivers of global change through impacts on biodiversity, ecosystem function, and habitat degradation (D’Antonio et al. 2001, McGeoch et al. 2010). Many invasive species can cause significant environmental and economic costs, compounded by increases in invasion frequency and number due to human population growth and global connectivity (Pimentel et al. 2005). Thus, there is a significant focus within invasion theory on understanding and predicting the success of an invader and its potential for spread (Pimentel et al. 2005). Biological invasions occur due to human-mediated dispersal beyond the natural range or dispersal capability of the species (Wilson et al. 2009). The invasion process generally follows the same pattern: 1) transport, overcoming geographic barriers, 2) introduction, 3) establishment through survival and reproduction, and 4) spread through successfully dispersing and overcoming environmental barriers in new locations (Blackburn et al. 2011). Before invasive species become widespread, biological constraints may limit their ability to spread (Arim et al. 2006).

Dispersal is limited by landscape heterogeneity, including geomorphology, resource availability, soil types, and habitat patches (Theoharides and Dukes 2007). Additionally, non-native species spread is influenced by dispersal mechanism, which can vary among species (Pyšek and Hulme 2005). Disturbance, or lack thereof, can also play a role in dispersal. Areas with more frequent disturbance or a higher level of disturbance can facilitate the spread of invasive species, whereas less disturbed, more natural areas may not offer as many pathways to spread (D’Antonio et al. 1999). 
Biotic resistance is emphasized in assembly theory as a large contributor to why invasions either succeed or fail (Case 1991). Biotic resistance theory indicates that the recipient community can limit colonization by and success of non-native species through competition, predation, and pathogens (Levine et al. 2004, Parker and Hay 2005, Alpert 2006). Some studies indicate that consistent release of propagules into an area can overcome biotic resistance (Levine 2000, Clark and Johnston 2009, Burgess and Marshall 2011).

\subsection{Marine Biological Invasions}

Coastal marine ecosystems have experienced some of the highest impacts from humans across all marine ecosystems (Halpern et al. 2008). With the vast majority of global trade being carried out by sea, there is high global connectivity between ports (Kaluza et al. 2010). Due in part to this global connectivity, coastal marine ecosystems have experienced an increasing influx of non-native species over the last 100 years (Cohen and Carlton 1998, Crooks 2005).

Marine species are transported by a variety of vectors, most of which are associated with anthropogenic activities (Carlton 1996). Shipping is the most common way that species are moved by humans among coastal marine ecosystems (Ruiz et al. 1997, 2000). Ballast water in commercial ships can transport planktonic larvae (Carlton 1985) and sessile adult stages can be transported attached to ships' hulls and sea chests (Carlton 1987, Carlton and Hodder 1995, Coutts et al. 2003, Chapman et al. 2013); with the increase in shipping frequency, larvae are much more likely to establish in novel environments (Carlton 1996). 
Many of the individuals that are moved via human-mediated transport perish before arriving or upon arrival in a new location, resulting in a comparatively small number of species that are able to survive and successfully establish in new habitats (Mack et al. 2000). Part of why many species do not survive upon arrival is due to lack of environmental match with their native range (Keller et al. 2011). Therefore, species that are transported between locations that are environmentally similar have a greater chance of survival (Keller et al. 2011). Additionally, improvements in the shipping industry have increased the ability for species to survive transport through increased speed and decreased transit time, better design of ballast water tanks, and increased size of ballast water tanks (Carlton 1996). Despite the fact that comparatively few species successfully establish and become invasive, those that are successful can have dramatic impacts (review by Lovell and Stone 2005). With increasing globalization and shipping frequency, there is a greater risk of impacts from marine invasive species (Hulme 2009), including threatening biodiversity, coastal infrastructure and industries, and human health (Bax et al. 2003).

Because shipping is considered the primary vector for the transport of non-native species (Carlton 1985, Ruiz et al. 2000), ports and harbors are generally the focus of marine non-native species research, though non-native species are sometimes found in other habitats as well (Carlton 2003, Preisler et al. 2009).

Infrastructure associated with harbors and ports is becoming increasingly common as urbanization becomes more widespread (Glasby 1999, Bulleri and Chapman 2004, Bulleri and Airoldi 2005, Dafforn et al. 2009a). The influx of anthropogenic 
infrastructure, such as floating docks, pier pilings, retaining walls, and other mechanisms to help curb erosion and promote human use, has significantly modified many nearshore environments, for which the associated environmental impacts are just beginning to be understood (Bulleri and Chapman 2010, Chapman and Underwood 2011).

Due to the strong influence of shipping, anthropogenic structures have been identified as invasion hotspots (Carlton and Geller 1993, Drake and Lodge 2004, Occhipinti-Ambrogi 2007, Bulleri and Chapman 2010) and may contribute to the establishment, persistence, and spread of marine invasive species (Bulleri and Airoldi 2005, Glasby et al. 2007). These anthropogenic structures can provide novel habitat for non-native species to colonize as well as depress native biodiversity (Glasby and Connell 1999, Dafforn et al. 2009b). For many invasive fouling organisms (invertebrates that attach to hard substrata), having available substrate upon arrival is crucial. Many nonnative or recently introduced species are almost exclusively restricted to man-made or disturbed environments, which has been shown at least in part to be due to the provided refuge from native predators as well as a lack of suitable natural substrate (Connell 2000, Bulleri and Chapman 2010, Aldred and Clare 2014). Additionally, partially enclosed marinas provide optimal conditions for the recruitment of fouling organisms (Floerl and Inglis 2003). Thus, anthropogenic structures tend to have not only a greater abundance of non-native species than nearby natural substrata but also different community structure (Glasby 1999, Connell and Glasby 1999, Wasson et al. 2005, Bulleri and Airoldi 2005, Glasby et al. 2007, Hedge and Johnston 2012, Marzinelli 2012). Non-native species have 
such a strong association with anthropogenic structures that this association has been used as a criterion for identifying non-native species (Chapman and Carlton 1991).

Because of the greater abundance of non-native species on anthropogenic structures, the associated invasion process has been well studied (Stachowicz et al. 1999, 2002, Tyrrell and Byers 2007, Ruiz et al. 2009, Mineur et al. 2012). However, the mechanisms that drive the difference between communities on anthropogenic structures and those on natural substrate have been explored less. These mechanisms include dispersal limitation and biotic resistance.

\subsection{The Fouling Community and Biological Invasions}

The fouling community is an epibenthic subtidal community that has the potential to cause economic harm (Woods Hole Oceanographic Institution 1952). It is comprised of mostly sessile filter-feeding invertebrates and mobile epifauna, such as ascidians, bryozoans, hydroids, sponges, barnacles, small crustaceans, and nudibranchs, which live primarily on hard substrata. Both biotic and abiotic factors help shape the fouling community, including predation (Sutherland 1974, Keough and Butler 1979, Osman et al. 1992, Osman and Whitlatch 1995, Connell 2001b, Nydam and Stachowicz 2007) and dispersal (Petersen and Svane 1995, Cañete et al. 2007, Chapman et al. 2013). Because of the association with hard substrata, non-native fouling species are prevalent due to shipping (Ruiz et al. 2000) and its associated infrastructure (Chapman 1988, Chapman and Carlton 1991). There tends to be a greater abundance of non-native species on anthropogenic structures than on natural habitats (Lambert 2002, Glasby et al. 2007, 
Mineur et al. 2012). Additionally, there are more frequent invasions of bays and estuaries than of open coasts (Wasson et al. 2005, Preisler et al. 2009, Ruiz et al. 2011).

\subsection{Effect of Flow and Dispersal on Recruitment}

Most marine species have a life history stage that is transported by ocean currents (Thorson 1950, Grantham et al. 2003). Due to tides and currents, larvae from the same spawning event can be transported different distances (Cowen et al. 2000). Therefore, dispersal distance is conceptualized as an area rather than a specific distance.

Additionally, sporadic mixing, such as would occur during heavy rainfall, and annual variation in currents can also impact larval dispersal (Siegel et al. 2008, Watson et al. 2012). Hydrodynamics play a large role in determining where and how far larvae are transported (Roughgarden et al. 1991, Rothlisberg and Church 1994, Shanks 1995) and where they settle (Koehl and Hadfield 2010). Waves and turbulence can have just as much impact on larval settlement as the regular current (reviewed in Koehl 2007), as can temporal variations such as upwelling (Barshis et al. 2011, McManus and Woodson 2012).

Both larval abundance and hydrodynamics influence the number of propagules (individuals) delivered to a given surface (Eckman 1983, Shanks 1983, Underwood and Fairweather 1989). Irregularities in the shoreline, such as headlands or embayments, create complex hydrodynamic features that alter how suspended material is dispersed (Okubo 1973, Pingree and Maddock 1979, Wolanski and Hamner 1988, Signell and Geyer 1991) and can cause zooplankton to aggregate in a particular area (Alldredge and Hamner 1980, Archambault and Bourget 1999). The construction of anthropogenic 
structures, such as breakwaters, can cause similar hydrodynamic modifications, reducing flow (Rivero et al. 2013) and affecting recruitment of species in surrounding habitats (McNeill et al. 1992, Floerl and Inglis 2003). Enclosed boat harbors have lower flow and can cause greater entrainment of larvae, increasing the amount of fouling on boat hulls and docks in marinas, potentially facilitating the spread of non-native species (Floerl and Inglis 2003). Local-scale factors, such as the influence of anthropogenic structures on environment and hydrodynamics, tend to have stronger influences on non-native species, reinforcing the concentration of non-native sessile invertebrates in marinas (Marzinelli et al. 2012, Simpson et al. 2017).

Dispersal distance is influenced by larval duration (Siegel et al. 2003, Grantham et al. 2003, Levin 2006), with longer larval durations correlating with greater dispersal distance (Todd 1998, Shanks et al. 2003), though subsequent research has shown this is not always the case (Shanks 2009, Morgan et al. 2009). Planktotrophic larvae, which usually spend a long period of time in the water column, can disperse significant distances (O'Connor et al. 2007), whereas lecithotrophic larvae spend less time in the water column and disperse much shorter distances (Pechenik 1990, Todd 1998). Species that can disperse greater distances can take better advantage of areas where habitat patches are spread out, while species that are more limited in their dispersal succeed more readily in areas with habitat patches in close proximity (Bode et al. 2011).

Additionally, water temperature can influence larval duration and dispersal, with colder water causing larvae to develop more slowly leading to longer larval duration (Kelly and Eernisse 2007, O’Connor et al. 2007, Bradbury et al. 2008). Thus, dispersal 
limitation directly affects species range (Zacherl et al. 2003, Gilman 2006, Lima et al. 2007, Ayre et al. 2009, Herbert et al. 2009, Kuo and Sanford 2009, Poloczanska et al. 2011), and population dynamics and community structure (Young 1990, Olafsson et al. 1994, Eckman 1996, Schiel 2004). Community structure is in part influenced by larval dispersal due to the interactions between species, such as the predator-prey relationship (Wieters et al. 2008, White and Samhouri 2011).

Therefore, dispersal ability may prevent the spread of non-native species from anthropogenic structures to natural substrate. Many benthic invertebrates have a pelagic larval stage that facilitates dispersal. A longer larval stage can potentially lead to dispersal over a larger area (Zinsmeister and Emerson 1979, Scheltema 1986a, 1986b, Bhaud 1993, Shanks et al. 2003), but this is not always the case as it can vary among species, especially nearshore species (Shanks 2009, Morgan et al. 2009). A shorter larval stage will be more restricted in distance from the source population (Mileikovsky 1971, Hedgecock 1986, Scheltema 1986b, Shanks et al. 2003), but these species are better able to take advantage of nearby suitable habitat (Jackson 1986, Keough and Chernoff 1987). Dispersal and propagule pressure are linked in that propagule pressure is mediated by dispersal (Johnston et al. 2009, Hedge and Johnston 2012). Changes in propagule pressure, defined as the number of individuals arriving or introduced to a location, can assist in facilitating or preventing an invasive species from establishing (Lonsdale 1999). When the cost of dispersal is high, propagules may not arrive in peak fitness or in as many numbers to establish successfully, leading to dispersal mediating propagule pressure (Burgess and Marshall 2011). 
While several studies have focused on propagule pressure as an agent of nonnative species' spread from anthropogenic structures to natural habitat (Clark and Johnston 2005, 2009, Hedge and Johnston 2012, Simkanin et al. 2017), few have studied dispersal ability as a limit to non-native species' spread in marine habitats. Much of the research surrounding dispersal focuses on individual species (Levin 2006). Such focus on species helps in identifying which species are likely to escape marinas but does not provide as much information at the community level.

\subsection{Predation and Biotic Resistance in Fouling Communities}

Once non-native species have overcome abiotic factors, the primary impediments to the establishment of non-native species are biotic interactions. Predation has been identified as a highly influential biotic interaction limiting invasion success (Levine et al. 2004, Harvey et al. 2004, Rilov 2009). In marine systems, several studies have shown the ability of predators to limit marine invaders (Barkai and Branch 1988, Byers 2002, Hunt and Yamada 2003, Castilla et al. 2004, Osman and Whitlatch 2004, de Rivera et al. 2005, Dumont et al. 2011a, Kremer and da Rocha 2016, Rogers et al. 2016)

It is generally accepted that non-native species succeed in new locations due to the lack of their natural enemies (Maron and Vila 2001, Keane and Crawley 2002, Torchin et al. 2003, Colautti et al. 2004, Liu and Stiling 2006, Prior et al. 2014), but native predators can sometimes exert the same pressures on non-native species in the new location as natural enemies did in the original location (Colautti et al. 2004, Wanger et al. 2011). Native organisms that depredate non-native species can help communities resist invasion and prevent spread (Levine et al. 2004, de Rivera et al. 2005, Wanger et al. 
2011, Dumont et al. 2011a, Forrest et al. 2013, Kimbro et al. 2013, Rogers et al. 2016). Additionally, predator abundances differ between anthropogenic and natural habitats (Chapman 2003, Chapman and Blockley 2009, Dumont et al. 2011b, 2011a). Native predators that are prevalent on natural substrate are not as common on anthropogenic structures, potentially providing a refuge for species that settle on anthropogenic structures (Chapman 2003, Dumont et al. 2011b), which allows non-native species to outcompete native fouling species on those structures (Tyrrell and Byers 2007). Additionally, non-native species may be less palatable than native species to small predators present on suspended structures, indirectly facilitating the invasion of those suspended structures (Kincaid 2016). For sessile marine invertebrates, two life history stages are particularly vulnerable to predation: the planktonic larval stage and just after settlement. Much of the work to date focuses on predation on the sessile stages of marine invertebrates.

The fouling community experiences impacts from both large predators (Dumont et al. 2011b, Forrest et al. 2013, Simkanin et al. 2013, Kremer and da Rocha 2016) and small predators (Osman et al. 1992, Osman and Whitlatch 1995, 2004, Nydam and Stachowicz 2007, Rogers et al. 2016). Few of the studies that focused on larger predators address the effects of smaller predators or trophic interactions between predators of differing sizes (Barkai and Branch 1988, Sala 1997, Osman and Whitlatch 2004, Sams and Keough 2007, Lavender et al. 2014, Oricchio et al. 2016). Exclusion studies in subtidal hard-substrate invertebrate systems suggest that larger predators, such as crabs and fish, influence community composition (Sutherland 1974, Russ 1980, Mook 1981, Barkai 
and Branch 1988, Sala 1997, Swain et al. 1998, Vieira et al. 2012, Simkanin et al. 2013). However, other studies indicate that top-down control may not be influencing communities as much as previously thought (Moran 1980, Keough 1984, Davis 1988, Connell 2001a, Sams and Keough 2007, Miller and Etter 2008, Grey 2010). Many of these studies did not acknowledge or identify possible artifacts from excluding large predators, such as the facilitation of mesopredators, which may alter interpretations. For example, Grey (2010) concluded that large predators do not have much of an impact on a non-native tunicate species, Botrylloides violaceus, and that release from large predators may not be an important mechanism contributing to the success of this tunicate in the study site. However, Grey acknowledged that mesopredators might be obscuring effects from large predators, potentially due to the impacts that large predator exclusion has on smaller predators that could obscure the effects of exclusion of large predators (Grey 2010). Miller and Etter (2008) also indicated that mesopredators might influence differences between predator exclusion and control plots, but not the extent to which mesopredators are impacted.

Predation from larger predators, such as crabs and fish, reduces the abundance of mesopredators, particularly gastropods (Hunt and Scheibling 1997). When larger predators are excluded, mesopredator abundance may increase due to having a refuge from their predators. Mesopredation has been shown to contribute to changes in community structure (Ritchie and Johnson 2009, Lavender et al. 2014, Oricchio et al. 2016), indicating that predation across trophic levels is important when considering the limitation of non-native species' spread. 
Predation does not influence fouling community structure alone, but in consort with other factors. Propagule pressure, which is the number of individuals introduced at a single time multiplied by the frequency of introduction events (Eppstein and Molofsky 2007), is important for not only the introduction of a non-native species but also its persistence and success (Colautti and MacIsaac 2004). When the number of introduced individuals is low, it is unlikely that they will establish and succeed, but higher propagule pressure leads to a higher chance of success (Clark and Johnston 2009). Anthropogenic structures associated with shipping are considered to be invasion hotspots (Drake and Lodge 2004), especially with respect to propagule pressure (Drake and Lodge 2007). With increased distance from anthropogenic structures, the occurrence of non-native species has been found to decrease, indicating that propagule pressure more strongly influences the successful establishment of non-native species than does predation (Hedge and Johnston 2012). When non-native species are established on anthropogenic structures, they have the potential to act as a source to supply constant propagules to the surrounding areas, which may influence the pressures both dispersal and predation have on limiting the spread of non-native species into natural habitat.

Few predation studies on limiting the spread of non-native species utilize a community-level approach. Fewer still have looked at the potential for both dispersal limitation and predation to limit the spread of non-native species, especially at the community level. My research aims to tease apart the mechanisms driving the limitation of non-native species' spread to natural habitat, whether it is primarily driven by predation, dispersal, or a combination. 


\section{Chapter 2: The limitation of spread of non-native marine invertebrates from anthropogenic structures to natural habitats}

\section{Introduction}

Biological invasions can be extremely harmful both ecologically and economically (Pimentel et al. 2005). Many invasive species are transported to new locations by humans, allowing them to overcome pre-existing barriers (Wilson et al. 2009). Limiting the further spread of invasive species is crucial to curbing ecological and economic impacts. In some cases, barriers to spread are due to biological or biotic constraints, such as dispersal or predation (Arim et al. 2006).

Marine biological invasions are particularly linked to anthropogenic habitats because of human-associated vectors, which increase the influx of non-native larvae (Carlton and Geller 1993, Floerl and Inglis 2005). Shipping is the primary vector for transport of non-native marine species (Carlton 1985, 1996, Ruiz et al. 1997, 2000). Due to increasing global connectivity, the abundance of non-native species in coastal marine ecosystems has increased over the last 100 years (Cohen and Carlton 1998, Crooks 2005). As shipping frequency increases, so too does influx of non-native larvae, giving them many opportunities to successfully establish (Carlton 1996). The increase in shipping frequency has also resulted in an increase in anthropogenic structures, such as floating docks and pier pilings, in coastal marine ecosystems (Glasby and Connell 1999, Airoldi et al. 2005, Bulleri and Chapman 2010). Because these anthropogenic structures provide unoccupied substrate, they are often preferentially colonized by non-native species over native species (Lambert and Lambert 1998, Glasby et al. 2007, Ruiz et al. 2009). As coastal environments become more developed, it will be crucial to understand 
the connection between anthropogenic structures and nearby natural substrate and how it relates to the spread of non-native species. The transport of non-native species between anthropogenic habitats by humans is well understood (Glasby and Connell 1999, Apte et al. 2000, Floerl et al. 2009, Darling et al. 2009, Darling and Folino-Rorem 2009, Goldstien et al. 2010, Airoldi et al. 2015); less understood is the scale and the mechanisms affecting the spread of non-native species between anthropogenic structures and natural substrate on a local scale.

Because there is high global connectivity between anthropogenic structures due to shipping, species that are better adapted to take advantage of unoccupied (Glasby et al. 2007, Dafforn et al. 2009b) or disturbed environments (Bulleri and Airoldi 2005, Piola and Johnston 2008) often successfully establish on these structures. Greater numbers of non-native species have been observed on natural substrata in bays and estuaries that have a large amount of anthropogenic structure, whereas bays and estuaries with much less anthropogenic habitat have far fewer non-native species on natural substrata (Wasson et al. 2005, Preisler et al. 2009, Ruiz et al. 2009). Additionally, within estuaries, fewer non-native sessile species have been found on natural substrate than on nearby anthropogenic structure (Bulleri and Chapman 2004, Glasby et al. 2007). There is also a difference in community composition between fixed and floating structures (Holloway and Connell 2002), potentially further driving differences between established communities on anthropogenic structures versus natural substrate. The mechanisms restricting the spread of non-native species from anthropogenic structures to natural 
habitats have been explored at the species-specific level but not as frequently at the community level.

For non-native species to successfully establish in a new location, there needs to be sufficient propagule pressure and environmental match to their native range (Catford et al. 2009). Dispersal ability can assist propagule pressure for the successful establishment of non-native species. However, limited dispersal ability may prevent the spread of non-native species from anthropogenic structures to natural substrate. Most benthic invertebrates have a pelagic larval stage that facilitates dispersal. A longer larval stage can potentially lead to dispersal over a larger area (Zinsmeister and Emerson 1979, Scheltema 1986a, 1986b, Bhaud 1993, Shanks et al. 2003), whereas a shorter larval stage will be more restricted in distance from the source population (Mileikovsky 1971, Hedgecock 1986, Scheltema 1986b, Shanks et al. 2003). However, the species with a shorter larval stage are better able to take advantage of nearby suitable habitat (Jackson 1986, Keough and Chernoff 1987). While several studies incorporate propagule pressure as an agent of non-native species' spread from anthropogenic structures to natural habitat (Clark and Johnston 2005, 2009, Hedge and Johnston 2012, Simkanin et al. 2017), few have studied dispersal ability as a limit to non-native species' spread. Fewer still have looked at the potential for both dispersal limitation and predation to limit the spread of non-native species.

When non-native species do successfully overcome environmental barriers and have sufficient propagule pressure to persist in a new area, the primary impediments to the establishment and spread of non-native species are biotic interactions (Catford et al. 
2009). Predation has been identified as an influential biotic interaction limiting invasion success (Harvey et al. 2004, Rilov 2009). In marine systems, several studies have shown the ability of predators to limit marine invaders (Barkai and Branch 1988, Byers 2002, Hunt and Yamada 2003, Castilla et al. 2004, Osman and Whitlatch 2004, Dumont et al. 2011a, Rogers et al. 2016). Native organisms that depredate non-native species can help communities resist invasion and prevent spread (Levine et al. 2004, de Rivera et al. 2005, Wanger et al. 2011, Dumont et al. 2011a, Forrest et al. 2013, Kimbro et al. 2013, Rogers et al. 2016). Native predators that are prevalent on natural substrate are not as common on anthropogenic structures, potentially providing a refuge for species that settle on anthropogenic structures (Chapman 2003, Dumont et al. 2011b), which allows non-native species to outcompete native fouling species on those structures (Tyrrell and Byers 2007).

Because the literature revealed a focus on species-specific studies, I examined community-level differences inside and outside of a marina to tease apart the mechanisms driving the limitation of non-native species' spread to natural habitat. Due to the greater number of non-native species on artificial structures, I hypothesized that the overall fouling community would be different inside the marina from outside of the marina, with greater dominance of non-native species inside the marina. I also predicted that there would be a difference in community structure between depth in the water column (suspended versus benthic) both inside and outside of the marina due to the combined influences of more non-native species on suspended structures inside marinas and greater benthic predation outside of marinas. Additionally, I hypothesized that predation would 
have a stronger influence outside of the marina than inside the marina, leading to differing community structures across suspended and benthic areas inside and outside of the marina. This is consistent with studies that have found artificial structures to be a refuge from predators, causing greater non-native species on these structures (Moreau et al. 2008, Dumont et al. 2011b, Forrest et al. 2013). I also hypothesized that both dispersal limitation and predation play a role in structuring fouling communities inside and outside of the marina. Because anthropogenic habitats influence hydrodynamics (Floerl and Inglis 2003, Marzinelli et al. 2012) and fouling community species have differences in larval duration (Grantham et al. 2003), dispersal ability likely plays a role in structuring fouling communities in addition to biotic interactions. Therefore, I addressed this information gap by conducting a fully crossed three-factor experiment, examining the influences of location (inside versus outside of the marina), depth (suspended versus benthic), and predation (tiles accessible to larger predators versus predators excluded by mesh) on the composition of the fouling community. I also transplanted tiles to examine the effects of predation on out-of-marina tiles that were not dispersal limited (originally colonized suspended inside the marina) for different development stages (juveniles and adults). I also compared which species were found in the marina to those found outside the marina and the overlap therein. Through this study, I aimed to discern the extent to which predation, dispersal, or a combination of both influenced fouling community structure as well as the role these mechanisms play in limiting the spread of non-native species. 


\section{Methods}

$\underline{\text { Study Site }}$

This study was conducted in two habitat types (anthropogenic structure and natural substrate) at the Embarcadero Marina in Newport, Oregon (44.629846 ${ }^{\circ}$ $124.041050^{\circ}$, Figure 1A). The marina is on the northern side of Yaquina Bay along with two other marinas and is enclosed by a man-made breakwater. A shipping terminal is located 600 meters east of the entrance to the marina. There are 223 year-round slips and the boats utilizing the marina included recreational vessels, some of which had been immobile for a significant length of time, and chartered fishing vessels. Anthropogenic structure in the marina consisted of floating docks and fixed pilings. Natural substrate adjacent to the marina included soft, muddy substrate, which was dominant, scattered eel grass (Zostera sp.) beds, and very little natural rock $(<1 \%)$ as well as some riprap.

While thermal and flow conditions varied between the marina and the surrounding habitat, some measures, like average depth, salinity, and dissolved oxygen, were similar across the two settings. Depth inside the marina ranged from 2.7 meters to 7.5 meters with an average of 4.72 meters. Depth outside the marina ranged from 3.4 meters to 5.7 meters with an average of 4.71 meters. The average temperature inside the marina was $14.38^{\circ} \mathrm{C}$ at the surface and $13.05^{\circ} \mathrm{C} 3$ meters below the surface. Average temperature outside the marina was $13.28^{\circ} \mathrm{C}$ at the surface and $12.29^{\circ} \mathrm{C} 3$ meters below the surface. Average salinity inside the marina was $32.88 \mathrm{ppt}$ at the surface and $33.32 \mathrm{ppt} 3$ meters below the surface. Outside the marina, average salinity was $33.22 \mathrm{ppt}$ at the surface and 33.47ppt 3 meters below the surface. Dissolved oxygen (DO) averaged 7.81 $\mathrm{mg} / \mathrm{L}$ inside the marina and $8.11 \mathrm{mg} / \mathrm{L}$ outside the marina. Inside the marina, DO ranged 
from $5.68 \mathrm{mg} / \mathrm{L}$ to $11.67 \mathrm{mg} / \mathrm{L}$. DO ranged from $5.21 \mathrm{mg} / \mathrm{L}$ to $12.47 \mathrm{mg} / \mathrm{L}$ outside the marina. Water flow was much calmer inside the marina than outside. There was often surface scum in the marina, especially furthest from the mouth of the marina.

\section{Field Sampling}

Community assemblages of sessile marine invertebrates were studied in JuneSeptember 2016 in Yaquina Bay, Newport, Oregon. This community is ideal for this experiment given the rapid community development and high occurrence of both native and non-native species in marinas (Ruiz et al. 2009). Paired unglazed ceramic tiles $(14.6 \mathrm{~cm} \times 14.6 \mathrm{~cm})$ were used as passive collectors for fouling community organisms. I used ceramic tiles because they more closely resemble natural submerged hard substrate than do PVC or wood panels and research suggests PVC enhances non-native species (Tyrrell and Byers 2007). Tidal regime and flow patterns (which could also affect dispersal patterns) were observed to determine the best locations for paired settling tiles.

The experimental design entailed deploying replicate experimental apparatuses inside and outside of the marina, each of which included a tile for each of the six predation-by-depth treatment combinations described below. The experimental apparatuses were anchored with a cinderblock and either suspended from docks (Inside Marina) or buoyed (Outside Marina). They held the tiles, unfinished side down, at each of two depths in the water column (Figure 1B). One group of tiles on the experimental apparatus was fixed $0.25 \mathrm{~m}$ above the substrate to measure recruitment to or survival near the benthos (Benthic). Tile depth varied, depending on tidal stage, between 2.5 meters 
and 7.25 meters inside the marina and between 3.25 meters and 5.5 meters outside the marina. The other group floated one meter below the surface, consistently due to being attached to either floating docks or floats, to mimic substrata available for colonization in the suspended environment far above the benthos (Suspended).

Three tiles were suspended at each depth, one tile for each of three levels of the predation treatment: Full Cage, Partial Cage, No Cage (Figure 1B). The mesh cages aimed to exclude larger predators (those greater than a diameter or width of $1.3 \mathrm{~cm}$ ) and were made from Vexar ${ }^{\circledR}$ plastic mesh. The partial cages, meant as a control for cage effects on recruitment, water flow, etc., included the cage sides but no cage bottom so predators could theoretically access the tiles. Caging was scrubbed off on a bi-weekly basis to remove any growth that might prevent natural water flow over the tiles and thus access by marine invertebrate larvae. Tiles were deployed for 12 weeks to allow sufficient time for recruitment of multiple species and growth of the organisms to aid identification. Some of the Inside Marina experimental apparatuses were lost soon after deployment, so replacement apparatuses were deployed 4 weeks after the initial deployment, allowing for only 8 weeks in the water. Community differences between the two deployment times were examined using used Permutational Multivariate Analysis of Variance (PERMANOVA) and none were found, so they were grouped together for the purposes of analysis.

To explore differences in recruitment and predation inside versus outside the marina, experimental apparatuses were deployed in and outside of the marina. Seven experimental apparatuses, holding 42 tiles in total, were deployed in the marina (Inside 
Marina, Figure 1C). These experimental apparatuses were distributed randomly across the four docks of the marina. Seven experimental apparatuses were also deployed randomly outside of the marina in a cluster at the edge of the channel between 115 and 160 meters from the entrance to the marina (Outside Marina, Figure 1C).

In addition, tiles were transplanted to examine predation when dispersal limitation of the community inside the marina is removed from the equation, i.e. what happens to both recruits and adults if they can get outside of the marina. Transplants of both recruit and adult communities were moved from Suspended Inside Marina Full Cage to Outside Marina and distributed randomly across the six predation-by-depth treatment combinations (Full Cage, Partial Cage, or No Cage, and Suspended or Benthic). A set of 42 caged tiles were suspended from the docks in the marina 1 meter below the water's surface on June 25, 2016. Another 42 caged tiles were suspended from the docks in the marina 1 meter below the water's surface on July 22, 2016. The tiles deployed in June were deployed for 12 weeks in the marina to allow the adult community to develop. After those 12 weeks, the tiles were transplanted, using the same experimental apparatus set up, to the same location outside of the marina (Adult Transplant Experiment, Figure 1D). The tiles were split randomly among the two depths, Suspended and Benthic, and three predation treatments, No Cage, Partial Cage, and Full Cage. The 7 experimental apparatuses were deployed outside of the marina for 1 week and then collected and transported back to Portland State University. Following, this transplant will be referred to as Adult Transplant Experiment. 
The remaining 42 tiles that were deployed in July were deployed in the marina for 5 weeks to allow the recruit community to develop (Recruit Transplant Experiment, Figure 1D). The recruit tiles were checked after three weeks but had only minimum colonization, so they were left in place for two more weeks. After 5 weeks, the Recruit Transplant Experiment tiles were temporarily retrieved and processed, recording counts per lowest taxonomic group possible, at the Hatfield Marine Science Center before redeployment. Structural group per phyla, such as clonal ascidians versus solitary ascidians, provided the lowest taxonomic grouping of these recruits that could reliably be useful given the size of the organisms and this quick check between deployments.

The Recruit Transplant Experiment tiles were then transplanted, using the same experimental apparatus set up as above, to the same location outside of the marina as the other experimental apparatuses. These Recruit Transplant Experiment tiles were randomly assigned to the six different depth-by-predation treatment combinations (Suspended or Benthic; Full Cage, Partial Cage, or No Cage). The experimental apparatuses were deployed outside of the marina for 10 days and then collected and transported back to Portland State University for processing while they were still alive. Following, this transplant will be referred to as Recruit Transplant Experiment.

At deployment, each biweekly cage cleaning, and retrieval, environmental data were collected at three different locations inside and three locations outside of the marina. Water temperature, dissolved oxygen, and salinity were collected for the entire water column at 1-meter intervals. Water clarity was collected using a Secchi disk. Depth was also collected. 


\section{$\underline{\text { Laboratory Data Collection }}$}

After all the experimental apparatuses were deployed for the length of time associated with their group (12 weeks for Inside and Outside Marina, 13 weeks for the Adult Transplant Experiment, 6.5 weeks for the Recruit Transplant Experiment), the tiles were collected and transported back to Portland State University. Each tile was stored in its own container on water tables for up to 21 days, depending on how long after transport the tile was processed, and examined live under microscopes. Despite the length of time on the water tables, species were equally identifiable later in the process as earlier. Residence time on the water tables was distributed by treatment. Therefore, the variance reported in the results may have increased but there was not a systematic bias.

Colonized species were identified to the lowest taxonomic level possible, typically to species, and point counts were conducted to estimate cover for all the tiles with adult communities (Inside Marina, Outside Marina, and Adult Transplant Experiment). For any species that I was unable to identify, I used morphospecies for which I identified the lowest taxonomic level possible, typically family or genus, and assigned a number based on morphology and kept identification consistent across all groups (i.e. Porifera 1). Because each species was distinct, they were included in species richness and community composition analyses.

To process the tiles, I followed procedures established by the Smithsonian Environmental Research Center's Marine Invasions Research Laboratory. Trained laboratory assistants and I conducted point counts using a 7x7 grid to ensure maximum coverage of the tile. For every square of the grid, we identified what species was in the 
upper right corner, if any, and then recorded a $50^{\text {th }}$ random point. If there were two overlapping species on the same point, the individual attached directly to the tile was recorded as the primary species and the overlapping individual was recorded as the secondary species. Because the Recruit Transplant Experiment tiles had been processed using total counts before redeployment, we conducted total counts again to the lowest taxonomic level as described above.

Once each tile was processed, a second person verified the point counts and species identifications to make sure nothing was missed.

\section{$\underline{\text { Data Analysis }}$}

Point counts were converted to percent cover for each tile for all species to characterize community assemblage for Suspended and Benthic depths within each group (Inside Marina, Outside Marina, and Adult Transplant Experiment). I calculated percent cover by dividing the total number of points, both primary and secondary, for each species, and then dividing by 50 (total number of points). Because of the overlapping nature of these organisms, total cover was greater than $100 \%$ cover in some cases. I converted percent cover per species to percent cover by invasion status using organisms that were identifiable to species. Clear patterns about non-native species emerged from the data even though not all morphospecies could be identified to species level and assigned to a native versus non-native classification. I also calculated species richness for Benthic and Suspended No Cage tiles both Inside and Outside Marina to characterize the community. I created generalized linear models (GLMs) to determine differences in the 
baseline communities using species richness, species richness by invasion status, and differences in non-native cover between the four groups (Inside Marina or Outside Marina and Suspended or Benthic). To generate the models, I used the R function "glm()" with Poisson error distribution (family = Poisson) and the log link function. I used Poisson error distribution for the GLM of non-native cover because of the high number of zeros in the data due to not finding anything at a particular point. For characterizing the baseline communities, two GLMs were performed. One used species richness as the dependent variable and the other used non-native species richness as the dependent variable while location (categorical: Inside or Outside Marina) and depth (categorical: Suspended or Benthic) served as the predictor variables for both models. For non-native cover, the proportion of identifiable percent cover that was non-native was the dependent variable while location (categorical: Inside or Outside Marina) and depth (categorical: Suspended or Benthic) served as the predictor variables. Additionally, I used the R function "glht()" from the "multcomp" R package (Hothorn et al. 2016) to perform a post hoc multiple comparison analysis for the interaction between predictor variables.

To determine if fouling community assemblages were different between No Cage and Partial Cage tiles, I used Permutational Multivariate Analysis of Variance (PERMANOVA) (Anderson 2001). To ensure that the data met the assumption for PERMANOVA (homogeneity of multivariate dispersions between groups), I used the "betadisper" function in the "Vegan" R package (Oksanen et al. 2017) to assess the groups with a Bray-Curtis dissimilarity measure. This function provides a multivariate equivalent of Levene's test. PERMANOVA was then performed for each location and 
depth combination (Inside, Outside, and Adult, and near the surface and near the benthos) to test the null hypothesis that the centroids of each location as defined in the space of Bray-Curtis dissimilarity were equivalent among locations using "adonis" in the "Vegan" R package (Oksanen et al. 2017). This comparison revealed that, for the most part, the caging did not have an impact. The only communities that were significantly different from one another with respect to No Cage versus Partial Cage were the Outside Marina Benthic tiles (Table 1). The tests for homogeneity of multivariate dispersions did not detect statistically significant heterogeneity in dispersions between caging treatment for any location and depth $(\mathrm{p}>0.05)$. Therefore, all subsequent analyses will only compare No Cage to Full Cage tiles.

I characterized distinctive aspects of each invertebrate assemblage by using the Dufrêne-Legendre indicator species analysis in R ("labdsv", Roberts 2016). The indicator value (IV) of a species for an assemblage was the product of the relative abundance and the relative frequency of the species in the assemblage. The statistical significance of the IV was tested using a permutation test. Only significant species $(\mathrm{p}<0.05)$ with IVs greater than 0.20 were reported because those species largely define the characteristics of the assemblage.

I used PERMANOVA to compare the invertebrate assemblages across the different experimental treatments. Before conducting any PERMANOVA analyses, I tested for homogeneity of multivariate dispersions among groups by using the "betadisper" function. If this test did not detect statistically significant heterogeneity in dispersions among locations and depths ( $>0.05)$, the assumption was considered met and 
I was able to report the results of the PERMANOVA. Specifically, I used PERMANOVA to determine whether the communities on the tiles differed given five comparisons of tiles aimed at exploring different, related questions. 1) I compared general differences among the communities Inside versus Outside Marina with no manipulation (No Cage tiles) to determine if the baseline communities were different from one another. 2) I compared differences among the communities Inside and Outside Marina when large predators were excluded (Full Cage tiles) to address dispersal. 3) I compared differences between the Inside Marina Suspended and the Outside Marina Benthic communities to address predation. 4) I compared differences between Suspended and Benthic Full Cage and No Cage Adult Transplant Experiment tiles to further explore predation. 5) I compared differences between Inside Marina Suspended Full Cage tiles and Adult Transplant Experiment Benthic Full Cage and No Cage tiles to explore the effects of large and small predators.

Whenever the null hypothesis was rejected for the overall model being tested, I conducted pairwise PERMANOVA tests using Bonferroni's correction on each pair of groups within the model to determine which factors contributed most strongly to the overall difference. Non-metric multidimensional scaling, based on a Bray-Curtis similarity matrix, plotted the community data from the different treatments and ellipses of standard error around the centroids of each group helped visualize their differences. All analyses were performed using R statistical software version 3.3.2 (R Development Core Team 2016). 

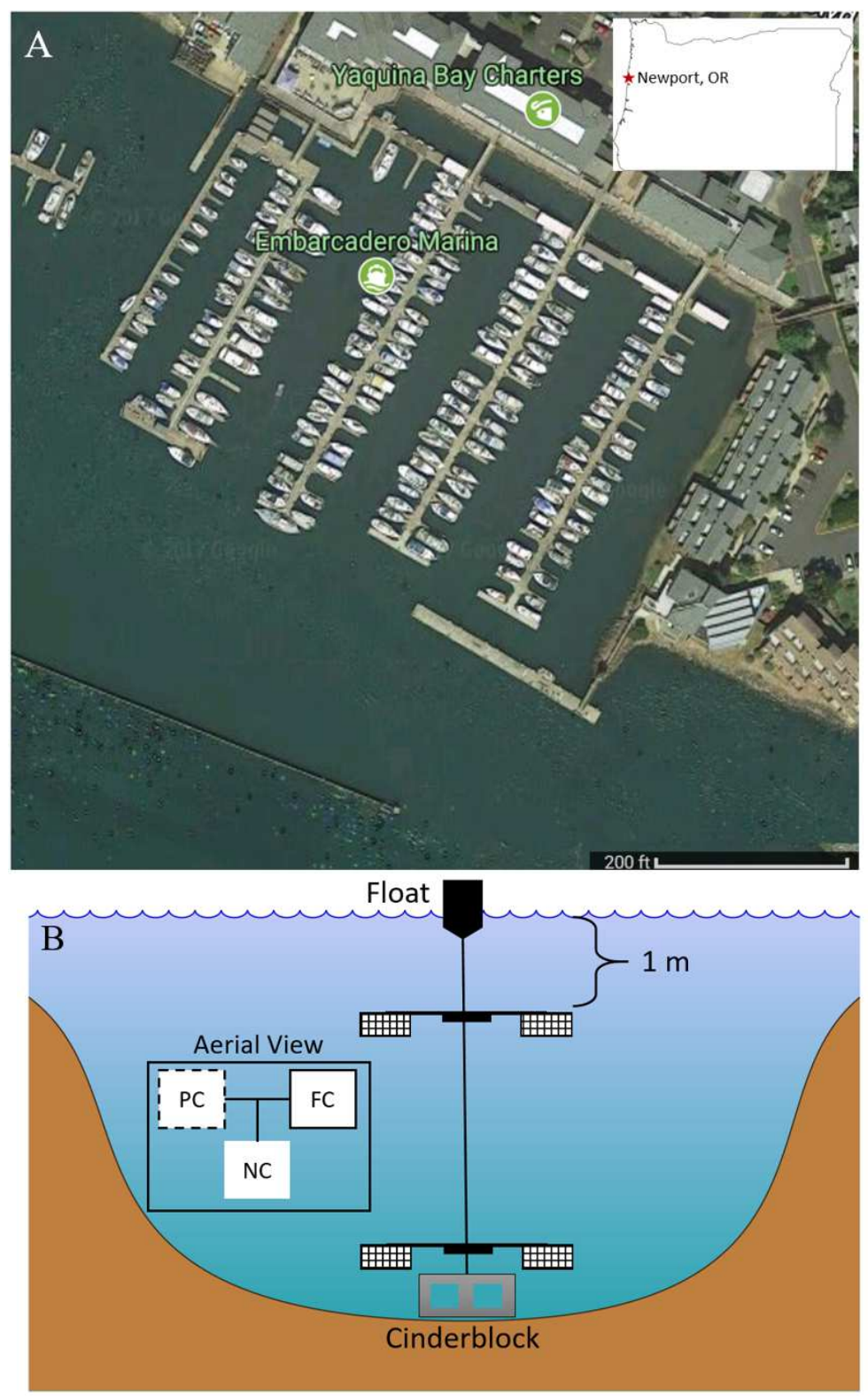

C

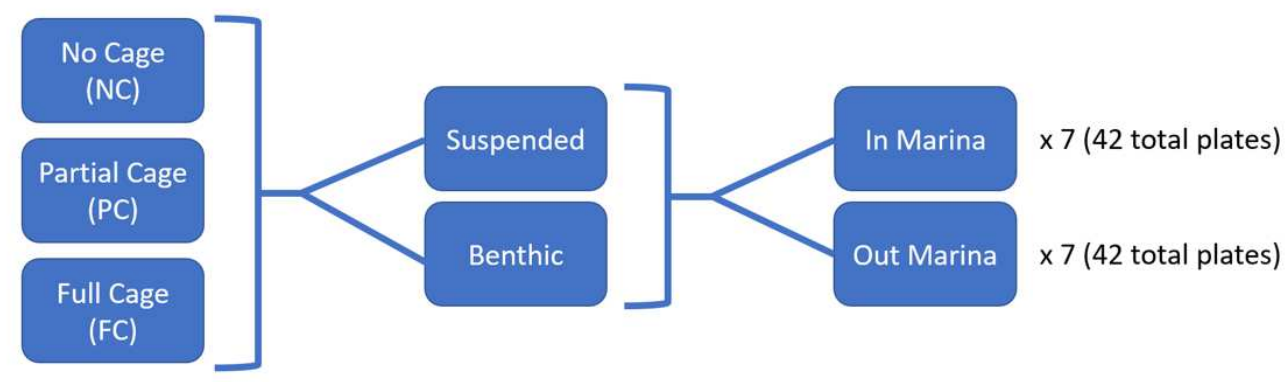




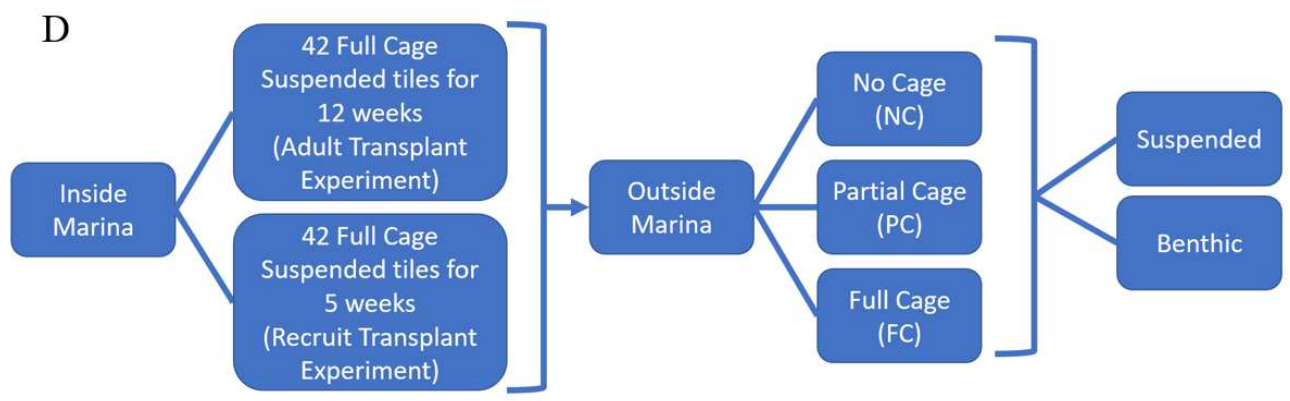

Figure 1. A) Map of study site. B) Experimental apparatus with paired settling tiles 1 meter below the surface (Suspended) and just above the cinder block near the substrate (Benthic) for Full Cage (FC), Partial Cage (PC), and No Cage (NC) predation treatments. 7 apparatuses were deployed inside the marina and 7 were deployed outside the marina. C) Three-factor experimental design set up. D) Settling tile transplant design set up.

Table 1. Analysis of distance tables assessing if there are caging artifacts (No cage vs. Partial cage) that might influence fouling community assemblages. Adult = inside the marina fully caged near the surface for 12 weeks and then moved outside of the marina across 2 depths and 3 caging treatments for one week. Inside = inside the marina for the duration of the experiment. Outside = outside the marina for the duration of the experiment. Suspended $=$ near surface. Benthic $=$ near benthos. $*$ indicates statistical significance $(p<0.05)$

\begin{tabular}{|c|c|c|c|c|c|c|}
\hline Source of variation & $\mathrm{df}$ & SS & MS & $\mathrm{F}$ & $\mathrm{R}^{2}$ & $\mathrm{P}$ value \\
\hline \multicolumn{7}{|c|}{ A. Adult Transplant Experiment Suspended } \\
\hline Cage treatment & 1 & 0.22 & 0.22 & 1.27 & 0.11 & 0.280 \\
\hline Residuals & 10 & 1.72 & 0.17 & & & \\
\hline \multicolumn{7}{|c|}{ B. Adult Transplant Experiment Benthic } \\
\hline Cage treatment & 1 & 0.13 & 0.13 & 0.82 & 0.08 & 0.600 \\
\hline Residuals & 10 & 1.54 & 0.15 & & & \\
\hline \multicolumn{7}{|c|}{ C. Inside Marina Suspended } \\
\hline Cage treatment & 1 & 0.26 & 0.26 & 0.78 & 0.08 & 0.611 \\
\hline Residuals & 9 & 3.00 & 0.33 & & & \\
\hline \multicolumn{7}{|c|}{ D. Inside Marina Benthic } \\
\hline Cage treatment & 1 & 0.04 & 0.04 & 0.45 & 0.04 & 0.793 \\
\hline Residuals & 10 & 0.80 & 0.08 & & & \\
\hline \multicolumn{7}{|c|}{ E. Outside Marina Suspended } \\
\hline Cage treatment & 1 & 0.01 & 0.01 & 0.22 & 0.02 & 0.952 \\
\hline Residuals & 12 & 0.58 & 0.03 & & & \\
\hline \multicolumn{7}{|c|}{ F. Outside Marina Benthic } \\
\hline Cage treatment & 1 & 0.65 & 0.65 & 5.78 & 0.33 & $0.008^{*}$ \\
\hline Residuals & 12 & 1.34 & 0.11 & & & \\
\hline
\end{tabular}

Each table was generated using permutational multivariate analysis of variance (PERMANOVA) $d f$ degree of freedom, $S S$ sum of squares, MS mean of squares, $F$ pseudo- $F$ ratio 


\section{Results}

Does Community Characterization Change Across Location and Depth?

The interaction between location and depth resulted in a significant difference in species richness (Figure 2, Table 2). This significant difference was in part driven by significant differences between Inside Marina and Outside Marina with respect to differences in depth. Namely, Inside Marina Suspended No Cage was significantly different from Outside Marina Suspended No Cage and Inside Marina Suspended No Cage was significantly different from Outside Marina Benthic No Cage (Table 3). However, the differences in depth did not influence species richness within a location. Inside Marina species richness was greater on the Suspended No Cage tiles than on the Benthic No Cage tiles but not significantly so (Figure 2, Table 3). Outside Marina species richness trends were opposite, with greater, but not significantly greater, richness on the Benthic No Cage tiles than on the Suspended No Cage tiles (Figure 2, Table 3). To explore what was driving some of these differences, I broke species richness down by invasion status (Figure 3). The average number of native species was similar across the four groups, but non-native species were significantly greater on Inside Marina Suspended tiles than in the other groups, indicating that the difference between Inside and Outside Marina is partially driven by the limitation of spread of non-native species (Table $4)$.

The composition of invertebrate assemblage on Inside Marina Suspended No Cage tiles was significantly different from the assemblage on No Cage tiles at the other three placements, Inside Marina Benthic, Outside Marina Suspended, and Outside Marina Benthic (Figure 4, Table 5). Most importantly for assessing the potential of invasion of 
fouling organisms on floating docks to the surrounding communities, the community assemblage Inside Marina Suspended was significantly different from the community assemblage Outside Marina Benthic (PERMANOVA, F=8.91, $\mathrm{p}=0.002$ ). Additionally, community assemblage on Suspended Outside Marina tiles significantly differed from community assemblages on Inside Marina Benthic tiles and Outside Marina Benthic tiles (PERMANOVA, $\mathrm{F}=7.41, \mathrm{p}=0.005 ; \mathrm{F}=22.72, \mathrm{p}=0.001$, respectively).

Point counts used for percent cover found non-native species only occurred in the point counts of Suspended tiles but not on Benthic tiles, with non-native species occurring both Inside and Outside Marina (Figure 5). The lack of non-native species from Outside Marina Benthic tile point counts may have been due to the domination of native species on these tiles, mostly Balanus crenatus. Because identification was to morphospecies for some species, the cover of non-native species may not reflect the exact composition and invasion load of the whole community, so I also looked at non-native cover as a proportion of total identifiable cover (Figure 6). There were no significant differences among the four groups for proportional non-native percent cover (GLM: $p$ > 0.05 for both predictor variables and the interaction between predictor variables). However, there was a clear difference between Inside Marina Suspended and Outside Marina Suspended (Figures 5,6). This difference in cover is partially attributed to the domination of Balanus crenatus, a native barnacle, outside the marina. Additionally, though non-native species were present outside the marina, they were not abundant enough to be picked up in the point counts, which I used to calculate percent cover. 
The Dufrêne-Legendre indicator species analysis identified significant indicator species ( $\mathrm{p} \leq 0.05$ ) for 6 out of 8 location-depth-caging combinations (Table 6 ). These species largely define the characteristics of the assemblages by combining their relative abundance with their relative frequency of occurrence and the resulting association between the species and the group of sites (Dufrêne and Legendre 1997). When species have significant, high indicator values, it indicates that species is particularly characteristic of that group. All but one of the indicator species for the Inside Marina assemblages was non-native. Invasion status for Alcyonidium sp. was unable to be determined because it was identified using morphospecies. Three of four Outside Marina depth-caging combinations (Benthic Caged, Suspended Caged, and Suspended Uncaged) were characterized by Balanus crenatus $(\mathrm{IV}=0.241, \mathrm{IV}=0.287, \mathrm{IV}=0.218, \mathrm{p}=0.001$ for all; Table 6). Balanus crenatus is the only one of the indicator species identified to species that is native. While none of the indicator species were isolated to one location, which would be indicated by an indicator value of 1 , separating by caging treatments and depth could have diluted the results somewhat.

Does Dispersal Play a Role in Structuring Fouling Communities and Contribute to Limiting the Spread of Non-Native Species?

When large predators were excluded (Full Cage tiles) so I could better examine the dispersal patterns, I found invertebrate assemblages Suspended Inside Marina were significantly different from Benthic Inside Marina, Suspended Outside Marina, and Benthic Outside Marina communities (Figure 7, Table 7). The difference between the 
Outside Marina communities and the Inside Marina Suspended community suggests that dispersal may be playing a role in what species are able to settle outside of the marina.

Thirty-one total species were found in the Inside Marina Suspended community (Table 8). I then looked at which of those species were not found outside of the marina at all to see if dispersal might be limited for those species. Of those 31 , three were not found outside the marina at all, Schizoporella errata, Kamptozoa 1, and Urochordata 2, but depth and predation could be impacting which species were not found outside the marina. Therefore, I looked at which of those 31 species were not found on Outside Marina Suspended tiles as well as those that were not found on Outside Marina Benthic tiles. Seven of those 31 species were not present in the Suspended Outside Marina community, including four bryozoans, two tunicates, and a kamptozoan (Table 8). Six species were not present in the Benthic Outside Marina community, three of which were also not found in the Suspended community (Schizoporella errata, Kamptozoa 1, and Urochordata 2). Interestingly, the other three species not present in the Benthic community (Conopeum cf. tenuissimum, Obelia longissima, and Oyster) were all present on the Outside Marina Suspended Full Cage tiles, indicating that they are able to get out of the marina but perhaps not to the benthos, or that small predators are eating the early settlers. The presence of some of these species on the Outside Marina Suspended tiles suggests that these species might be able to use floating structures, such as buoys, outside of the marina to facilitate spread. Additionally, all the identifiable species not present in either Suspended or Benthic communities outside of the marina are non-native. 
However, there are species that can make it out of the marina, but were in low numbers or restricted to Full Cage tiles, indicating impacts from predation. Seven species of the 31 present in the Suspended Inside Marina community were also present on Outside Marina Suspended Full Cage tiles but not on Outside Marina Suspended No Cage tiles. Of those, four were identified to species and three of those four are nonnative. Five of the 31 species present in the Suspended Inside Marina community were present on the Outside Marina Benthic Full Cage tiles but not on the Outside Marina Benthic No Cage tiles. Three of those were identified to species and two of these are nonnative (Table 8). The fact that these species were found on the Full Cage tiles indicated that they could disperse out but that predation is likely limiting their spread. However, if there are floating structures, such as buoys, close to the marina, they could act as stepping stones for these species to spread, especially for the species that made it only to the Outside Marina Suspended tiles.

\section{Does Predation Play a Role in Structuring Fouling Communities and Contribute to}

\section{Limiting the Spread of Non-Native Species?}

Comparing the No Cage communities to the Full Cage communities allowed me to examine the influence of predation on community composition. The comparison between the No Cage and Full Cage communities inside the marina and outside of the marina revealed differences (Figure 8, Table 9). Outside Marina Benthic No Cage invertebrate assemblages were significantly different from Outside Marina Benthic Full Cage assemblages, indicating that predation influence community composition in these 
benthic areas (PERMANOVA, $\mathrm{p}=0.001$ ). In contrast, the Inside Marina Suspended communities of Full Cage versus No Cage tiles overlapped substantially (Figure 8). The differences between Outside Marina Benthic Full Cage and No Cage communities might be slightly greater due to possible influences from the caging itself (rather than just its exclusion of predators) given that the No Cage and Partial Cage communities were significantly different from one another in this one setting $(\mathrm{p}=0.008$, Table 1$)$.

To further tease apart the potential impacts of predation given the difference between inside and outside of the marina, I compared Suspended and Benthic, Full Cage and No Cage Adult Transplant Experiment communities after the 1-week transplant (Figure 9, Table 10). Using the Adult Transplant Experiment Full Cage and No Cage communities allowed me to look at the impact of predation outside the marina on the Inside Marina Suspended Full Cage community and provided the same starting community. While the Benthic Full Cage and Benthic No Cage communities were not significantly different, the Suspended Full Cage and Suspended No Cage communities were significantly different from one another (PERMANOVA, $\mathrm{p}=0.004$ ), indicating impacts from fish predation or some other swimming predator.

To determine the impacts of predation on the Benthic Adult Transplant Experiment community, I compared Adult Transplant Experiment Benthic Full Cage and No Cage communities to their starting community (Inside Marina Suspended Full Cage), which revealed some slight differences (Figure 10, Table 11). The PERMANOVA indicated that there was a significant difference among groups, but none of the pairwise PERMANOVAs came out as significant given the Bonferroni correction. However, the 
difference between the Adult Transplant Experiment Benthic Full Cage community and the Inside Marina Suspended Full Cage community was very close to the significance threshold ( $\mathrm{p}=0.018$ ), indicating that the difference between those two communities is driving the significant difference in the PERMANOVA. The fact that the Adult Transplant Experiment Benthic No Cage community was not significantly different from the Inside Marina Suspended Full Cage community potentially suggested that large predators are not depredating adult fouling species and predation is more likely shaping the community as recruits, though the $p$-value is still very low $(p=0.061)$, not allowing for a definitive conclusion.

The proportion of bare space on the tiles among the different groups reinforced the idea that predation from large predators had more of an impact on recruits than on adults. The amount of bare space on the Outside Marina Benthic tiles was significantly greater on the No Cage tiles than on the Full Cage tiles (Figure 11, GLM post-hoc: $\mathrm{p}<$ 0.001). The same pattern was true of the Adult Transplant Experiment Suspended tiles, again indicating predation by predators in the water column, such as fish (GLM post-hoc: $\mathrm{p}<0.001)$. There was more significantly bare space on Inside Marina Suspended No Cage tiles than on Outside Marina Suspended No Cage tiles (GLM post-hoc: $\mathrm{p}<0.001$ ) as well as significantly more bare space on Inside Marina Benthic Full Cage tiles than on Outside Marina Benthic Full Cage tiles (Figure 11, GLM post-hoc: $\mathrm{p}<0.001$ ). Even though bare space is zero on the Outside Marina Suspended Full Cage tiles, there is no significant difference from the Inside Marina Suspended Full Cage tiles. Outside Marina Benthic No Cage tiles had significantly more bare space than did Inside Marina Benthic 
No Cage tiles (Figure 11, GLM post-hoc: $\mathrm{p}<0.001$ ). Outside Marina Suspended Full Cage and No Cage tiles had very little or no bare space as did the Outside Marina Suspended Full Cage tiles.

One factor that could have impacted the effects of large predators is predation from small predators (mesopredators) that were able to fit through the caging, such as nudibranchs and small crabs. The greatest number of mesopredators was found on the Outside Marina tiles upon retrieval, especially the Benthic tiles (Figure 12). A generalized linear model (Mesopredator Abundance $\sim$ Location*Depth*Caging) did not reveal any significant differences among the groups. However, the low number of mesopredators found on Inside Marina tiles and that three of the Inside Marina groups had zero mesopredators could be washing out potential differences. Therefore, I looked at differences between the different Outside Marina groups.

Mesopredator abundance was greater on Full Cage tiles than on No Cage tiles between Suspended and Benthic tiles (Fisher's exact $p<0.001$ ), indicating that the caging is possibly providing mesopredators with a refuge from larger predators, potentially impacting the results from the exclusion of large predators. Mesopredation could be assisting in limiting the spread of species from inside the marina to outside the marina by not only depredating recruits but also adults. There were many fewer mesopredators on the Adult Transplant Experiment tiles, indicating that either the mesopredators did not have enough time to get to those tiles during the week they spent outside the marina or that mesopredators typically eat early settlers rather than adults. However, anecdotally, I saw many nudibranchs presumably eating barnacles on the tiles 
both as I retrieved them in the field and later as I processed the tiles in the lab and I found many empty barnacle shells. It is also interesting to note for the Adult Transplant Experiment tiles that the mesopredators were only found on caged tiles and, for the rest of the tiles, they were similarly only found on Full Cage tiles in all but the Outside Marina Benthic setting, again indicating that caging may be providing a refuge for these smaller predators.

Due to the late recruitment of many species onto the tiles that were moved from inside the marina to outside the marina after 5 weeks of development fully caged near the surface (Recruit Transplant Experiment), the data aimed at evaluating predation on many structural phyla groups were inconclusive. Therefore, only two structural phyla groups were used for analysis: clonal erect bryozoans and solitary erect Porifera. There were no significant differences among caging treatments for either structural phyla group (Kruskal-Wallis, Bryozoa: $\mathrm{p}=0.93$, Porifera: $\mathrm{p}=0.15$ ).

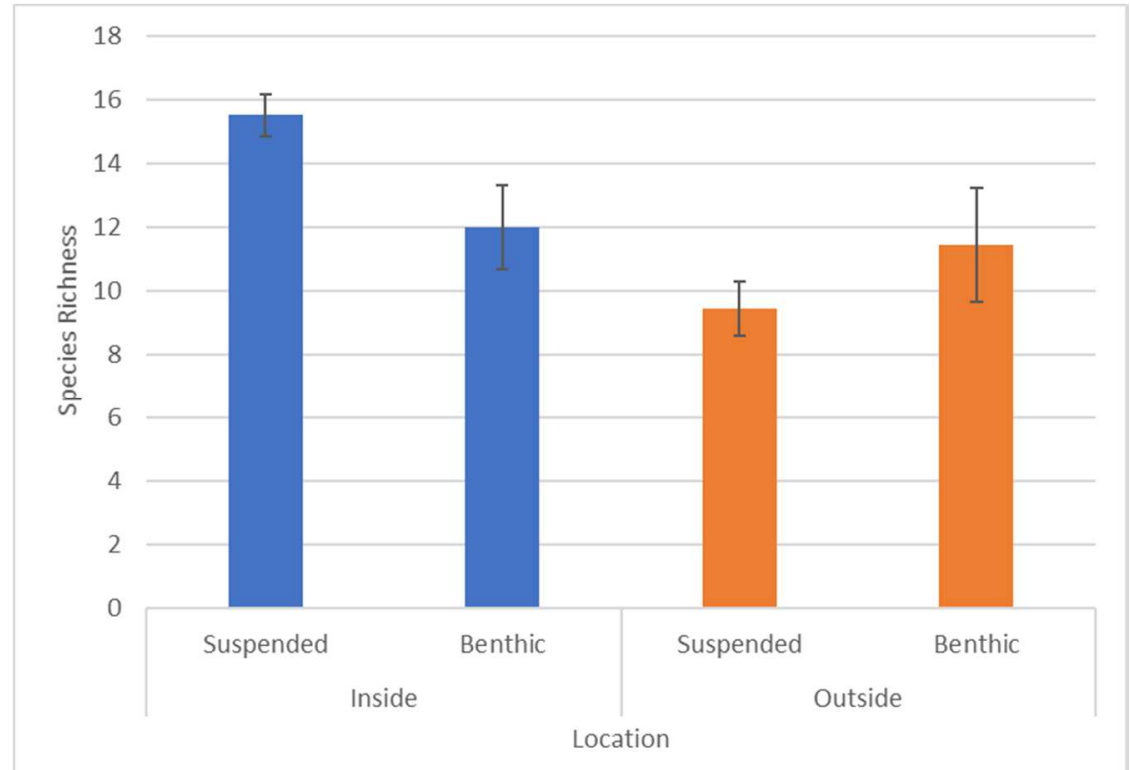

Figure 2. Average species richness on No Cage tiles across 2 depths (Suspended and Benthic) and 2 locations (Inside = inside the marina for the duration of the experiment, Outside = outside the marina for the duration of the experiment). Error bars are \pm 1 standard error. 
Table 2. Generalized linear model summary output for species richness on No Cage tiles across 2 depths (Suspended and Benthic) and 2 locations (Inside = inside the marina for the duration of the experiment, Outside $=$ outside the marina for the duration of the experiment). Model: Species Richness $\sim$

Location*Depth. * indicates statistical significance $(p<0.05)$.

\begin{tabular}{|l|l|l|l|l|}
\hline & $\begin{array}{c}\text { Estimate } \\
\text { (Coefficient) }\end{array}$ & $\begin{array}{c}\text { Standard } \\
\text { error }\end{array}$ & \multicolumn{1}{|c|}{$z$} & $p$ \\
\hline (Intercept) & 2.48 & 0.12 & 21.09 & $<0.00001$ \\
\hline Location & -0.05 & 0.16 & -0.30 & 0.764 \\
\hline Depth & 0.26 & 0.16 & 1.63 & 0.103 \\
\hline Location:Depth & -0.51 & 0.24 & -2.17 & $0.030^{*}$ \\
\hline
\end{tabular}

Table 3. Summary output of post-hoc generalized linear model comparisons of means for average species richness on No Cage tiles across 2 depths (Suspended and Benthic) and 2 locations (Inside Marina and Outside Marina). p-values are unadjusted. ${ }^{*}$ indicates statistical significance $(p<0.05)$.

\begin{tabular}{|l|l|l|l|c|}
\hline & $\begin{array}{c}\text { Estimate } \\
\text { (Coefficient) }\end{array}$ & $\begin{array}{c}\text { Standard } \\
\text { error }\end{array}$ & $z$ & $p$ \\
\hline $\begin{array}{l}\text { Inside Marina Suspended vs. } \\
\text { Inside Marina Benthic }\end{array}$ & 0.26 & 0.16 & 1.63 & 0.10302 \\
\hline $\begin{array}{l}\text { Inside Marina Suspended vs. } \\
\text { Outside Marina Suspended }\end{array}$ & -0.56 & 0.17 & -3.27 & $0.00109^{*}$ \\
\hline $\begin{array}{l}\text { Inside Marina Suspended vs. } \\
\text { Outside Marina Benthic }\end{array}$ & 0.30 & 0.15 & 1.99 & $0.04568^{*}$ \\
\hline $\begin{array}{l}\text { Inside Marina Benthic vs. } \\
\text { Outside Marina Suspended }\end{array}$ & -0.31 & 0.18 & -1.69 & 0.09050 \\
\hline $\begin{array}{l}\text { Inside Marina Benthic vs. } \\
\text { Outside Marina Benthic }\end{array}$ & -0.05 & 0.16 & -0.30 & 0.76391 \\
\hline $\begin{array}{l}\text { Outside Marina Suspended vs. } \\
\text { Outside Marina Benthic }\end{array}$ & -0.26 & 0.18 & -1.45 & 0.14584 \\
\hline
\end{tabular}




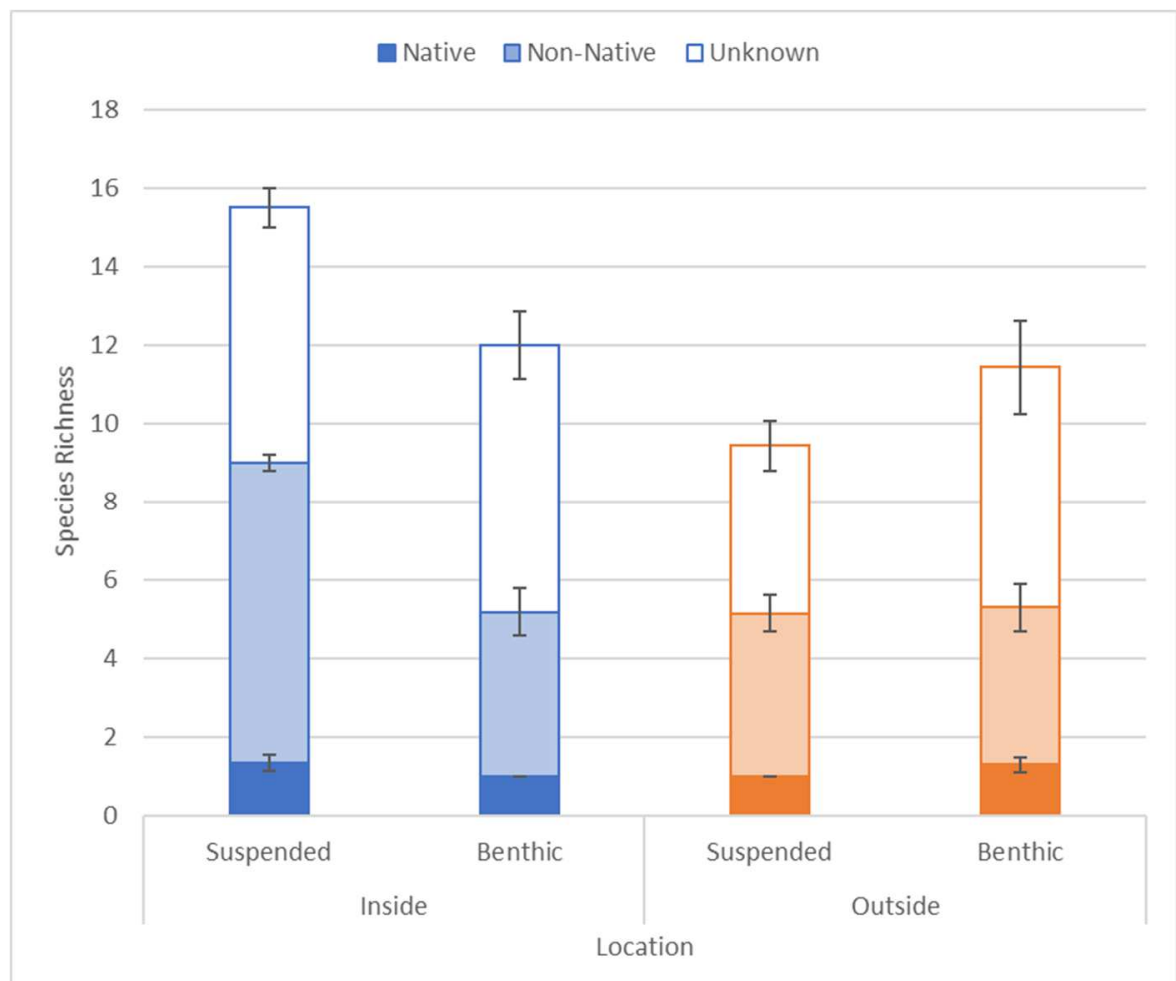

Figure 3. Average species richness by invasion status on No Cage tiles across 2 depths (Suspended and Benthic) and 2 locations (Inside = inside the marina for the duration of the experiment, Outside = outside the marina for the duration of the experiment). Error bars are \pm 1 standard error. Solid colored bars indicate native species. Faded bars indicate non-native species. White bars indicate unknown species, including cryptogenic species and morphospecies for which I was unable to identify invasion status.

Table 4. Summary output of post-hoc generalized linear model comparisons of means for average nonnative species richness on No Cage tiles across 2 depths (Suspended and Benthic) and 2 locations (Inside Marina and Outside Marina). p-values are unadjusted. Model: Non-Native Species Richness Location $*$ Depth. * indicates statistical significance $(p<0.05)$.

\begin{tabular}{|l|l|l|l|c|}
\hline & $\begin{array}{c}\text { Estimate } \\
\text { (Coefficient) }\end{array}$ & $\begin{array}{c}\text { Standard } \\
\text { error }\end{array}$ & $z$ & $p$ \\
\hline $\begin{array}{l}\text { Inside Marina Suspended vs. } \\
\text { Inside Marina Benthic }\end{array}$ & 0.61 & 0.25 & 2.45 & $0.01413^{*}$ \\
\hline $\begin{array}{l}\text { Inside Marina Suspended vs. } \\
\text { Outside Marina Suspended }\end{array}$ & -0.62 & 0.24 & -2.59 & $0.00944^{*}$ \\
\hline $\begin{array}{l}\text { Inside Marina Suspended vs. } \\
\text { Outside Marina Benthic }\end{array}$ & 0.65 & 0.24 & 2.71 & $0.00664^{*}$ \\
\hline $\begin{array}{l}\text { Inside Marina Benthic vs. } \\
\text { Outside Marina Suspended }\end{array}$ & -0.01 & 0.27 & -0.02 & 0.98325 \\
\hline $\begin{array}{l}\text { Inside Marina Benthic vs. } \\
\text { Outside Marina Benthic }\end{array}$ & -0.04 & 0.28 & -0.15 & 0.88206 \\
\hline $\begin{array}{l}\text { Outside Marina Suspended vs. } \\
\text { Outside Marina Benthic }\end{array}$ & 0.04 & 0.26 & 0.13 & 0.89463 \\
\hline
\end{tabular}




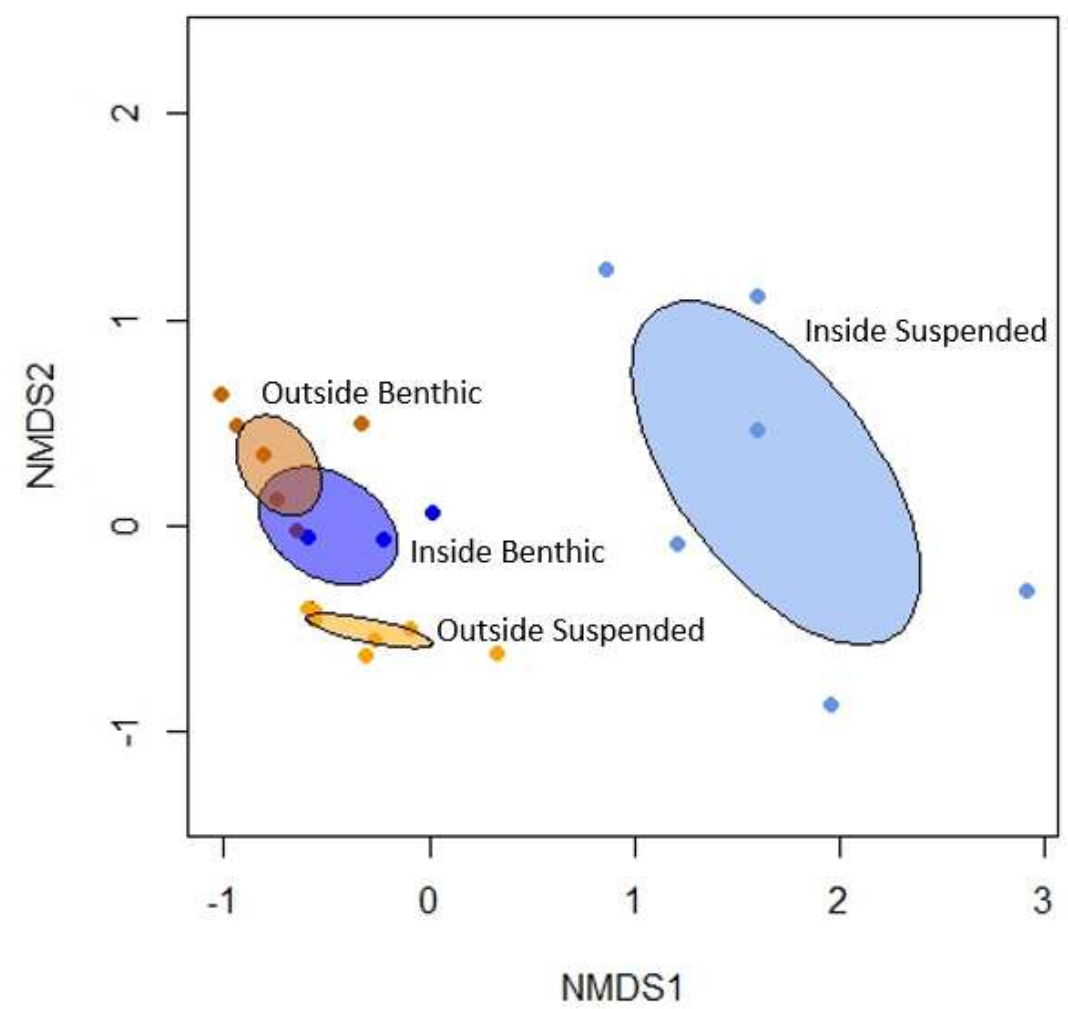

Figure 4. Nonmetric multidimensional scaling (NMDS) results showing the comparison between Suspended and Benthic No Cage sessile invertebrate assemblages inside and outside of the marina. Ellipses include standard error around the centroids. Stress $=0.06$

Table 5. Analysis of distance tables showing the effect of location (Inside Marina or Outside Marina) and depth (Suspended or Benthic) on No Cage fouling community assemblage. * indicates statistical significance $(p<0.05$ for $A, p<0.008$ for $B-G)$

\begin{tabular}{|l|l|l|l|}
\hline Source of variation & $\mathrm{F}$ & $\mathrm{R}^{2}$ & $\mathrm{P}$ value \\
\hline A. Among 2 locations and 2 depths & 9.57 & 0.566 & $0.00005^{*}$ \\
\hline $\begin{array}{l}\text { B. Inside Marina Benthic vs. } \\
\text { Inside Marina Suspended }\end{array}$ & 7.38 & 0.424 & $0.004^{*}$ \\
\hline $\begin{array}{l}\text { C. Inside Marina Benthic vs. } \\
\text { Outside Marina Benthic }\end{array}$ & 3.21 & 0.226 & 0.083 \\
\hline $\begin{array}{l}\text { D. Inside Marina Benthic vs. } \\
\text { Outside Marina Suspended }\end{array}$ & 7.41 & 0.403 & $0.005^{*}$ \\
\hline $\begin{array}{l}\text { E. Inside Marina Suspended vs. } \\
\text { Outside Marina Benthic }\end{array}$ & 8.91 & 0.448 & $0.002^{*}$ \\
\hline $\begin{array}{l}\text { F. Inside Marina Suspended vs. } \\
\text { Outside Marina Suspended }\end{array}$ & 12.39 & 0.530 & $0.003^{*}$ \\
\hline $\begin{array}{l}\text { G. Outside Marina Benthic vs. } \\
\text { Outside Marina Suspended }\end{array}$ & 22.72 & 0.654 & $0.001^{*}$ \\
\hline
\end{tabular}

Each table was generated using permutational multivariate analysis of variance (PERMANOVA)

Bonferroni-corrected $\alpha=0.008$ for multiple pairwise PERMANOVA tests $(B-G)$ 


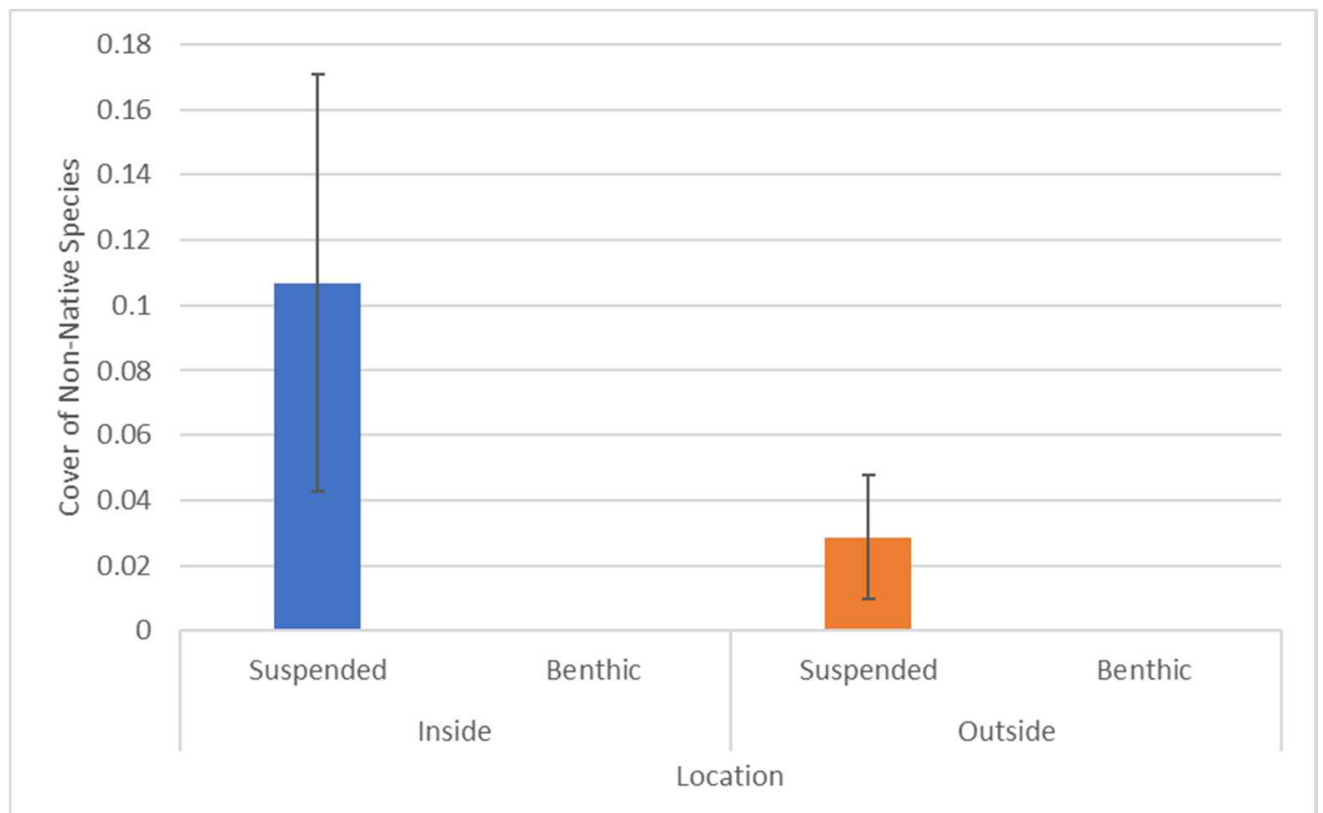

Figure 5. Average cover of identifiable non-native species across two depths (Suspended and Benthic) in two locations (Inside = Inside Marina, inside the marina for the duration of the experiment; Outside = Outside Marina, outside the marina for the duration of the experiment) for No Cage tiles, the base community. Error bars are \pm 1 standard error.

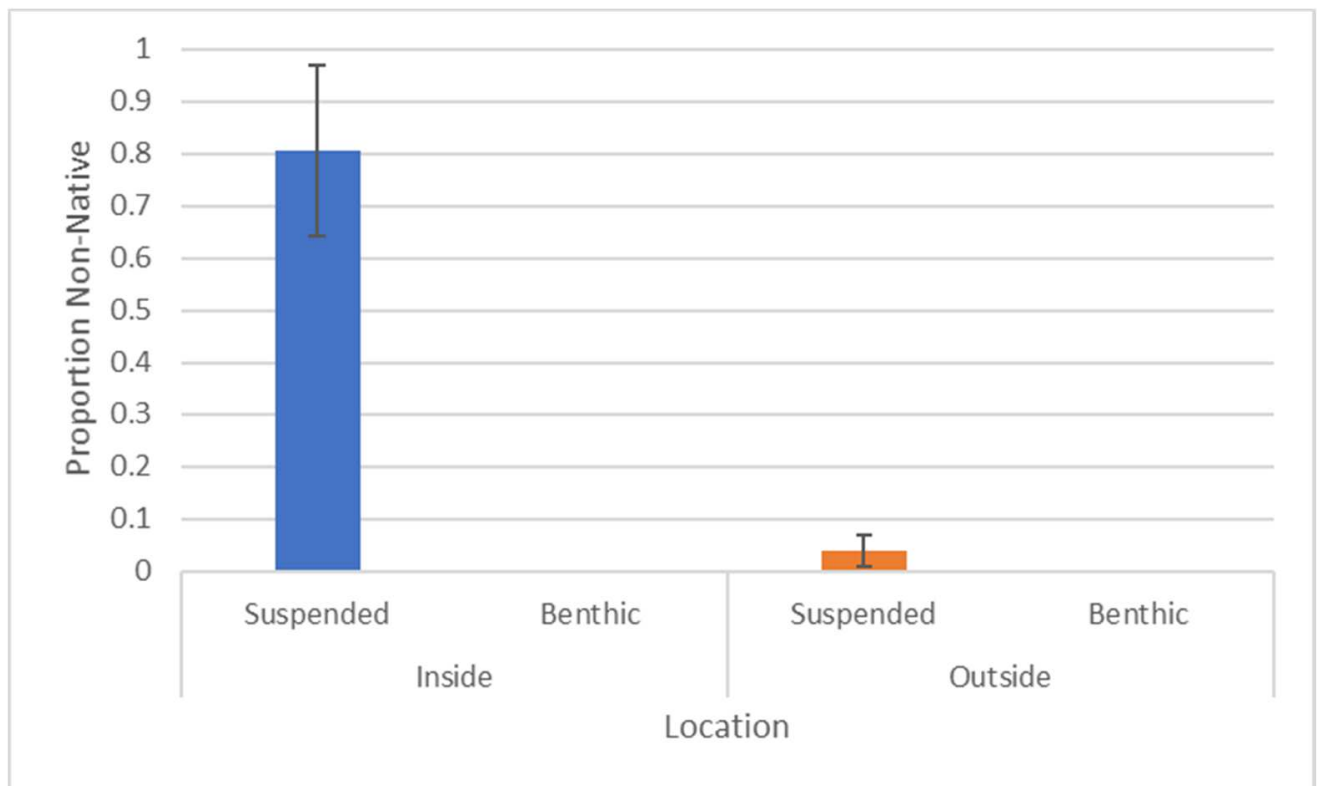

Figure 6. Average proportion of identified species cover that was non-native across two depths (Suspended and Benthic) in two locations (Inside = Inside Marina, inside the marina for the duration of the experiment; Outside = Outside Marina, outside the marina for the duration of the experiment) for No Cage tiles, the base community. Error bars are \pm 1 standard error. 
Table 6. Results of indicator species analysis showing significant indicator taxa for each location, depth, and cage treatment. Indicator value indicates how representative the species is of a group. $S=S$ Suspended, $B=$ Benthic. $N C=$ No Cage, $F C=$ Full Cage. Inside $=$ Inside Marina, inside the marina for the duration of the experiment; Outside = Outside Marina, outside the marina for the duration of the experiment.

\begin{tabular}{|l|l|l|l|l|}
\hline Indicator Species & Location & $\begin{array}{l}\text { Depth } \\
\text { and Cage } \\
\text { Treatment }\end{array}$ & $\begin{array}{l}\text { Indicator } \\
\text { value (IV) }\end{array}$ & $\begin{array}{l}P \\
\text { value }\end{array}$ \\
\hline Alcyonidium gelatinosum $*$ & Inside & B-FC & 0.400 & 0.009 \\
\hline Alcyonidium sp. & Inside & S-NC & 0.462 & 0.003 \\
\hline Alcyonidium sp. & Inside & S-FC & 0.205 & 0.003 \\
\hline Garveia franciscana** & Inside & S-FC & 0.485 & 0.003 \\
\hline Bugulina stolonifera** & Inside & S-FC & 0.350 & 0.015 \\
\hline Schizoporella japonica** & Inside & S-FC & 0.619 & 0.001 \\
\hline Balanus crenatus & Outside & S-FC & 0.287 & 0.001 \\
\hline Balanus crenatus & Outside & B-FC & 0.241 & 0.001 \\
\hline Balanus crenatus & Outside & S-NC & 0.218 & 0.001 \\
\hline
\end{tabular}

$*=$ cryptogenic $; *=$ introduced

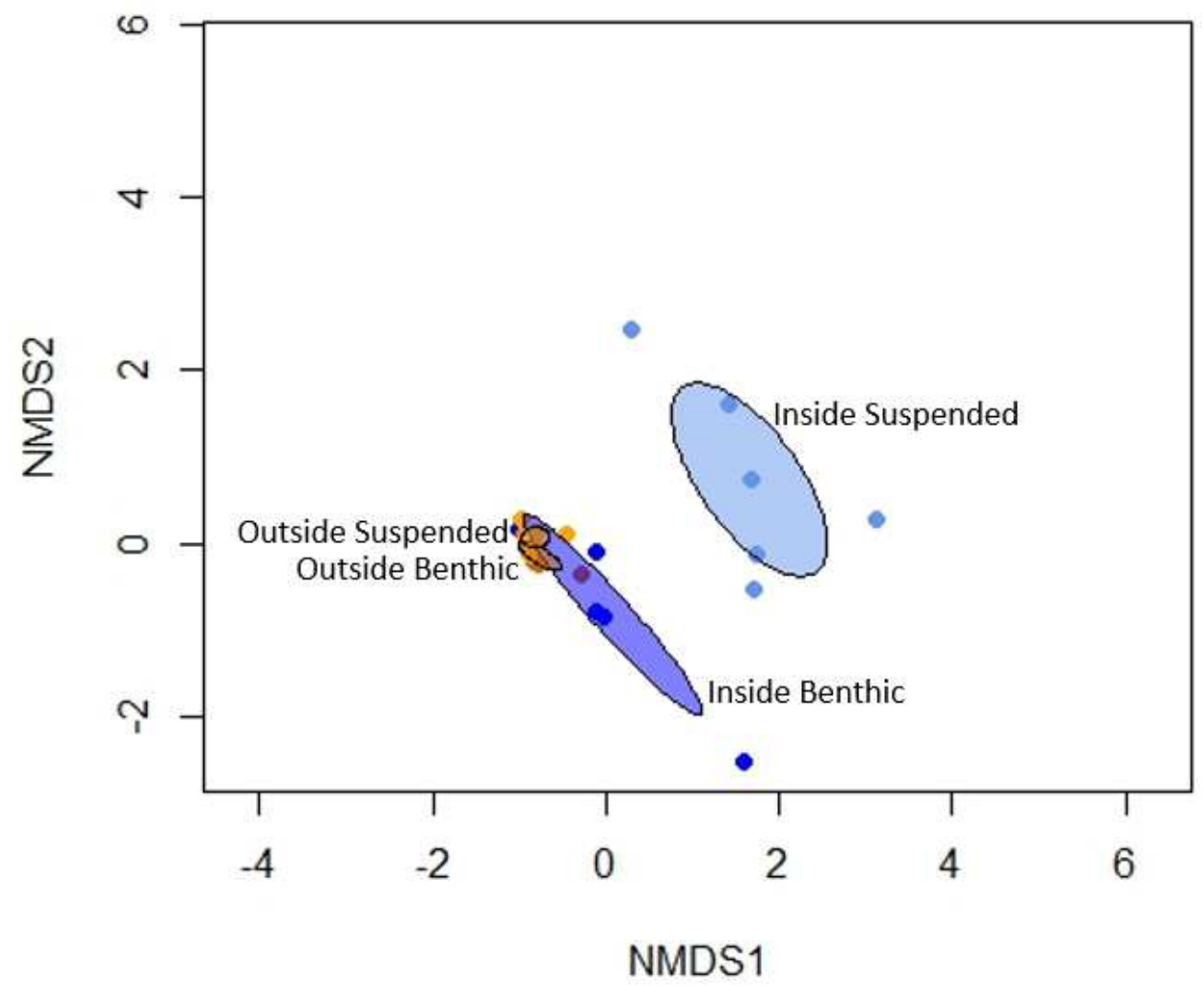

Figure 7. Nonmetric multidimensional scaling (NMDS) results showing the comparison between Full Cage sessile invertebrate assemblages near the surface (Suspended) and near the benthos (Benthic) for inside and outside of the marina. Ellipses include standard error around the centroid. Stress $=0.06$ 
Table 7. Analysis of distance tables showing the effect of location inside or outside of the marina on caged fouling community assemblage. Inside Marina = inside the marina for the duration of the experiment,

Outside Marina $=$ outside the marina for the duration of the experiment. Suspended $=$ near surface,

Benthic $=$ near benthos. $*$ indicates significance $(p<0.05$ for $A$ and $p<0.008$ for $B-G)$

\begin{tabular}{|l|l|l|l|}
\hline Source of variation & $\mathrm{F}$ & $\mathrm{R}^{2}$ & $\mathrm{P}$ value \\
\hline A. Among 2 locations and 2 depths & 6.684 & 0.501 & $0.00005^{*}$ \\
\hline $\begin{array}{l}\text { B. Inside Marina Benthic vs. } \\
\text { Inside Marina Suspended }\end{array}$ & 3.535 & 0.282 & $0.001^{*}$ \\
\hline $\begin{array}{l}\text { C. Inside Marina Benthic vs. } \\
\text { Outside Marina Benthic }\end{array}$ & 2.417 & 0.212 & 0.060 \\
\hline $\begin{array}{l}\text { D. Inside Marina Benthic vs. } \\
\text { Outside Marina Suspended }\end{array}$ & 4.240 & 0.298 & $0.008^{*}$ \\
\hline $\begin{array}{l}\text { E. Inside Marina Suspended vs. } \\
\text { Outside Marina Benthic }\end{array}$ & 10.911 & 0.522 & $0.001^{*}$ \\
\hline $\begin{array}{l}\text { F. Inside Marina Suspended vs. } \\
\text { Outside Marina Suspended }\end{array}$ & 13.346 & 0.548 & $0.001^{*}$ \\
\hline $\begin{array}{l}\text { G. Outside Marina Benthic vs. } \\
\text { Outside Marina Suspended }\end{array}$ & 1.384 & 0.112 & 0.254 \\
\hline
\end{tabular}

Each table was generated using permutational multivariate analysis of variance (PERMANOVA)

Bonferroni-corrected $\alpha=0.008$ for multiple pairwise PERMANOVA tests $(B-G)$

Table 8. Comparison of Inside Marina Suspended species to Inside Marina Benthic, Outside Marina Suspended, and Outside Marina Benthic. For each species, life history strategy and invasion status are listed, if known. Larval Type: $L=$ Lecithotrophic, $P=$ Planktotrophic. Invasion Status for Oregon: Crypto $=$ Cryptogenic, Nat $=$ Native, Intro $=$ Introduced. In $=$ Inside Marina, Out $=$ Outside Marina, Sus $=$ Suspended, Ben = Benthic

\begin{tabular}{|l|l|l|l|l|l|l|l|l|}
\hline $\begin{array}{l}\text { All Species } \\
\text { found In-Sus }\end{array}$ & $\begin{array}{l}\text { Larval } \\
\text { Type }\end{array}$ & $\begin{array}{l}\text { Invasion } \\
\text { Status } \\
\text { for OR }\end{array}$ & $\begin{array}{l}\text { Presence } \\
\text { Caged } \\
\text { Out-Sus }\end{array}$ & $\begin{array}{l}\text { Presence } \\
\text { Caged } \\
\text { Out-Ben }\end{array}$ & $\begin{array}{l}\text { Presence } \\
\text { Caged } \\
\text { In-Ben }\end{array}$ & $\begin{array}{l}\text { Presence } \\
\text { Uncaged } \\
\text { Out-Sus }\end{array}$ & $\begin{array}{l}\text { Presence } \\
\text { Uncaged } \\
\text { Out-Ben }\end{array}$ & $\begin{array}{l}\text { Presence } \\
\text { Uncaged } \\
\text { In-Ben }\end{array}$ \\
\hline $\begin{array}{l}\text { Alcyonidium } \\
\text { gelatinosum }\end{array}$ & $\mathrm{L}^{1}$ & Crypto & Yes & Yes & Yes & Yes & No & No \\
\hline $\begin{array}{l}\text { Alcyonidium } \\
\text { sp. } 1\end{array}$ & & & No & No & No & No & Yes & Yes \\
\hline Anthozoa 1 & $\mathrm{L}^{2}$ & & Yes & Yes & Yes & Yes & No & No \\
\hline $\begin{array}{l}\text { Balanus } \\
\text { crenatus }\end{array}$ & $\mathrm{P}^{3}$ & Nat & Yes & Yes & Yes & Yes & Yes & Yes \\
\hline $\begin{array}{l}\text { Bowerbankia } \\
\text { gracilis }\end{array}$ & $\mathrm{L}^{1}$ & Intro & Yes & Yes & Yes & Yes & Yes & Yes \\
\hline Bryozoan 1 & & & No & No & Yes & No & Yes & Yes \\
\hline Bryozoan 3 & & & No & No & No & No & Yes & No \\
\hline $\begin{array}{l}\text { Bugulina } \\
\text { stolonifera }\end{array}$ & $\mathrm{L}^{1}$ & Intro & Yes & No & No & No & Yes & Yes \\
\hline $\begin{array}{l}\text { Celleporella } \\
\text { hyalina }\end{array}$ & $\mathrm{L}^{1}$ & Intro & Yes & Yes & Yes & Yes & Yes & Yes \\
\hline Clam & & & Yes & Yes & Yes & Yes & Yes & Yes \\
\hline Clytia sp. & & & Yes & Yes & No & No & Yes & Yes \\
\hline
\end{tabular}




\begin{tabular}{|c|c|c|c|c|c|c|c|c|}
\hline $\begin{array}{l}\text { Conopeum } \\
\text { cf. } \\
\text { tenuissimum }\end{array}$ & $\mathrm{P}^{1}$ & Intro & Yes & No & No & No & No & No \\
\hline $\begin{array}{l}\text { Cryptosula } \\
\text { pallasiana }\end{array}$ & $\mathrm{L}^{1}$ & Intro & Yes & No & Yes & Yes & Yes & No \\
\hline $\begin{array}{l}\text { Garveia } \\
\text { franciscana }\end{array}$ & $\mathrm{L}^{4}$ & Intro & Yes & Yes & Yes & Yes & Yes & Yes \\
\hline $\begin{array}{l}\text { Hiatella } \\
\text { arctica }\end{array}$ & $\mathrm{L}^{5}$ & Nat & Yes & Yes & Yes & No & Yes & No \\
\hline Kamptozoa 1 & & & No & No & Yes & No & No & No \\
\hline $\begin{array}{l}\text { Molgula } \\
\text { manhattensis }\end{array}$ & $\mathrm{L}^{6}$ & Intro & No & Yes & No & No & No & No \\
\hline Mytilus sp. & & & Yes & Yes & Yes & Yes & Yes & Yes \\
\hline $\begin{array}{l}\text { Obelia } \\
\text { longissima }\end{array}$ & $\mathrm{L}^{7}$ & Intro & Yes & No & Yes & No & No & Yes \\
\hline Oyster & & & Yes & No & Yes & No & No & No \\
\hline Porifera 1 & & & Yes & Yes & Yes & Yes & Yes & Yes \\
\hline Porifera 2 & & & Yes & No & No & No & Yes & Yes \\
\hline Sabellid & & & Yes & Yes & Yes & Yes & Yes & Yes \\
\hline Scallop & & & No & Yes & No & Yes & No & Yes \\
\hline $\begin{array}{l}\text { Schizoporella } \\
\text { errata }\end{array}$ & $\mathrm{L}^{8}$ & Intro & No & No & No & No & No & No \\
\hline $\begin{array}{l}\text { Schizoporella } \\
\text { japonica }\end{array}$ & $\mathrm{L}^{8}$ & Intro & Yes & Yes & Yes & Yes & Yes & Yes \\
\hline Serpulid & & & Yes & Yes & Yes & Yes & Yes & Yes \\
\hline $\begin{array}{l}\text { Spirorbid } \\
(C C W)\end{array}$ & & & No & No & Yes & Yes & Yes & Yes \\
\hline $\begin{array}{l}\text { Urochordata } \\
1\end{array}$ & & & No & No & No & Yes & Yes & No \\
\hline $\begin{array}{l}\text { Urochordata } \\
2\end{array}$ & & & No & No & No & No & No & Yes \\
\hline $\begin{array}{l}\text { Watersipora } \\
\text { subtorquata }\end{array}$ & $\mathrm{L}^{1}$ & Intro & No & Yes & Yes & Yes & No & Yes \\
\hline
\end{tabular}

References: 1. Waeschenbach et al. 2012 2. Nielsen 2009 3. Rainbow 1984 4. Calder 1971 5. Lebour 1938 6. Grave 1933 7. Gili and Hughes 1995 8. Watts and Thorpe 2006 


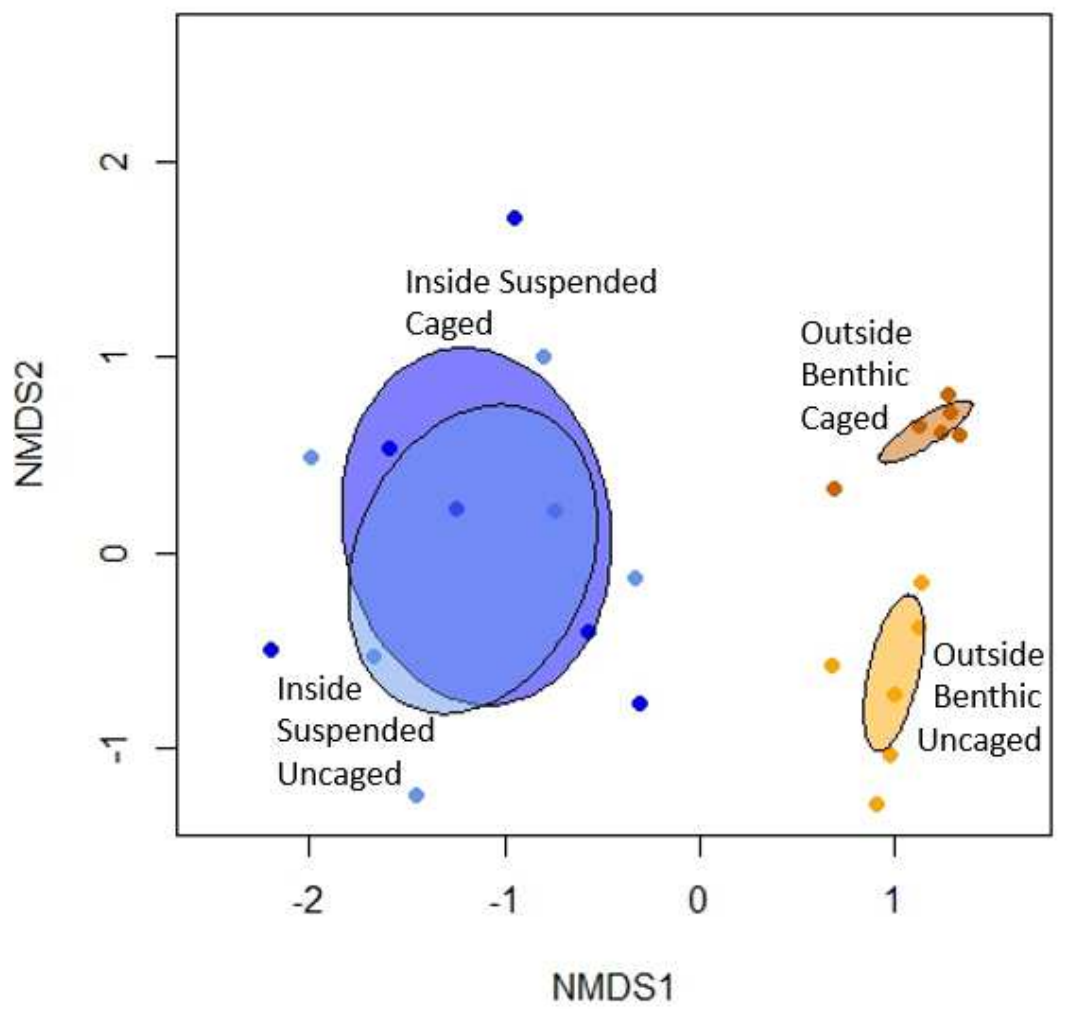

Figure 8. Nonmetric multidimensional scaling (NMDS) results showing the comparison among sessile invertebrate assemblages between caged (Full Cage) and uncaged (No Cage) tiles inside the marina near the surface (Inside Marina Suspended) and outside near the benthos (Outside Marina Benthic). Ellipses include standard error around the centroid. Stress $=0.08$

Table 9. Analysis of distance tables showing the effects of location (Inside or Outside Marina), depth (Suspended or Benthic), and predation (No Cage or Full Cage) on fouling community assemblage. * indicates statistical significance $(p<0.05$ for $A, p<0.008$ for $B-G)$

\begin{tabular}{|l|l|l|l|}
\hline Source of variation & $\mathrm{F}$ & $\mathrm{R}^{2}$ & $\mathrm{P}$ value \\
\hline A. Among 2 locations and 2 caging treatments & 8.01 & 0.53 & $0.00005^{*}$ \\
\hline $\begin{array}{l}\text { B. Inside Marina Suspended No Cage vs. } \\
\text { Outside Marina Benthic No Cage }\end{array}$ & 8.91 & 0.45 & $0.001^{*}$ \\
\hline $\begin{array}{l}\text { C. Inside Marina Suspended No Cage vs. } \\
\text { Outside Marina Benthic Full Cage }\end{array}$ & 10.72 & 0.52 & $0.002^{*}$ \\
\hline $\begin{array}{l}\text { D. Inside Marina Suspended No Cage vs. } \\
\text { Inside Marina Suspended Full Cage }\end{array}$ & 0.95 & 0.09 & 0.489 \\
\hline $\begin{array}{l}\text { E. Outside Marina Benthic No Cage vs. } \\
\text { Outside Marina Benthic Full Cage }\end{array}$ & 19.22 & 0.64 & $0.001^{*}$ \\
\hline $\begin{array}{l}\text { F. Outside Marina Benthic No Cage vs. } \\
\text { Inside Marina Suspended Full Cage }\end{array}$ & 8.67 & 0.44 & $0.001^{*}$ \\
\hline $\begin{array}{l}\text { G. Outside Marina Benthic Full Cage vs. } \\
\text { Inside Marina Suspended Full Cage }\end{array}$ & 10.91 & 0.52 & $0.004^{*}$ \\
\hline
\end{tabular}

Each table was generated using permutational multivariate analysis of variance (PERMANOVA)

Bonferroni-corrected $\alpha=0.008$ for multiple pairwise PERMANOVA tests $(B-G)$ 


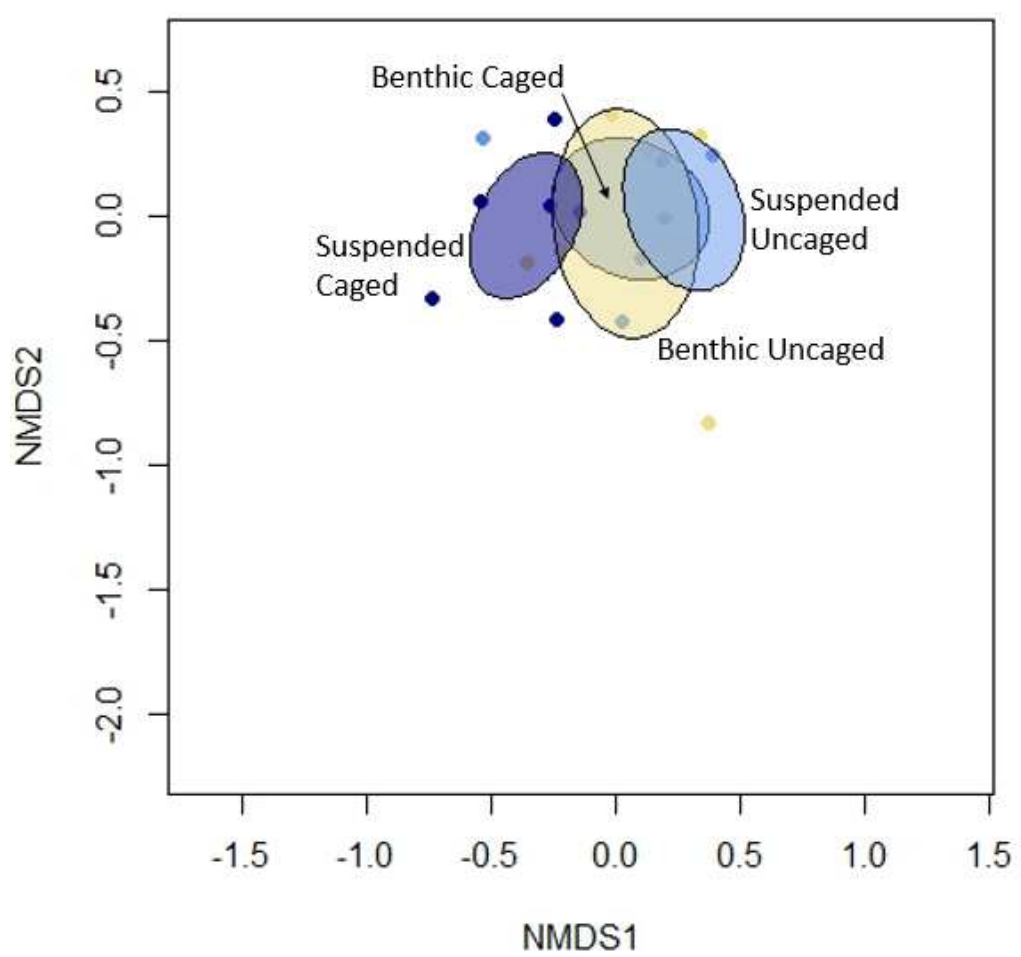

Figure 9. Nonmetric multidimensional scaling (NMDS) results showing the comparison among sessile invertebrate assemblages for the Adult Transplant Experiment (moved from inside to outside of the marina) tiles among caging treatments (Caged = Full Cage, Uncaged $=$ No Cage) and depths (Suspended, Benthic). Ellipses include standard error around the centroid. Stress $=0.216$

Table 10. Analysis of distance tables showing the effect of caging treatment (No Cage or Full Cage) and depth (Suspended or Benthic) on Adult Transplant Experiment fouling community assemblage. * indicates statistical significance ( $p<0.05$ for $A, p<0.008$ for $B-G)$

\begin{tabular}{|l|l|l|l|}
\hline Source of variation & F & $\mathrm{R}^{2}$ & P value \\
\hline A. Among 2 caging treatments and 2 depths & 1.711 & 0.204 & $0.01932^{*}$ \\
\hline B. Suspended Full Cage vs. Benthic Full Cage & 1.865 & 0.157 & 0.047 \\
\hline C. Suspended Full Cage vs. Benthic No Cage & 1.755 & 0.149 & 0.102 \\
\hline D. Suspended Full Cage vs. Suspended No Cage & 3.996 & 0.286 & $0.004^{*}$ \\
\hline E. Benthic Full Cage vs. Benthic No Cage & 0.591 & 0.056 & 0.790 \\
\hline F. Benthic Full Cage vs. Suspended No Cage & 1.301 & 0.115 & 0.281 \\
\hline G. Benthic No Cage vs. Suspended No Cage & 1.135 & 0.102 & 0.348 \\
\hline
\end{tabular}

Each table was generated using permutational multivariate analysis of variance (PERMANOVA) Bonferroni-corrected $\alpha=0.008$ for multiple pairwise PERMANOVA tests $(B-G)$ 


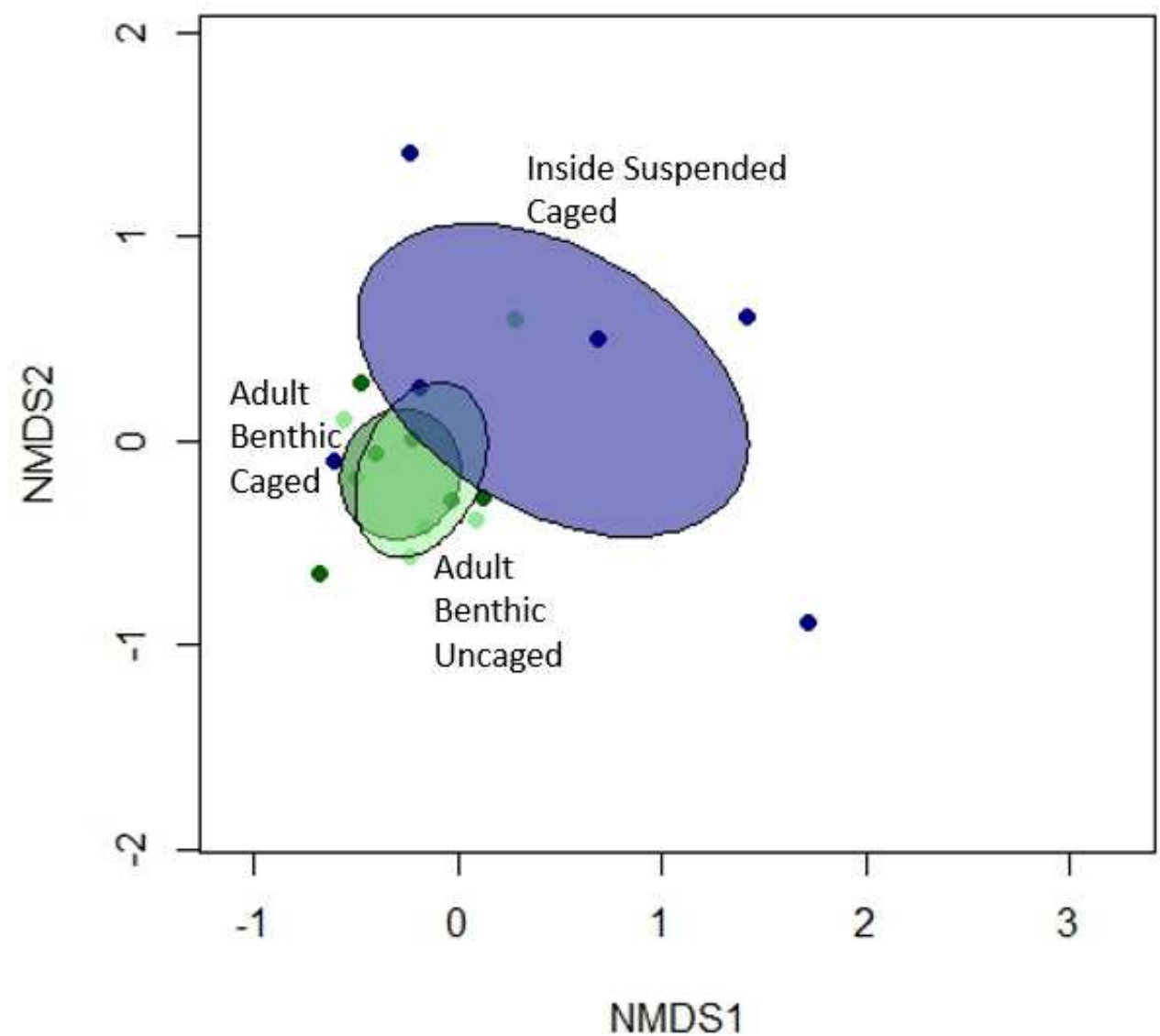

Figure 10. Nonmetric multidimensional scaling (NMDS) results showing the comparison among sessile invertebrate assemblages between Adult Transplant Experiment Benthic Full and No Cage and Inside Marina Suspended Full Cage. Ellipses include standard error around the centroid. Stress $=0.11$

Table 11. Analysis of distance tables showing the effect of caging treatment (No Cage or Full Cage), depth (Suspended or Benthic), and location (Inside Marina or Adult Transplant Experiment) on fouling community assemblage. Inside = Inside Marina, inside the marina for the duration of the experiment; Adult $=$ Adult Transplant Experiment, moved from inside to outside of the marina. * indicates significance ( $p<$ 0.05 for $A, p<0.017$ for $B-D$ )

\begin{tabular}{|l|l|l|l|}
\hline Source of variation & $\mathrm{F}$ & $\mathrm{R}^{2}$ & $\mathrm{P}$ value \\
\hline $\begin{array}{l}\text { A. Among 2 caging treatments, 2 depths, } \\
\text { and 2 locations }\end{array}$ & 1.828 & 0.196 & $0.02723^{*}$ \\
\hline $\begin{array}{l}\text { B. Adult Benthic Full Cage vs. Adult } \\
\text { Benthic No Cage }\end{array}$ & 0.591 & 0.056 & 0.803 \\
\hline $\begin{array}{l}\text { C. Adult Benthic Full Cage vs. Inside } \\
\text { Suspended Full Cage }\end{array}$ & 2.554 & 0.203 & 0.018 \\
\hline $\begin{array}{l}\text { D. Adult Benthic No Cage vs. Inside } \\
\text { Suspended Full Cage }\end{array}$ & 1.915 & 0.161 & 0.061 \\
\hline
\end{tabular}

Each table was generated using permutational multivariate analysis of variance (PERMANOVA) Bonferroni-corrected $\alpha=0.017$ for multiple pairwise PERMANOVA tests $(B-D)$ 


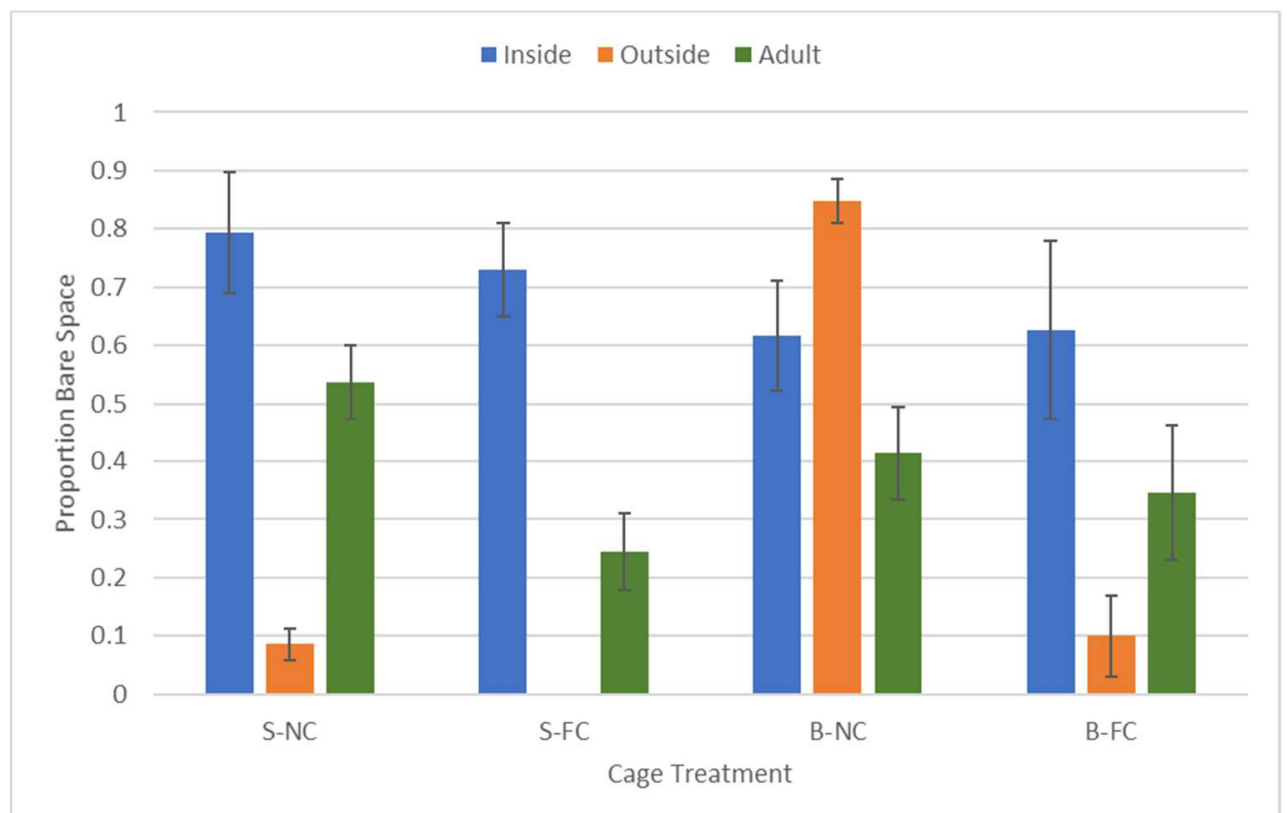

Figure 11. The average proportion of bare space across 2 depths $(S=$ Suspended, $B=$ Benthic), 2 caging treatments $(N C=$ No Cage, $F C=$ Full Cage), and 3 locations (Inside $=$ inside the marina for the duration of the experiment; Outside = outside the marina for the duration of the experiment; Adult = Adult Transplant Experiment, moved from inside to outside of the marina). Error bars are \pm 1 standard error.

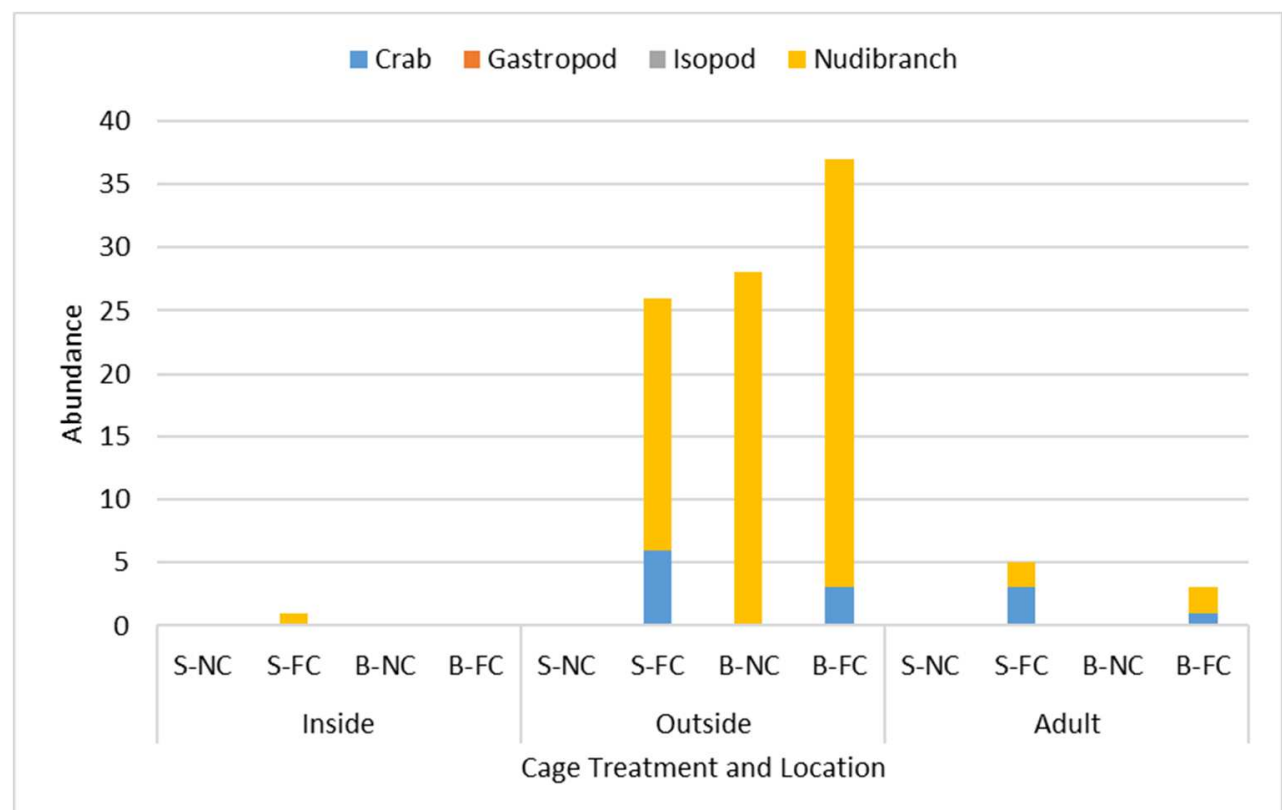

Figure 12. Total abundance of small predators upon retrieval across 2 depths $(S=$ Suspended, $B=$ Benthic), 2 caging treatments $(N C=N o$ Cage, $F C=$ Full Cage), and 3 locations (Inside $=$ inside the marina for the duration of the experiment; Outside = outside the marina for the duration of the experiment; Adult $=$ Adult Transplant Experiment, moved from inside to outside of the marina). 


\section{Discussion}

Anthropogenic structures linked with shipping provide habitat for non-native sessile marine invertebrates (Bulleri and Airoldi 2005). Other anthropogenic structures not necessarily associated with shipping also create suitable habitat. This and other studies have demonstrated that native predators help to prevent successful recruitment of non-native species outside of marinas (Dumont et al. 2011a). In addition to predation, larval duration and its relationship with dispersal and propagule pressure have been shown to decrease the abundances of fouling organisms on natural substrate as the distance from anthropogenic structures increases (Hedge and Johnston 2012). These results suggest that both dispersal and predation by both large and small organisms contribute to the limitation of spread of non-native species outside of marinas.

I used predator exclusion to both quantify predation pressure via comparison with predator-exposed (No Cage) tiles and to reduce predation on recruits, with the goal of improving the ability to detect whether the same species that were found in marinas also dispersed to non-marina locations. Indeed, exclusion of large predators resulted in differences in community composition, especially between suspended communities inside the marina and both suspended and benthic communities outside of the marina, further reinforcing the differences in community composition previously found between benthic and suspended habitats (Connell 2001b, Simkanin et al. 2012). The differences in species that were found suspended inside the marina but not outside the marina, either suspended or benthic, suggests that either the larvae cannot get there (dispersal limitation) or that small predators that can fit through the caging are influencing the ability of fouling organisms to establish outside the marina. There were many more 
mesopredators outside of the marina than inside, indicating strong predation pressure. Additionally, because there were also more mesopredators inside the caging in all groups, it is likely that caging provided a refuge for these small predators that may be affecting on the overall trends seen for predation.

Because this project did not directly measure dispersal, I cannot say conclusively whether or not dispersal limitation is playing a role in structuring communities, though other research has shown that propagule pressure mediated by dispersal can influence fouling community composition (Hedge and Johnston 2012). However, data on mesopredators can be used to determine if mesopredators have a role in creating the differences in caged communities suspended from the docks compared to the other groups. When large predators were excluded outside of the marina, the native barnacle Balanus crenatus completely dominated the community, allowing very little primary space for other species. The dominance of barnacles on Outside Marina Full Cage tiles as well as the high amount of bare space on Outside Marina Benthic No Cage tiles seem to suggest that large predators preferentially depredate the barnacles. Given the potential ability of small predators to influence community composition (Lavender et al. 2014), the large abundance of these mesopredators that I observed outside of the marina suggests that mesopredators may be playing a key role in the difference between in versus out of marina caged tiles. Additionally, there were more mesopredators on caged tiles across all locations, further indicating that they are influencing the difference between inside and outside communities but also potentially driving some of the difference between caged and uncaged tiles seen outside of the marina. 
Given the role of mesopredators, this community data do not directly indicate that dispersal is limiting species from getting outside the marina, though dispersal limitation may still certainly be contributing to the differences in the communities (Hedge and Johnston 2012). Dispersal ability, specifically larval duration, can influence how far species are able to disperse and settle, regardless of whether they are native or non-native. The longer larvae are planktonic, the greater the distance they can travel (Levin 2006); however, greater swimming times have other consequences in terms of fitness (Pechenik et al. 1993, 1998, Burgess and Marshall 2011). In addition, just because they are in the water column longer, they do not necessarily disperse farther (Shanks 2009, Morgan et al. 2009). Nonetheless, natural substrates closer to anthropogenic structures experience greater abundance and frequency of non-native propagules (Floerl and Inglis 2003, Clark and Johnston 2005, 2009) as well as larvae that are in better condition (Pechenik et al. 1993).

Interestingly, the majority of the identified non-native species found outside of the marina in this study have a lecithotrophic larval stage, which usually correlates to a shorter larval duration and dispersal distance (Pechenik 1990, Todd 1998). Only three species, the common non-native Schizoporella errata, and two rare species, Kamptozoa 1 and Urochordata 2, were never found on any of the tiles outside the marina. Several other marina species were found outside the marina, but only rarely. Of these, Conopeum cf. tenuissimum is notable because, unlike the other identified species that rarely escaped the docks if at all, it is planktotrophic. Hence, the fact that not all the species present 
inside the marina were found outside of the marina or were found rarely indicates that, at least for those species, dispersal limitation might be contributing to limiting their spread.

The configuration of the marina could be manipulating flow in a way that entrains larvae (Floerl and Inglis 2003) and prevents species from successfully settling outside of the marina. Additionally, propagule pressure could be playing a role in which species are able to succeed outside of the marina (Lange and Marshall 2016). If the population inside the marina is small or the larvae released into the water column are not able to overcome hydrodynamics, there will be a limit to how many individuals can establish outside the marina. However, given that some species were found both inside and outside of the marina in this study, it is likely that there is a suite of factors contributing to fouling community composition. It is also possible that I would see greater differences if I conducted this study with a greater distance between the marina and outside of the marina. Allowing for greater distance between source populations and the receiving habitat may further discern the mechanisms driving these differences.

Natural substrate that experiences disturbance, such as impacts from boat anchors, can also be more vulnerable to non-native species due to suitable primary substrate becoming available (Clark and Johnston 2009). Natural substrate further away from anthropogenic structures is less vulnerable to establishment by non-native species, but other floating structures such as buoys could provide a pathway for species to settle successfully further from anthropogenic structures (Astudillo et al. 2009). In this study, the species that were found suspended inside the marina and outside of the marina, but 
not near the benthos outside of the marina indicated that these species might be able to use buoys or other floating structures to successfully spread outside of the marina.

Changes in community structure due to predation were clearer in this study than changes due to dispersal limitation. Excluding large predators suspended inside the marina did not influence community assemblage. However, excluding large predators outside of the marina near the benthos altered community assemblage significantly compared to uncaged tiles in that location. Benthic predators appear to have a large effect on barnacles outside the marina. The native barnacle Balanus crenatus dominated the benthic caged tiles outside the marina, with an average of $96 \%$ cover, whereas the uncaged tiles only had an average cover of $14.9 \%$. By contrast, suspended tiles outside the marina were dominated by Balanus crenatus regardless of caging treatment (115\% cover for caged tiles, $87 \%$ cover for uncaged tiles), indicating that benthic predators are shaping the community in a way that may provide open space for other species or exerting similar effects on newly settled species. The community could also be influenced by competition with Balanus crenatus, where this barnacle species outcompetes everything else for space, potentially also reducing the number of nonnative species that successfully establish outside of marinas. Additionally, there may be some caging artifacts for the outside benthic group as there was a significant difference between uncaged and partially caged tiles $(\mathrm{p}=0.008)$. Due to how the experimental apparatuses were set up outside the marina, the tiles moved around with incoming and outgoing tides, giving the bottom half of the apparatus an opportunity to rest on the benthos when the water level was lower, potentially causing the partially caged tiles to 
become fully enclosed temporarily. This interaction with the substrata is likely why there were differences between the uncaged and partially caged communities outside the marina for the benthic tiles.

The influence of predation (as measured by Full Cage versus No Cage tile communities) on the Adult Transplant Experiment communities was restricted to the suspended tiles, suggesting that fish (or other swimming predators) predation helps to shape those communities (such as might grow on buoys and channel markers), as has been shown for other fouling communities (Kremer and da Rocha 2016, Masi et al. 2016). When the Benthic Adult Transplant Experiment communities were compared to the Inside Marina Suspended Full Cage community (the origin community for the Adult Transplant Experiment tiles), there was no difference between the Inside Marina Suspended Full Cage community and the Benthic Adult Transplant Experiment No Cage community, indicating that predation from large predators on adults is not shaping the community. However, the difference between the Inside Marina Suspended Full Cage community and the Benthic Adult Transplant Experiment Full Cage community indicates that small predators that can fit through the caging are having an influence. Overall, these results reinforce the patterns found in previous research that predators are providing biotic resistance to non-native species and demonstrate those patterns at the community level.

I attempted to determine the effects of predation on early settlers, but a midsummer spawning/recruitment event made that impossible. The abundance counts 
between pre- and post-transplant increased by several hundred in some cases (Cirripedia and Bivalvia), making it impossible to discern the effects of predation.

Predation is acknowledged as a strong biotic interaction limiting the success of non-native species (Harvey et al. 2004, de Rivera et al. 2005, Dumont et al. 2011a, Kimbro et al. 2013). However, in many predator exclusion studies, mesopredators such as nudibranchs can fit through the caging, potentially altering the results. Excluding larger predators through caging may, in fact, provide mesopredators with a refuge, allowing them to thrive.

The sessile marine invertebrate community is influenced by predation and is particularly vulnerable shortly after individuals have settled (Osman and Whitlatch 2004). I observed many more mesopredators outside the marina than anywhere else, indicating that some of the strong differences in predation between caging treatments outside the marina could be attributed to mesopredation. This is further illustrated by the greater number of mesopredators on caged tiles than on uncaged tiles across all locations. The interaction between mesopredators and their predators has been extensively studied across many different types of habitats (see review by Ritchie and Johnson 2009). Other studies have attempted to discern the impacts of mesopredation on the fouling community, with some success (Nydam and Stachowicz 2007, Lavender et al. 2014, Rogers et al. 2016). All three of these studies demonstrated that mesopredators themselves or the interactive effects of both large and small predators contribute to overall community composition, but overall there is a paucity of information regarding the role mesopredators play in limiting the spread of non-native species. This study 
emphasizes the importance of considering small predators as well as large predators when studying biotic resistance to non-native fouling organisms. Additionally, it will be important to consider the effects of excluding large predators on smaller predators, thereby having an amplified effect on the community, similar to other trophic cascade research (Byrnes et al. 2006). Further studies both in the field and in the lab will need to be conducted to determine the full extent of mesopredation.

In contrast to what has been found in other marinas and bays, the Embarcadero Marina and Yaquina Bay have very few tunicates. Usually, both solitary and colonial tunicates dominate these communities. Nevertheless, this anomaly does not prevent these results from being widely applicable. Most tunicate species are lecithotrophic in their planktonic larval stage (Millar 1971), potentially limiting their dispersal ability far beyond marinas. The species found in this study encompass both planktonic and lecithotrophic larval stages, allowing these conclusions to be applied more broadly.

Overall, my findings supported my hypothesis that the fouling communities would be different inside versus outside of the marina, driven by more non-native species inside the marina. Predation was stronger outside of the marina than inside the marina, especially between the suspended community inside the marina and the benthic community outside of the marina. Though I was not able to conclusively say that dispersal limitation is playing a role in structuring communities, my data shows that it is likely interacting with predation from both large and small predators to contribute to the differences in community composition inside versus outside of the marina. 
The results from this study suggest that resilience to invasibility is more than just biotic resistance or dispersal limitation. These factors act together to prevent non-native species from spreading to natural substrate. It is also important to consider the surrounding area in determining the likelihood of spread of a particular species. Species that are not as successful from inside the marina to the benthic non-marina communities are likely to colonize nearby floating structures such as buoys or channel markers which could more easily facilitate spread. Both marina and nearby floating structures can act as source populations for non-native species. Additionally, exploring the mechanisms that prevent spread at the community level rather than from a species-specific perspective has allowed me to reinforce what has been found for specific species for the overall community. Dumont et al. (2011) demonstrated that benthic predators prevented an invasive ascidian, Ciona intestinalis, from successfully colonizing natural substrata. My research showed similar results for the overall community, where benthic predators had a strong influence in shaping the community on natural substrata. Additionally, Simkanin et al. (2017) demonstrated the role of propagule pressure and dispersal in limiting the establishment of another invasive ascidian, Botrylloides violaceus. While my results regarding dispersal were less conclusive, I was able to show differences between communities that could be attributed to dispersal limitation, such as the species from the inside marina community only found suspended outside of the marina.

In looking at the overall community, I was able to get a more thorough picture of which species are driving differences in the overall community and I was able to see that non-native species are, in some cases, able to make it outside of the marina but are not 
succeeding once they are out. Even though the community approach is more challenging, I believe it reinforced and added to the existing literature for invasions ecology, especially regarding biotic resistance. Additionally, looking at both predation and dispersal limitation jointly rather than just one or the other allowed me to see the interaction that these mechanisms have, rather than what occurs in a vacuum.

This research provides the groundwork for future research. The impact of mesopredators needs to be further explored to determine the extent to which they are modifying the community in the absence of large predators. Additionally, dispersal needs to be more successfully addressed as does predation on early settlers/recruits, both of which could be done using this same set-up without a late-summer spawning event. To truly tease apart the role of dispersal, I would conduct larval tracking experiments for different species to get an idea of the limiting and facilitating factors larvae encounter in dispersing to natural habitats. Overall, this research provides answers as to how both predation and dispersal limitation are structure fouling communities and causing the difference seen between communities on anthropogenic structures and natural substrate. 


\section{Chapter 3: Conclusions}

The goal of this research was to tease apart the mechanisms that limit the spread of non-native species from anthropogenic to natural habitat and examine the patterns from a community-level perspective. Though there have been many studies on predation as biotic resistance to non-native species, most have been done for only a few species rather than at the community level, especially in marine settings. Additionally, there has been significant research on larval dispersal in general, but not specifically as a limit to the spread of non-native species, nor in congruence with predation. Through field work and laboratory analysis, I was able to show that predation from large predators is having an impact on community structure, that small predators are likely playing a role in structuring the community, and that dispersal limitation is potentially affecting what species can successfully arrive on habitats just outside marinas for some species with lecithotrophic and even planktotrophic larvae.

The results presented in this thesis suggest several future research directions. The true influence of mesopredators as a method of biotic resistance is not yet known, though research suggests that they are having some impact (Lavender et al. 2014). The results from this study showed that there seem to be more mesopredators outside of the marina, potentially contributing to community structure. However, a study that specifically examines the impacts of mesopredators on fouling community structure both in the presence and absence of larger predators would be helpful to determine the impacts of biotic resistance across trophic levels. Additionally, because the study of dispersal and predation on the recruit community was not able to be successfully analyzed here, further study of how the community is impacted by predation (across trophic levels) and 
dispersal at the early stages of settlement will be key to completing the picture of how these mechanisms interact to limit the spread of non-native species.

A more thorough understanding of the factors that impact the distribution and spread of non-native species and how those factors interact is important for curbing and managing the spread of invasive species (Mack et al. 2000, Hulme 2009). The greater cover of identifiable introduced species on anthropogenic structures reinforces other work that indicates that these structures are invasion hubs and may provide the origin point for the spread of non-native species. Because anthropogenic structures are most often associated with human activities, such as shipping and recreational boating (Floerl and Inglis 2005, Ruiz et al. 2009), management should focus on these areas for monitoring and eradication for newly arrived species. Reducing the number of invasive species on anthropogenic structures will result in reducing the propagule pressure on natural habitats, thus limiting the dispersal of non-native species.

Non-native fouling organisms can have significant ecological and economic impacts (Johnson and Carlton 1996, Castilla and Neill 2009, Dafforn et al. 2011). Both introduced species and habitat modification threaten native biodiversity (Gurevitch and Padilla 2004, Didham et al. 2005, 2007, Molnar et al. 2008). Anthropogenic structures will continue to increase in coastal ecosystems with both increasing urbanization and shipping (Connell and Glasby 1999, Bulleri and Chapman 2010). Because these habitats often host different assemblages of species (Connell 2001b, Chapman 2003, Bulleri and Chapman 2010), many of which are non-native (Bulleri and Airoldi 2005, Dafforn et al. 2009b), it is important to consider the impacts that anthropogenic structures have and 
could have on surrounding natural substrate. Additionally, managers should be aware of other floating structures that can act as stepping stones for species that are dispersallimited as a potential mechanism for spread. Floating buoys have been shown to be a potential avenue for dispersal of non-native species (Astudillo et al. 2009). Biotic resistance from predation can help limit the spread of non-native species, but it should not be the only factor on which we rely because benthic predators cannot prey upon species establishing on these other floating structures that can also act as source populations. Therefore, managers should consider periodic cleaning of buoys and channel markers, similar to the regulations for cleaning boat hulls, to prevent these structures from acting as stepping stones or beachheads.

As the globe continues to experience the effects of climate change, non-native species may be better able to spread to natural substrate. Larval duration and settlement success can be influenced by temperature (O'Connor et al. 2007, Reinhardt et al. 2013), so ocean warming may change the suite of species that are able to disperse from anthropogenic structures to natural habitats. Not only does increased ocean temperature have implications for range expansion for native species along a coast, but may also have implications for range expansion for invasive species that already cause ecological and economic problems. Fully exploring the connection between anthropogenic structures and natural habitat with regard to non-native species will be key for formulating management decisions and actions. 


\section{References}

Airoldi, L., M. Abbiati, M. W. Beck, S. J. Hawkins, P. R. Jonsson, D. Martin, P. S. Moschella, A. Sundelöf, R. C. Thompson, and P. Åberg. 2005. An ecological perspective on the deployment and design of low-crested and other hard coastal defence structures. Coastal Engineering 52:1073-1087.

Airoldi, L., X. Turon, S. Perkol-Finkel, and M. Rius. 2015. Corridors for aliens but not for natives: Effects of marine urban sprawl at a regional scale. Diversity and Distributions 21:755-768.

Aldred, N., and A. S. Clare. 2014. Mini-review: Impact and dynamics of surface fouling by solitary and compound ascidians. Biofouling 30:259-270.

Alldredge, A. L., and W. M. Hamner. 1980. Recurring aggregation of zooplankton by a tidal current. Estuarine and Coastal Marine Science 10:31-37.

Alpert, P. 2006. The advantages and disadvantages of being introduced. Biological Invasions 8:1523-1534.

Anderson, M. J. 2001. A new method for non-parametric multivariate analysis of variance. Austral Ecology 26:32-46.

Apte, S., B. S. Holland, L. S. Godwin, and J. P. A. Gardner. 2000. Jumping ship: a stepping stone event mediating transfer of a non-indigenous species via a potentially unsuitable environment. Biological Invasions 2:75-79.

Archambault, P., and E. Bourget. 1999. Influence of shoreline configuration on spatial variation of meroplanktonic larvae, recruitment and diversity of benthic subtidal communities. Journal of Experimental Marine Biology and Ecology 238:161-184.

Arim, M., S. R. Abades, P. E. Neill, M. Lima, and P. A. Marquet. 2006. Spread dynamics of invasive species. Proceedings of the National Academy of Sciences 103:374-378.

Astudillo, J. C., M. Bravo, C. P. Dumont, and M. Thiel. 2009. Detached aquaculture buoys in the SE Pacific: potential dispersal vehicles for associated organisms. Aquatic Biology 5:219-231.

Ayre, D. J., T. E. Minchinton, and C. Perrin. 2009. Does life history predict past and current connectivity for rocky intertidal invertebrates across a marine biogeographic barrier? Molecular Ecology 18:1887-1903.

Barkai, A., and G. M. Branch. 1988. The influence of predation and substratal complexity on recruitment to settlement plates: a test of the theory of alternative states. Journal of Experimental Marine Biology and Ecology 124:215-237. 
Barshis, D. J., E. E. Sotka, R. P. Kelly, A. Sivasundar, B. A. Menge, J. A. Barth, and S. R. Palumbi. 2011. Coastal upwelling is linked to temporal genetic variability in the acorn barnacle Balanus glandula. Marine Ecology Progress Series 439:139-150.

Bax, N., A. Williamson, M. Aguero, E. Gonzalez, and W. Geeves. 2003. Marine invasive alien species: A threat to global biodiversity. Marine Policy.

Bhaud, M. R. 1993. Relationship between larval type and geographic range in marine species: complementary observations on gastropods. Oceanologica Acta 16:191198.

Blackburn, T. M., P. Pyšek, S. Bacher, J. T. Carlton, R. P. Duncan, V. Jarošík, J. R. U. Wilson, and D. M. Richardson. 2011. A proposed unified framework for biological invasions. Trends in Ecology and Evolution 26:333-339.

Bode, M., L. Bode, and P. R. Armsworth. 2011. Different dispersal abilities allow reef fish to coexist. Proceedings of the National Academy of Sciences 108:16317-16321.

Bradbury, I. R., B. Laurel, P. V. R. Snelgrove, P. Bentzen, and S. E. Campana. 2008. Global patterns in marine dispersal estimates: the influence of geography, taxonomic category and life history. Proceedings of the Royal Society B: Biological Sciences 275:1803-1809.

Bulleri, F., and L. Airoldi. 2005. Artificial marine structures facilitate the spread of a non-indigenous green alga, Codium fragile ssp. tomentosoides, in the north Adriatic Sea. Journal of Applied Ecology 42:1063-1072.

Bulleri, F., and M. G. Chapman. 2004. Intertidal assemblages on artificial and natural habitats in marinas on the north-west coast of Italy. Marine Biology 145:381-391.

Bulleri, F., and M. G. Chapman. 2010. The introduction of coastal infrastructure as a driver of change in marine environments. Journal of Applied Ecology 47:26-35.

Burgess, S. C., and D. J. Marshall. 2011. Are numbers enough? Colonizer phenotype and abundance interact to affect population dynamics. Journal of Animal Ecology 80:681-687.

Byers, J. E. 2002. Physical habitat attribute mediates biotic resistance to non-indigenous species invasion. Oecologia 130:146-156.

Byrnes, J. E., J. J. Stachowicz, K. M. Hultgren, A. R. Hughes, S. V. Olyarnik, and C. S. Thornber. 2006. Predator diversity strengthens trophic cascades in kelp forests by modifying herbivore behaviour. Ecology Letters 9:61-71.

Calder, D. R. 1971. Hydroids and hydromedusae of Southern Chesapeake Bay. Special Papers in Marine Science no 1., Virginia Institute of Marine Science, College of 
William and Mary. http://doi.org/10.21220/V5MS31

Cañete, J. I., C. S. Gallardo, M. Romero, and R. Ambler. 2007. Planktonic drifting dispersal of early juvenile Trochita calyptraeaformis Born 1778 [Gastropoda: Calyptraeidae]. Journal of Experimental Marine Biology and Ecology 346:1-7.

Carlton, J. T. 1985. Transoceanic and interoceanic dispersal of coastal marine organisms: the biology of ballast water. Oceanography and Marine Biology Annual Review $23: 313-371$.

Carlton, J. T. 1987. Patterns of transoceanic marine biological invasions in the Pacific Ocean. Bulletin of Marine Science 41:452-465.

Carlton, J. T. 1996. Pattern, process, and prediction in marine invasion ecology. Biological Conservation 78:97-106.

Carlton, J. T. 2003. Community assembly and historical biogeography in the North Atlantic Ocean: the potential role of human-mediated dispersal vectors. Hydrobiologia 503:1-8.

Carlton, J. T., and J. B. Geller. 1993. Ecological roulette: the global transport of nonindigenous marine organisms. Science 1:78-82.

Carlton, J. T., and J. Hodder. 1995. Biogeography and dispersal of coastal marine organisms: experimental studies on a replica of a 16th-century sailing vessel. Marine Biology 121:721-730.

Case, T. J. 1991. Invasion resistance, species build-up and community collapse in metapopulation models with interspecies competition. Biological Journal of the Linnean Society 42:239-266.

Castilla, J. C., R. Guiñez, A. U. Caro, and V. Ortiz. 2004. Invasion of a rocky intertidal shore by the tunicate Pyura praeputialis in the Bay of Antofagasta, Chile. Proceedings of the National Academy of Sciences of the United States of America 101:8517-8524.

Castilla, J. C., and P. E. Neill. 2009. Marine Bioinvasions in the Southeastern Pacific: Status, Ecology, Economic Impacts, Conservation and Management. Pages 439-457 in G. Rilov and J. A. Crooks, editors. Biological Invasions in Marine Ecosystems. Springer-Verlag, Berlin, Heidelberg.

Catford, J. A., R. Jansson, and C. Nilsson. 2009. Reducing redundancy in invasion ecology by integrating hypotheses into a single theoretical framework. Diversity and Distributions 15:22-40.

Chapman, J. W. 1988. Invasions of the Northeast Pacific by Asian and Atlantic 
Gammaridean amphipod crustaceans, including a new species of Corophium. Journal of Crustacean Biology 8:364-382.

Chapman, J. W., R. A. Breitenstein, and J. T. Carlton. 2013. Port-by-port accumulations and dispersal of hull fouling invertebrates between the Mediterranean sea, the Atlantic ocean and the Pacific ocean. Aquatic Invasions 8:249-260.

Chapman, J. W., and J. T. Carlton. 1991. A test of criteria for introduced species: the global invasion by the isopod Synidotea laevidorsalis (Miers, 1881). Journal of Crustacean Biology 11:386-400.

Chapman, M. G. 2003. Paucity of mobile species on constructed seawalls: Effects of urbanization on biodiversity. Marine Ecology Progress Series 264:21-29.

Chapman, M. G., and D. J. Blockley. 2009. Engineering novel habitats on urban infrastructure to increase intertidal biodiversity. Oecologia 161:625-635.

Chapman, M. G., and A. J. Underwood. 2011. Evaluation of ecological engineering of "armoured" shorelines to improve their value as habitat. Journal of Experimental Marine Biology and Ecology 400:302-313.

Clark, G. F., and E. L. Johnston. 2005. Manipulating larval supply in the field: A controlled study of marine invasibility. Marine Ecology Progress Series 298:9-19.

Clark, G. F., and E. L. Johnston. 2009. Propagule pressure and disturbance interact to overcome biotic resistance of marine invertebrate communities. Oikos 118:16791686.

Cohen, A. N., and J. T. Carlton. 1998. Accelerating invasion rate in a highly invaded estuary. Science 279:555-558.

Colautti, R. I., and H. I. MacIsaac. 2004. A neutral terminology to define "invasive" species. Diversity and Distributions 10:135-141.

Colautti, R. I., A. Ricciardi, I. A. Grigorovich, and H. J. MacIsaac. 2004. Is invasion success explained by the enemy release hypothesis? Ecology Letters 7:721-733.

Connell, S. D. 2000. Floating pontoons create novel habitats for subtidal epibiota. Journal of Experimental Marine Biology and Ecology 247:183-194.

Connell, S. D. 2001a. Predatory fish do not always affect the early development of epibiotic assemblages. Journal of Experimental Marine Biology and Ecology 260:112.

Connell, S. D. 2001b. Urban structures as marine habitats: an experimental comparison of the composition and abundance of subtidal epibiota among pilings, pontoons and 
rocky reefs. Marine Environmental Research 52:115-125.

Connell, S. D., and T. M. Glasby. 1999. Do urban structures influence local abundance and diversity of subtidal epibiota? A case study from Sydney Harbour, Australia. Marine Environmental Research 47:373-387.

Coutts, A. D. M., K. M. Moore, and C. L. Hewitt. 2003. Ships' sea chest: an overlooked transfer mechanism for non-indigenous marine species? Marine Pollution Bulletin 46:1504-1515.

Cowen, R. K., K. M. M. Lwiza, S. Sponaugle, C. B. Paris, and D. B. Olson. 2000. Connectivity of Marine Populations: Open or Closed? Science 287:857-859.

Crooks, J. A. 2005. Lag times and exotic species: The ecology and management of biological invasions in slow-motion. Ecoscience 12:316-329.

D’Antonio, C. M., T. L. Dudley, and M. Mack. 1999. Disturbance and biological invasions: Direct effects and feedbacks. Pages 413-452 in L. R. Walker, editor. Ecosystems of Disturbed Ground. First edition. Elsevier Science B.V., Amsterdam.

D’Antonio, C., L. A. Meyerson, and J. S. Denslow. 2001. Exotic species and conservation. Pages 59-80 in M. E. Soulé and G. H. Orians, editors. Conservation Biology: Research Priorities for the Next Decade. Island Press, Washington, DC.

Dafforn, K. A., T. M. Glasby, and E. L. Johnston. 2009a. Links between estuarine condition and spatial distributions of marine invaders. Diversity and Distributions 15:807-821.

Dafforn, K. A., E. L. Johnston, and T. M. Glasby. 2009b. Shallow moving structures promote marine invader dominance. Biofouling 25:277-287.

Dafforn, K. A., J. A. Lewis, and E. L. Johnston. 2011. Antifouling strategies: History and regulation, ecological impacts and mitigation. Marine Pollution Bulletin 62:453465.

Darling, J. A., and N. C. Folino-Rorem. 2009. Genetic analysis across different spatial scales reveals multiple dispersal mechanisms for the invasive hydrozoan Cordylophora in the Great Lakes. Molecular Ecology 18:4827-4840.

Darling, J. A., A. Kuenzi, and A. M. Reitzel. 2009. Human-mediated transport determines the non-native distribution of the anemone Nematostella vectensis, a dispersal-limited estuarine invertebrate. Marine Ecology Progress Series 380:137146.

Davis, A. R. 1988. Colony regeneration following damage and size-dependent mortality in the Australian ascidian Podoclavella moluccensis Sluiter. Journal of Experimental 
Marine Biology and Ecology 123:269-285.

Didham, R. K., J. M. Tylianakis, N. J. Gemmell, T. A. Rand, and R. M. Ewers. 2007. Interactive effects of habitat modification and species invasion on native species decline. Trends in Ecology and Evolution 22:489-496.

Didham, R. K., J. M. Tylianakis, M. A. Hutchison, R. M. Ewers, and N. J. Gemmell. 2005. Are invasive species the drivers of ecological change? Trends in Ecology and Evolution 20:470-474.

Drake, J. M., and D. M. Lodge. 2004. Global hot spots of biological invasions: evaluating options for ballast-water management. Proceedings of the Royal Society B: Biological Sciences 271:575-580.

Drake, J. M., and D. M. Lodge. 2007. Rate of species introductions in the Great Lakes via ships' ballast water and sediments. Canadian Journal of Fisheries and Aquatic Sciences 64:530-538.

Dufrêne, M., and P. Legendre. 1997. Species assemblages and indicator species: The need for a flexible asymmetrical approach. Ecological Monographs 67:345-366.

Dumont, C. P., C. F. Gaymer, and M. Thiel. 2011a. Predation contributes to invasion resistance of benthic communities against the non-indigenous tunicate Ciona intestinalis. Biological Invasions 13:2023-2034.

Dumont, C. P., L. G. Harris, and C. F. Gaymer. 2011b. Anthropogenic structures as a spatial refuge from predation for the invasive bryozoan Bugula neritina. Marine Ecology Progress Series 427:95-103.

Eckman, J. E. 1983. Hydrodynamic processes affecting benthic recruitment. Limnology and Oceanography 28:241-257.

Eckman, J. E. 1996. Closing the larval loop: linking larval ecology to the population dynamics of marine benthic invertebrates. Journal of Experimental Marine Biology and Ecology 200:207-237.

Eppstein, M. J., and J. Molofsky. 2007. Invasiveness in plant communities with feedbacks. Ecology Letters 10:253-263.

Floerl, O., and G. J. Inglis. 2003. Boat harbour design can exacerbate hull fouling. Austral Ecology 28:116-127.

Floerl, O., and G. J. Inglis. 2005. Starting the invasion pathway: the interaction between source populations and human transport vectors. Biological Invasions 7:589-606.

Floerl, O., G. J. Inglis, K. Dey, and A. Smith. 2009. The importance of transport hubs in 
stepping-stone invasions. Journal of Applied Ecology 46:37-45.

Forrest, B. M., L. M. Fletcher, J. Atalah, R. F. Piola, and G. A. Hopkins. 2013. Predation limits spread of Didemnum vexillum into natural habitats from refuges on anthropogenic structures. PLoS ONE 8:1-12.

Gili, J.-M., and R. G. Hughes. 1995. The ecology of marine benthic hydroids. Oceanography and Marine Biology: An Annual Review 33:351-426.

Gilman, S. E. 2006. The northern geographic range limit of the intertidal limpet Collisella scabra: a test of performance, recruitment, and temperature hypotheses. Ecography 29:709-720.

Glasby, T. M. 1999. Differences between subtidal epibiota on pier pilings and rocky reefs at marinas in Sydney, Australia. Estuarine, Coastal and Shelf Science 48:281-290.

Glasby, T. M., and S. D. Connell. 1999. Urban structures as marine habitats. Ambio 28:595-598.

Glasby, T. M., S. D. Connell, M. G. Holloway, and C. L. Hewitt. 2007. Nonindigenous biota on artificial structures: could habitat creation facilitate biological invasions? Marine Biology 151:887-895.

Goldstien, S. J., D. R. Schiel, and N. J. Gemmell. 2010. Regional connectivity and coastal expansion: differentiating pre-border and post-border vectors for the invasive tunicate Styela clava. Molecular Ecology 19:874-885.

Grantham, B. A., G. L. Eckert, and A. L. Shanks. 2003. Dispersal potential of marine invertebrates in diverse habitats. Ecological Applications 13:S108-S116.

Grave, B. H. 1933. Rate of growth, age at sexual maturity, and duration of life of certain sessile organisms, at Woods Hole, Massachusetts. The Biological Bulletin 65:375386.

Grey, E. K. 2010. Effects of large enemies on success of exotic species in marine fouling communities of Washington, USA. Marine Ecology Progress Series 411:89-100.

Gurevitch, J., and D. K. Padilla. 2004. Are invasive species a major cause of extinctions? Trends in Ecology and Evolution 19:470-474.

Halpern, B. S., S. Walbridge, K. A. Selkoe, C. V. Kappel, F. Micheli, C. D’Agrosa, J. F. Bruno, K. S. Casey, C. Ebert, H. E. Fox, R. Fujita, D. Heinemann, H. S. Lenihan, E. M. P. Madin, M. T. Perry, E. R. Selig, M. Spalding, R. Steneck, and R. Watson. 2008. A global map of human impact on marine ecosystems. Science 319:948-952.

Harvey, B. C., J. L. White, and R. J. Nakamoto. 2004. An emergent multiple predator 
effect may enhance biotic resistance in a stream fish assemblage. Ecology 85:127133.

Hedge, L. H., and E. L. Johnston. 2012. Propagule pressure determines recruitment from a commercial shipping pier. Biofouling 28:73-85.

Hedgecock, D. 1986. Is gene flow from pelagic larval dispersal important in the adaptation and evolution of marine invertebrates? Bulletin of Marine Science. 39:550-564.

Herbert, R. J. H., A. J. Southward, R. T. Clarke, M. Sheader, and S. J. Hawkins. 2009. Persistent border: An analysis of the geographic boundary of an intertidal species. Marine Ecology Progress Series 379:135-150.

Holloway, M. G., and S. D. Connell. 2002. Why do floating structures create novel habitats for subtidal epibiota? Marine Ecology Progress Series 235:43-52.

Hothorn, T., F. Bretz, P. Westfall, R. M. Heiberger, A. Schuetzenmeister, and S. Scheibe. 2016. multcomp: Simultaneous Inference in General Parametric Models.

Hulme, P. E. 2009. Trade, transport and trouble: managing invasive species pathways in an era of globalization. Journal of Applied Ecology 46:10-18.

Hunt, C. E., and S. B. Yamada. 2003. Biotic resistance experienced by an invasive crustacean in a temperate estuary. Biological Invasions 5:33-43.

Hunt, H. L., and R. E. Scheibling. 1997. Role of early post-settlement mortality in recruitment of benthic marine invertebrates. Marine Ecology Progress Series 155:269-301.

Jackson, J. B. C. 1986. Modes of dispersal of clonal benthic invertebrates: consequences for species' distributions and genetic structure of local populations. Bulletin of Marine Science 39:588-606.

Johnson, L. E., and J. T. Carlton. 1996. Post-establishment spread in large-scale invasions: Dispersal mechanisms of the zebra mussel Dreissena polymorpha. Ecology 77:1686-1690.

Johnston, E. L., R. F. Piola, and G. F. Clark. 2009. The Role of Propagule Pressure in Invasion Success. Pages 133-151 in G. Rilov and J. A. Crooks, editors. Biological Invasions in Marine Ecosystems. Springer-Verlag, Berlin.

Kaluza, P., A. Kölzsch, M. T. Gastner, and B. Blasius. 2010. The complex network of global cargo ship movements. Journal of The Royal Society Interface 7:1093-1103.

Keane, R. M., and M. J. Crawley. 2002. Exotic plant invasions and the enemy release 
hypothesis. Trends in Ecology and Evolution 17:164-170.

Keller, R. P., J. M. Drake, M. B. Drew, and D. M. Lodge. 2011. Linking environmental conditions and ship movements to estimate invasive species transport across the global shipping network. Diversity and Distributions 17:93-102.

Kelly, R. P., and D. J. Eernisse. 2007. Southern hospitality: A latitudinal gradient in gene flow in the marine environment. Evolution 61:700-707.

Keough, M. J. 1984. Dynamics of the Epifauna of the Bivalve Pinna bicolor: Interactions Among Recruitment, Predation, and Competition. Ecology 65:677-688.

Keough, M. J., and A. J. Butler. 1979. The role of asteroid predators in the organization of a sessile community on pier pilings. Marine Biology 51:167-177.

Keough, M. J., and H. Chernoff. 1987. Dispersal and population variation in the bryozoan Bugula neritina. Ecology 68:199-210.

Kimbro, D. L., B. S. Cheng, and E. D. Grosholz. 2013. Biotic resistance in marine environments. Ecology Letters 16:821-833.

Kincaid, E. S. 2016. Biofouling Management in the Pacific Northwest and Predation on Native versus Non-native Ascidians. Portland State University.

Koehl, M. A. R., and M. G. Hadfield. 2010. Hydrodynamics of larval settlement from a larva's point of view. Integrative and Comparative Biology 50:539-551.

Koehl, M. R. A. 2007. Mini review: Hydrodynamics of larval settlement into fouling communities. Biofouling 23:357-368.

Kremer, L. P., and R. M. da Rocha. 2016. The biotic resistance role of fish predation in fouling communities. Biological Invasions 18:3223-3237.

Kuo, E. S. L., and E. Sanford. 2009. Geographic variation in the upper thermal limits of an intertidal snail: Implications for climate envelope models. Marine Ecology Progress Series 388:137-146.

Lambert, C. C., and G. Lambert. 1998. Non-indigenous ascidians in southern California harbors and marinas. Marine Biology 130:675-688.

Lambert, G. 2002. Nonindigenous ascidians in tropical waters. Pacific Science 56:291298.

Lange, R., and D. J. Marshall. 2016. Propagule size and dispersal costs mediate establishment success of an invasive species. Ecology 97:569-575. 
Lavender, J. T., K. A. Dafforn, and E. L. Johnston. 2014. Meso-predators: A confounding variable in consumer exclusion studies. Journal of Experimental Marine Biology and Ecology 456:26-33.

Lebour, M. V. 1938. Notes on the breeding of some lamellibranchs from Plymouth and their larvae. Journal of the Marine Biological Association of the United Kingdom 23:119-144.

Levin, L. A. 2006. Recent progress in understanding larval dispersal: New directions and digressions. Integrative and Comparative Biology 46:282-297.

Levine, J. M. 2000. Species Diversity and Biological Invasions : Relating Local Process to Community Pattern. Science 288:852-854.

Levine, J. M., P. B. Adler, and S. G. Yelenik. 2004. A meta-analysis of biotic resistance to exotic plant invasions. Ecology Letters 7:975-989.

Lima, F. P., P. A. Ribeiro, N. Queiroz, R. Xavier, P. Tarroso, S. J. Hawkins, and A. M. Santos. 2007. Modelling past and present geographical distribution of the marine gastropod Patella rustica as a tool for exploring responses to environmental change. Global Change Biology 13:2065-2077.

Liu, H., and P. Stiling. 2006. Testing the enemy release hypothesis: A review and metaanalysis. Biological Invasions 8:1535-1545.

Lonsdale, W. M. 1999. Global patterns of plant invasions and the concept of invasibility. Ecology 80:1522-1536.

Lovell, S. J., and S. F. Stone. 2005. The Economic Impacts of Aquatic Invasive Species: A Review of the Literature. Washington, D.C.

Mack, R. N., D. Simberloff, W. M. Lonsdale, H. Evans, M. Clout, and F. A. Bazzaz. 2000. Biotic Invasions: Causes, Epidemiology, Global Consequences, and Control. Ecological Applications 10:689-710.

Maron, J. L., and M. Vila. 2001. When do herbivores affect plant invasion? Evidence for the natural enemies and biotic resistance hypotheses. Oikos 95:361-373.

Marzinelli, E. M. 2012. Artificial structures influence fouling on habitat-forming kelps. Biofouling 28:339-349.

Marzinelli, E. M., A. J. Underwood, and R. A. Coleman. 2012. Modified habitats change ecological processes affecting a non-indigenous epibiont. Marine Ecology Progress Series 446:119-129.

Masi, B. P., I. Zalmon, and R. Coutinho. 2016. Effects of structural factors on upwelling 
fouling community, Southeast Brazil. Brazilian Journal of Oceanography 64:387400 .

McGeoch, M. A., S. H. M. Butchart, D. Spear, E. Marais, E. J. Kleynhans, A. Symes, J. Chanson, and M. Hoffmann. 2010. Global indicators of biological invasion: Species numbers, biodiversity impact and policy responses. Diversity and Distributions 16:95-108.

McManus, M. A., and C. B. Woodson. 2012. Plankton distribution and ocean dispersal. The Journal of Experimental Biology 215:1008-1016.

McNeill, S. E., D. G. Worthington, D. J. Ferrell, and J. D. Bell. 1992. Consistently outstanding recruitment of five species of fish to a seagrass bed in Botany Bay, NSW. Australian Journal of Ecology 17:359-365.

Mileikovsky, S. A. 1971. Types of larval development in marine bottom invertebrates, their distribution and ecological significance: a re-evaluation. Marine Biology 10:193-213.

Millar, R. H. 1971. The Biology of Ascidians. Advances in Marine Biology 9:1-100.

Miller, R. J., and R. J. Etter. 2008. Shading facilitates sessile invertebrate dominance in the rocky subtidal Gulf of Maine. Ecology 89:452-462.

Mineur, F., E. J. Cook, D. Minchin, K. Bohn, A. Macleod, and C. A. Maggs. 2012. Changing coasts: Marine aliens and artificial structures. Oceanography and Marine Biology Annual Review 50:189-234.

Molnar, J. L., R. L. Gamboa, C. Revenga, and M. D. Spalding. 2008. Assessing the global threat of invasive species to marine biodiversity. Frontiers in Ecology and the Environment 6:485-492.

Mook, D. H. 1981. Effects of Disturbance and Initial Settlement on Fouling Community Structure. Ecology 62:522-526.

Moran, P. J. 1980. Natural physical disturbance and predation: their importance in structuring a marine sessile community. Australian Journal of Ecology 5:193-200.

Moreau, S., C. Péron, K. A. Pitt, R. M. Connolly, S. Y. Lee, and T. Meziane. 2008. Opportunistic predation by small fishes on epibiota of jetty pilings in urban waterways. Journal of Fish Biology 72:205-217.

Morgan, S. G., J. L. Fisher, S. H. Miller, S. T. McAfee, and J. L. Largier. 2009. Nearshore larval retention in a region of strong upwelling and recruitment limitation. Ecology 90:3489-3502. 
Nielsen, C. 2009. How Did Indirect Development With Planktotrophic Larvae Evolve? The Biological Bulletin 216:203-215.

Nydam, M., and J. J. Stachowicz. 2007. Predator effects on fouling community development. Marine Ecology Progress Series 337:93-101.

O’Connor, M. I., J. F. Bruno, S. D. Gaines, B. S. Halpern, S. E. Lester, B. P. Kinlan, and J. M. Weiss. 2007. Temperature control of larval dispersal and the implications for marine ecology, evolution, and conservation. Proceedings of the National Academy of Sciences of the United States of America 104:1266-1271.

Occhipinti-Ambrogi, A. 2007. Global change and marine communities: Alien species and climate change. Marine Pollution Bulletin 55:342-352.

Oksanen, J., F. G. Blanchet, M. Friendly, R. Kindt, P. Legendre, D. McGlinn, P. R. Minchin, R. B. O’Hara, G. L. Simpson, P. Solymos, M. H. H. Stevens, E. Szoecs, and H. Wagner. 2017, April. vegan: Community Ecology Package.

Okubo, A. 1973. Effect of shoreline irregularities on streamwise dispersion in estuaries and other embayments. Netherlands Journal of Sea Research 6:213-224.

Olafsson, E. B., C. H. Peterson, and W. G. Ambrose Jr. 1994. Does recruitment limitation structure populations and communities of macro-invertebrates in marine soft sediments: the relative significance of pre- and post-settlement processes. Oceanography and Marine Biology Annual Review 32:65-109.

Oricchio, F. T., A. A. V. Flores, and G. M. Dias. 2016. The importance of predation and predator size on the development and structure of a subtropical fouling community. Hydrobiologia 776:209-219.

Osman, R. W., and R. B. Whitlatch. 1995. The influence of resident adults on recruitment: a comparison to settlement. Journal of Experimental Marine Biology and Ecology 190:169-198.

Osman, R. W., and R. B. Whitlatch. 2004. The control of the development of a marine benthic community by predation on recruits. Journal of Experimental Marine Biology and Ecology 311:117-145.

Osman, R. W., R. B. Whitlatch, and R. J. Malatesta. 1992. Potential role of micropredators in determining recruitment into a marine community. Marine Ecology Progress Series 83:35-43.

Parker, J. D., and M. E. Hay. 2005. Biotic resistance to plant invasions? Native herbivores prefer non-native plants. Ecology Letters 8:959-967.

Pechenik, J. A. 1990. Delayed metamorphosis by larvae of benthic marine invertebrates: 
Does it occur? Is there a price to pay? Ophelia 32:63-94.

Pechenik, J. A., D. Rittschof, and A. R. Schmidt. 1993. Influence of delayed metamorphosis on survival and growth of juvenile barnacles Balanus amphitrite. Marine Biology 115:287-294.

Pechenik, J. A., D. E. Wendt, and J. N. Jarrett. 1998. Metamorphosis is not a new beginning: larval experience influences juvenile performance. BioScience 48:901910.

Petersen, J. K., and I. Svane. 1995. Larval dispersal in the ascidian Ciona intestinalis (L.). Evidence for a closed population. Journal of Experimental Marine Biology and Ecology 186:89-102.

Pimentel, D., R. Zuniga, and D. Morrison. 2005. Update on the environmental and economic costs associated with alien-invasive species in the United States. Ecological Economics 52:273-288.

Pingree, R. D., and L. Maddock. 1979. The tidal physics of headland flows and offshore tidal bank formation. Marine Geology 32:269-289.

Piola, R. F., and E. L. Johnston. 2008. Pollution reduces native diversity and increases invader dominance in marine hard-substrate communities. Diversity and Distributions 14:329-342.

Poloczanska, E. S., S. Smith, L. Fauconnet, J. Healy, I. R. Tibbetts, M. T. Burrows, and A. J. Richardson. 2011. Little change in the distribution of rocky shore faunal communities on the Australian east coast after 50 years of rapid warming. Journal of Experimental Marine Biology and Ecology 400:145-154.

Preisler, R. K., K. Wasson, W. J. Wolff, and M. C. Tyrrell. 2009. Invasions of estuaries vs the adjacent open coast: a global perspective. Pages 587-618 in G. Rilov and J. A. Crooks, editors. Biological Invasions in Marine Ecosystems. Springer-Verlag, Berlin.

Prior, K. M., T. H. Q. Powell, A. L. Joseph, and J. J. Hellmann. 2014. Insights from community ecology into the role of enemy release in causing invasion success: the importance of native enemy effects. Biological Invasions 17:1283-1297.

Pyšek, P., and P. E. Hulme. 2005. Spatio-temporal dynamics of plant invasions: Linking pattern to process. Ecoscience 12:302-315.

R Development Core Team. 2016. R: a language and environment for statistical computing. R Foundation for Statistical Computing, Vienna, Austria.

Rainbow, P. S. 1984. An introduction to the biology of British littoral barnacles. Field 
Studies 6:1-51.

Reinhardt, J. F., R. B. Whitlatch, and R. W. Osman. 2013. Effects of temperature on the recruitment phenology and niche overlap of shallow epifaunal assemblages in southern New England. Marine Ecology Progress Series 489:61-74.

Rilov, G. 2009. Predator-prey interactions of marine invaders. Pages 261-285 in J. A. Crooks and G. Rilov, editors. Biological Invasions in Marine Ecosystems. SpringerVerlag, Berlin.

Ritchie, E. G., and C. N. Johnson. 2009. Predator interactions, mesopredator release and biodiversity conservation. Ecology Letters 12:982-998.

de Rivera, C. E., G. M. Ruiz, A. H. Hines, and P. Jivoff. 2005. Biotic resistance to invasion: native predator limits abundance and distribution of an introduced crab. Ecology 86:3364-3376.

Rivero, N. K., K. A. Dafforn, M. A. Coleman, and E. L. Johnston. 2013. Environmental and ecological changes associated with a marina. Biofouling 29:803-815.

Roberts, D. W. 2016. labdsv: Ordination and Multivariate Analysis for Ecology.

Rogers, T. L., J. E. Byrnes, and J. J. Stachowicz. 2016. Native predators limit invasion of benthic invertebrate communities in Bodega Harbor, California, USA. Marine Ecology Progress Series 545:161-173.

Rothlisberg, P. C., and J. A. Church. 1994. Processes controlling the larval dispersal and postlarval recruitment of Penaeid prawns. Pages 235-252 in P. W. Sammarco and M. L. Heron, editors. The Bio-Physics of Marine Larval Dispersal. American Geophysical Union, Washington, D.C.

Roughgarden, J., J. T. Pennington, D. S. Stoner, S. Alexander, and K. M. Miller. 1991. Collisions of upwelling fronts with the intertidal zone: the cause of recruitment pulses in barnacle populations of central California. Oecologia 12:35-51.

Ruiz, G. M., J. T. Carlton, E. D. Grosholz, and A. H. Hines. 1997. Global invasions of marine and estuarine habitats by non-indigenous species: mechanisms, extent, and consequences. Integrative and Comparative Biology 37:621-632.

Ruiz, G. M., P. W. Fofonoff, J. T. Carlton, M. J. Wonham, and A. H. Hines. 2000. Invasion of coastal marine communities in North America: Apparent patterns, processes, and biases. Annual Review of Ecology \& Systematics 31:481-531.

Ruiz, G. M., P. W. Fofonoff, B. P. Steves, S. F. Foss, and S. N. Shiba. 2011. Marine invasion history and vector analysis of California: a hotspot for western North America. Diversity and Distributions 17:362-373. 
Ruiz, G. M., A. L. Freestone, P. W. Fofonoff, and C. Simkanin. 2009. Habitat distribution and heterogeneity in marine invasion dynamics: the importance of hard substrate and artificial structure. Pages 321-332in M. Wahl, editor.Marine Hard Bottom Communities: Patterns, Dynamics, Diversity, and Change.

Russ, G. R. 1980. Effects of predation by fishes, competition, and structural complexity of the substratum on the establishment of a marine epifaunal community. Journal of Experimental Marine Biology and Ecology 42:55-69.

Sala, E. 1997. The role of fishes in the organisation of a Mediterranean sublittoral community - II: Epifaunal communities. Journal of Experimental Marine Biology and Ecology 212:45-60.

Sams, M. A., and M. J. Keough. 2007. Predation during early post-settlement varies in importance for shaping marine sessile communities. Marine Ecology Progress Series 348:85-101.

Scheltema, R. S. 1986a. Long-distance dispersal by planktonic larvae of shoal-water benthic invertebrates among central Pacific Islands. Bulletin of Marine Science, 39(2): 241-256. Bulletin of Marine Science 39:241-256.

Scheltema, R. S. 1986b. On dispersal and planktonic larvae of benthic invertebrates: an eclectic overview and summary of problems. Bulletin of Marine Science 39:290322.

Schiel, D. R. 2004. The structure and replenishment of rocky shore intertidal communities and biogeographic comparisons. Journal of Experimental Marine Biology and Ecology 300:309-342.

Shanks, A. L. 1983. Surface slicks associated with tidally forced internal waves may transport pelagic larvae of benthic invertebrates and fishes shoreward. Marine Ecology Progress Series 13:311-315.

Shanks, A. L. 1995. Mechanisms of cross-shelf dispersal of larval invertebrates and fish. Pages 323-368 in L. R. McEdward, editor. Ecology of Marine Invertebrate Larvae. CRC Press Inc., Boca Raton, Florida.

Shanks, A. L. 2009. Pelagic larval duration and dispersal distance revisited. Biological Bulletin 216:373-385.

Shanks, A. L., B. A. Grantham, and M. H. Carr. 2003. Propagule Dispersal Distance and the Size and Spacing of Marine Reserves. Ecological Applications 13:159-169.

Siegel, D. A., B. P. Kinlan, B. Gaylord, and S. D. Gaines. 2003. Lagrangian descriptions of marine larval dispersion. Marine Ecology Progress Series 260:83-96. 
Siegel, D. A., S. Mitarai, C. J. Costello, S. D. Gaines, B. E. Kendall, R. R. Warner, and K. B. Winters. 2008. The stochastic nature of larval connectivity among nearshore marine populations. Proceedings of the National Academy of Sciences 105:89748979.

Signell, R. P., and W. R. Geyer. 1991. Transient eddy formation around headlands. Journal of Geophysical Research 96:2561-2575.

Simkanin, C., I. C. Davidson, J. F. Dower, G. Jamieson, and T. W. Therriault. 2012. Anthropogenic structures and the infiltration of natural benthos by invasive ascidians. Marine Ecology 33:499-511.

Simkanin, C., I. C. Davidson, T. W. Therriault, G. Jamieson, and J. F. Dower. 2017. Manipulating propagule pressure to test the invasibility of subtidal marine habitats. Biological Invasions.

Simkanin, C., J. F. Dower, N. Filip, G. Jamieson, and T. W. Therriault. 2013. Biotic resistance to the infiltration of natural benthic habitats: Examining the role of predation in the distribution of the invasive ascidian Botrylloides violaceus. Journal of Experimental Marine Biology and Ecology 439:76-83.

Simpson, T. J. S., D. A. Smale, J. I. McDonald, and T. Wernberg. 2017. Large scale variability in the structure of sessile invertebrate assemblages in artificial habitats reveals the importance of local-scale processes. Journal of Experimental Marine Biology and Ecology 494:10-19.

Stachowicz, J. J., J. R. Terwin, R. B. Whitlatch, and R. W. Osman. 2002. Linking climate change and biological invasions : Ocean warming facilitates nonindigenous species invasions. Proceedings of the National Academy of Sciences of the United States of America 99:15497-15500.

Stachowicz, J. J., R. B. Whitlatch, and R. W. Osman. 1999. Species Diversity and Invasion Resistance in a Marine Ecosystem. Science 286:1577-1579.

Sutherland, J. P. 1974. Multiple stable points in natural communities. The American Naturalist 108:859-873.

Swain, G. W., W. G. Nelson, and S. Preedeekanit. 1998. The influence of biofouling adhesion and biotic disturbance on the development of fouling communities on non $\square$ toxic surfaces. Biofouling 12:257-269.

Theoharides, K. A., and J. S. Dukes. 2007. Plant invasion across space and time: factors affecting nonindigenous species success during four stage of invasion. New Phytologist 176:256-273.

Thorson, G. 1950. Reproductive and larval ecology of marine bottom invertebrates. 
Biological Reviews 25:1-45.

Todd, C. D. 1998. Larval supply and recruitment of benthic invertebrates: do larvae always disperse as much as we believe? Hydrobiologia 375/376:1-21.

Torchin, M. E., K. D. Lafferty, A. P. Dobson, V. J. McKenzie, and A. M. Kuris. 2003. Introduced species and their missing parasites. Nature 421:628-630.

Tyrrell, M. C., and J. E. Byers. 2007. Do artificial substrates favor nonindigenous fouling species over native species? Journal of Experimental Marine Biology and Ecology 342:54-60.

Underwood, A. J., and P. G. Fairweather. 1989. Supply-side ecology and benthic marine assemblages. Trends in Ecology \& Evolution 4:16-20.

Vieira, E. A., L. F. L. Duarte, and G. M. Dias. 2012. How the timing of predation affects composition and diversity of species in a marine sessile community? Journal of Experimental Marine Biology and Ecology.

Waeschenbach, A., P. D. Taylor, and D. T. J. Littlewood. 2012. A molecular phylogeny of bryozoans. Molecular Phylogenetics and Evolution 62:718-735.

Wanger, T. C., A. C. Wielgoss, I. Motzke, Y. Clough, B. W. Brook, N. S. Sodhi, and T. Tscharntke. 2011. Endemic predators, invasive prey and native diversity. Proceedings of the Royal Society of London B: Biological Sciences 278:690-694.

Wasson, K., K. Fenn, and J. S. Pearse. 2005. Habitat differences in marine invasions of central California. Biological Invasions 7:935-948.

Watson, J. R., B. E. Kendall, D. A. Siegel, and S. Mitarai. 2012. Changing Seascapes, Stochastic Connectivity, and Marine Metapopulation Dynamics. The American Naturalist 180:99-112.

Watts, P. C., and J. P. Thorpe. 2006. Influence of contrasting larval developmental types upon the population-genetic structure of cheilostome bryozoans. Marine Biology 149:1093-1101.

White, J. W., and J. F. Samhouri. 2011. Oceanographic coupling across three trophic levels shapes source-sink dynamics in marine metacommunities. Oikos 120:11511164.

Wieters, E. A., S. D. Gaines, S. A. Navarrete, C. A. Blanchette, and B. A. Menge. 2008. Scales of Dispersal and the Biogeography of Marine Predator $\square$ Prey Interactions. The American Naturalist 171:405-417.

Wilson, J. R. U., E. E. Dormontt, P. J. Prentis, A. J. Lowe, and D. M. Richardson. 2009. 
Something in the way you move: dispersal pathways affect invasion success. Trends in Ecology and Evolution 24:136-144.

Wolanski, E., and W. M. Hamner. 1988. Topographically controlled fronts in the ocean and their biological influence. Science 241:177-181.

Woods Hole Oceanographic Institution. 1952. Marine fouling and its prevention. United States Naval Institute, Annapolis, MD.

Young, C. M. 1990. Larval ecology of marine invertebrates: A sesquicentennial history. Ophelia 32:1-48.

Zacherl, D., S. D. Gaines, and S. I. Lonhart. 2003. The limits to biogeographical distributions: Insights from the northward range extension of the marine snail, Kelletia kelletii (Forbes, 1852). Journal of Biogeography 30:913-924.

Zinsmeister, W. J., and W. K. Emerson. 1979. The role of passive dispersal in the distribution of hemipelagic invertebrates, with examples from the tropical Pacific Ocean. Veliger 22:32-40. 


\section{Appendix Figures and Tables}

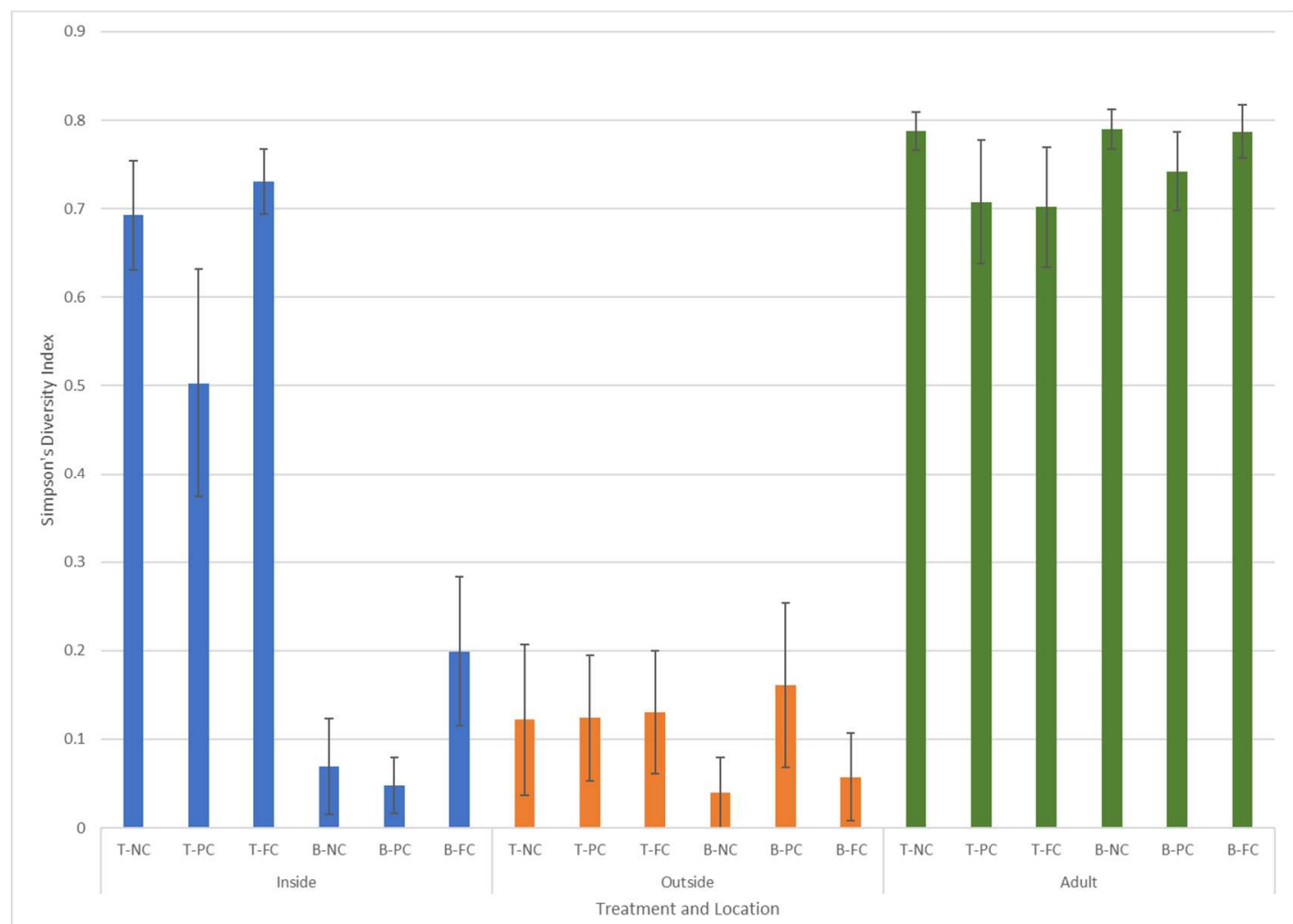

Figure 1. Simpson's diversity index across 2 depths ( $T=$ Suspended, $B=$ Benthic), 3 caging treatments (NC $=$ no cage, $P C=$ partial cage, $F C=$ full cage), and 3 locations (Inside = inside the marina for the duration of the experiment, Outside = outside the marina for the duration of the experiment, Adult $=$ Adult

Transplant Experiment, inside the marina fully caged near the surface for 12 weeks and then moved outside of the marina across 2 depths and 3 caging treatments for one week). 


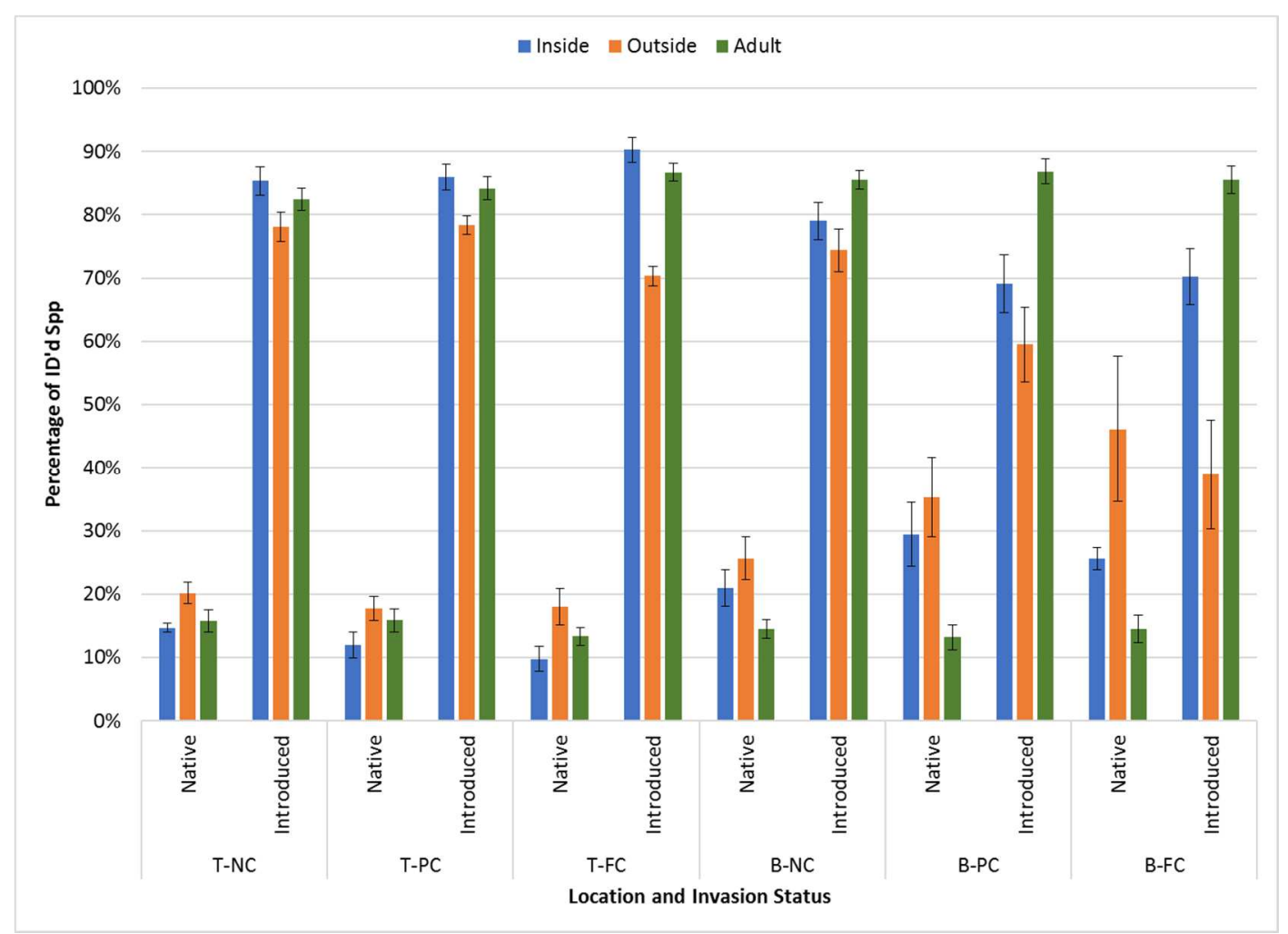

Figure 2. Percentage of total identified species: native versus introduced (non-native) species for each depth and cage treatment combination ( 2 depths: $T=$ Suspended, $B=$ Benthic; 3 caging treatments: $N C=$ no cage, $P C=$ partial cage, $F C=$ full cage) and three locations (Inside $=$ inside the marina for the duration of the experiment, Outside = outside the marina for the duration of the experiment, Adult $=$ Adult Transplant Experiment, inside the marina fully caged near the surface for 12 weeks and then moved outside of the marina across 2 depths and 3 caging treatments for one week). Invasion status was only applied to organisms that were identified to species, so not all species are included in this figure. 


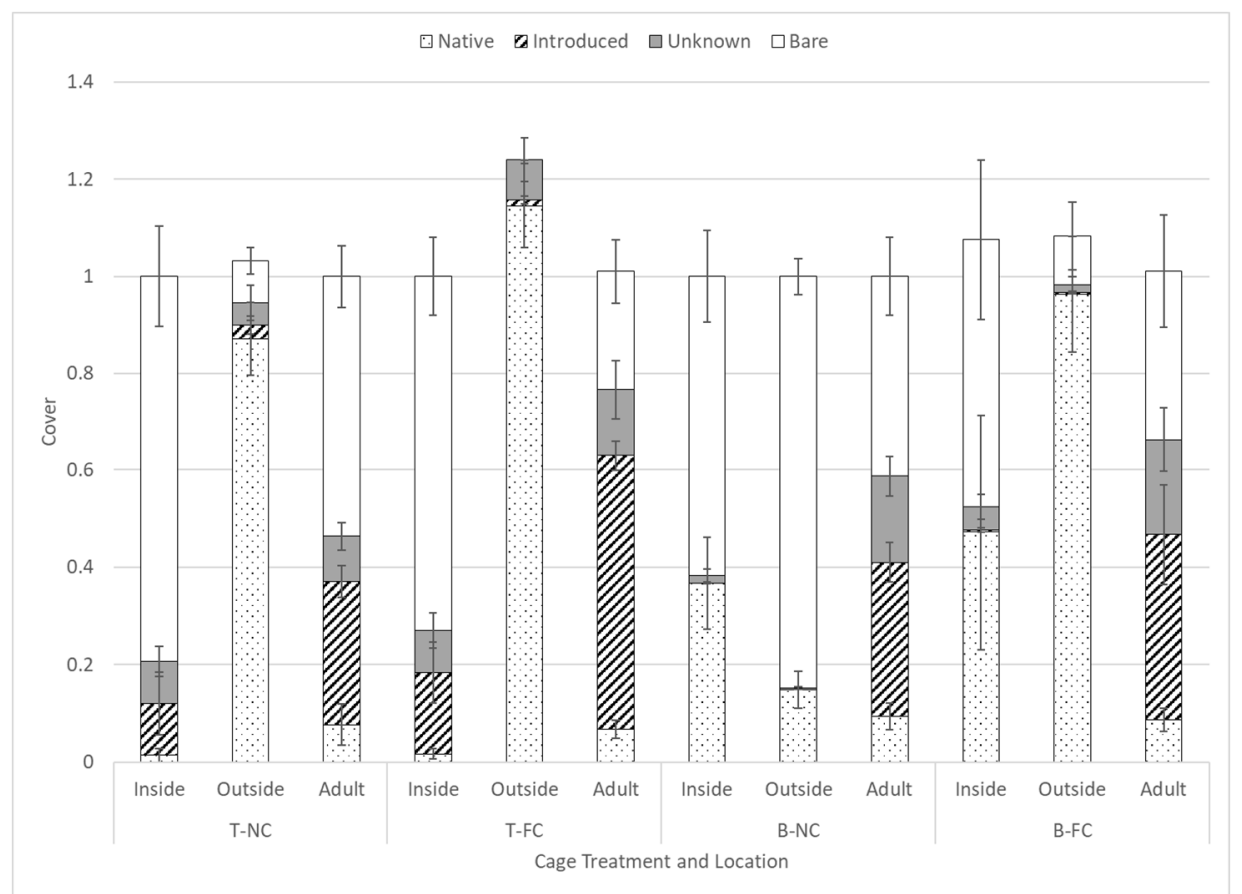

Figure 3. Average cover by invasion status across 2 caging treatments $(N C=$ No Cage, $F C=$ Full Cage), 2 depths $(T=$ Suspended, $B=$ Benthic), and three locations (Inside = inside the marina for the duration of the experiment; Outside = outside the marina for the duration of the experiment; Adult = Adult Transplant Experiment, moved from inside to outside of the marina). Error bars are \pm 1 standard error.

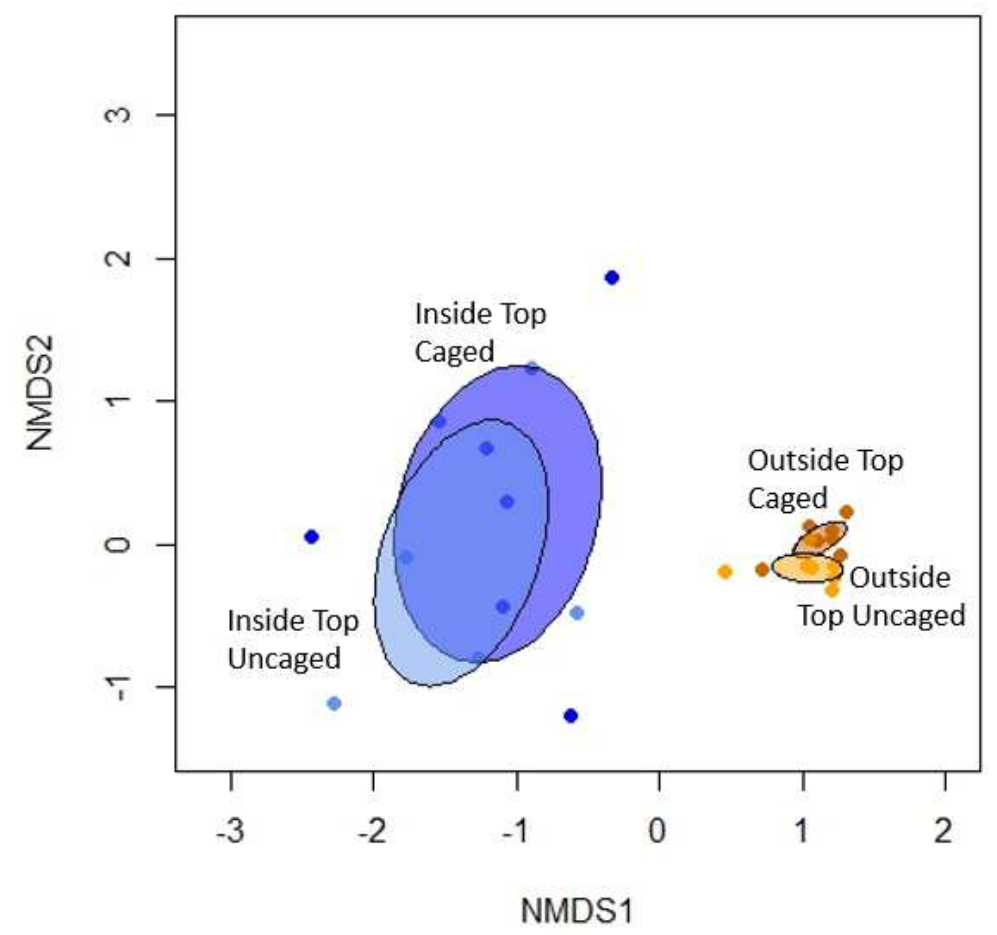

Figure 6. Nonmetric multidimensional scaling (NMDS) results showing the comparison among sessile invertebrate assemblages between inside marina suspended caged and uncaged tiles and outside marina suspended caged and uncaged tiles. Ellipses include standard error around the centroids. Stress $=0.0998$ 
Table 1. Analysis of distance tables showing the effect of caging treatment (Full Cage or No Cage) and location (Inside Marina or Outside Marina) on fouling community assemblage for suspended tiles inside and outside of the marina. $*$ indicates significance $(p<0.05, p<0.008$ for $B-G)$.

\begin{tabular}{|l|l|l|l|}
\hline Source of variation & $\mathrm{F}$ & $\mathrm{R}^{2}$ & $\mathrm{P}$ value \\
\hline A. Among 2 caging treatments and 2 locations & 8.9389 & 0.54933 & $0.00005^{*}$ \\
\hline $\begin{array}{l}\text { B. Inside Marina Suspended No Cage vs. } \\
\text { Inside Marina Suspended Full Cage }\end{array}$ & 0.952 & 0.087 & 0.498 \\
\hline $\begin{array}{l}\text { C. Inside Marina Suspended No Cage vs. } \\
\text { Outside Marina Suspended Full Cage }\end{array}$ & 13.302 & 0.547 & $0.002^{*}$ \\
\hline $\begin{array}{l}\text { D. Inside Marina Suspended No Cage vs. } \\
\text { Inside Marina Suspended No Cage }\end{array}$ & 0.530 & 0.530 & $0.001^{*}$ \\
\hline $\begin{array}{l}\text { E. Outside Suspended No Cage vs. } \\
\text { Outside Suspended Full Cage }\end{array}$ & 2.277 & 0.160 & 0.099 \\
\hline $\begin{array}{l}\text { F. Outside Suspended No Cage vs. } \\
\text { Inside Suspended Full Cage }\end{array}$ & 12.476 & 0.531 & $0.001^{*}$ \\
\hline $\begin{array}{l}\text { G. Outside Suspended Caged vs. } \\
\text { Inside Suspended Caged }\end{array}$ & 13.346 & 0.548 & $0.001^{*}$ \\
\hline
\end{tabular}

Each table was generated using permutational multivariate analysis of variance (PERMANOVA)

Bonferroni-corrected $\alpha=0.008$ for multiple pairwise PERMANOVA tests $(B-G)$ 